\title{
Fire Protection Significance Determination Process (SDP) P-108
}

September 2014

United States

Nuclear Regulatory Commission
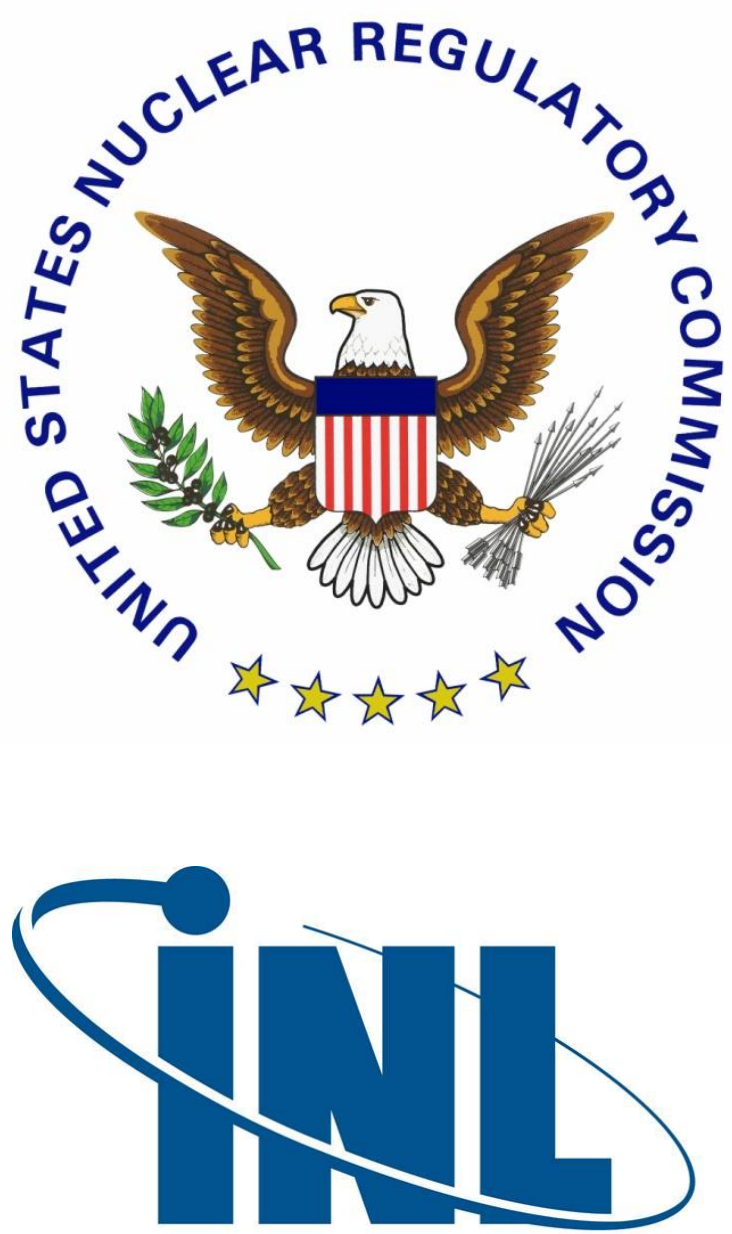

Idaho National Laboratory 


\section{DISCLAIMER NOTICE}

This report was prepared as an account of work sponsored by an agency of the United States Government. Neither the United States Government nor any agency thereof, or any of their employees, makes any warranty, expressed or implied, or assumes any legal liability of responsibility for any third party's use, or the results of such use, or any information, apparatus, product or process disclosed in this report, or represents that its use by such third party would not infringe privately owned rights. 


\section{Fire Protection Significance Determination Process (SDP) P-108}

Course Presented by
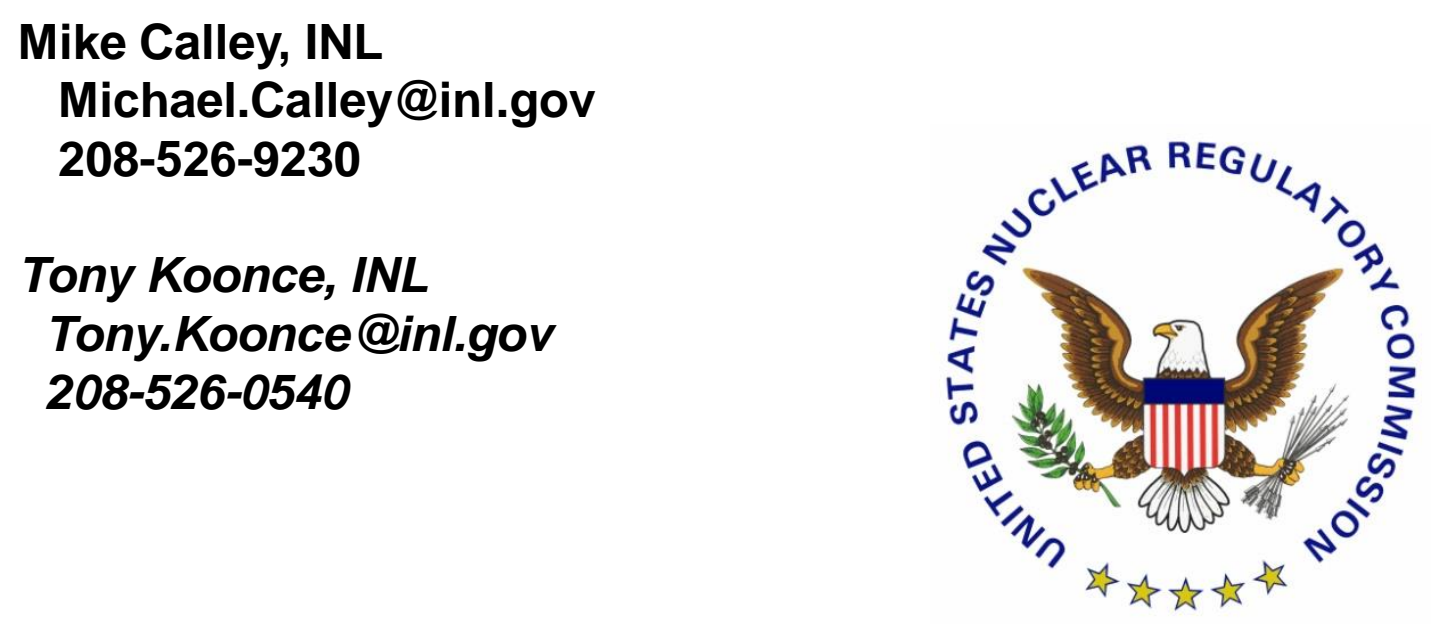

September 23-25, 2014

NRC Professional Development Center

Rockville, MD 


\section{Acknowledgments:}

The INL gratefully acknowledges Mr. Steven Nowlen, Sandia National Laboratories. Mr. Nowlen originally developed the Fire Protection SDP - Application

Training for New Analysis Procedure (P-108)

Course. Mr. Nowlen facilitated this course by providing his original P-108 course material. 


\section{Outline}

- Day 1:

- Module 1: Introduction to Fire SDP Philosophy and Example Problem

- Module 2: Concepts, Terminology, and Fire Scenario Introduction

- Module 3: Process Overview

- A quick trip through Phases 1 and 2

- Day 2:

- Module 4: Phase 1 Details

- Module 5: Phase 2 Details

- Day 3:

- Module 5: Phase 2 Details (continued)

- Module 6: Special Topics

- Module 6A - High Energy Arcing Faults in Electrical Distribution and Switching Equipment

- Module 6B - Cable Tray Fires

- Module 6C - Reverse Engineering The Hot Gas Layer

- Module 6D: Flexibility

- Discussion and Closing 


\section{Page Intentionally Left Blank}




\section{Module 1: Introduction to Fire SDP Philosophy and Example Problem}




\section{Introduction to Fire SDP Philosophy and Example Problem}

- Objective: Describe the philosophy underlying the Fire Protection Significance Determination Process (SDP)

- This section provides a very brief and high level overview of the process, including similarities and differences with the SDP for internal events 


\section{Fire SDP Overview}

- Entry conditions (what is a finding?)

- Risk significance (color assignment) criteria

- Duration factor plays the same role as in internal events SDP

- Focus on credible fire scenarios

- You are asked to develop one or more credible fire scenarios

- Use of plant notebooks and pre-solved worksheets for post-fire safe shutdown

- Your use of judgment is critical!

\section{Idaho National Laboratory}




\section{Fire SDP Overview}

- Process is tied rather directly to fire PRA

- Simplified versions of common PRA methods

- "The equation" is the PRA equation - that just means we multiply factors directly instead of adding their exponents

- Scenarios are tied to a timeline

- Timing of critical events drives Phase 2 in particular

- Time to damage versus time to suppression

- Many steps, but each step is focused

- Each step is aimed at a specific bit of information needed to quantify fire risk increase

\section{Idaho National Laboratory}




\section{Fire SDP Overview}

- Aggressive efforts to identify Green findings as soon as information is sufficient to justify

- Low degradation findings are automatically Green

- "Screen-to-Green" checks included in most steps

- Much supporting guidance

- That's why the "book" is so thick!

- Most inputs come from look-up tables

- Use made of Fire Dynamics Tools (FDTs)

- Excel spreadsheets

\section{Idaho National Laboratory}




\section{Fire Dynamics Tools}

- The NRR Fire Dynamics Tools (FDT) are used to support analysis:

- Temperature conditions in the fire plume and hot gas layer

- Fire detection/suppression actuation times

- Cable fire spread

- Pool fires and radiant heating

- Documented in NUREG-1805

- V\&V documented in NUREG-1824

\section{Idaho National Laboratory}




\section{Desired Outcomes of Fire SDP}

- Quickly identify Green findings

- If a finding is potentially greater than Green, the Phase 2 analysis should be:

- Systematic

- Repeatable

- Accurate

- Defensible

- Reduce analysis burden at all levels (Phase 1, 2, 3)

\section{Idaho National Laboratory}




\section{Problems With Fire SDP Have Not Yet All Been Solved}

- Some issues remain pending in context of SDP treatment - the guidance for assessment is just not there

- If you hit one of these, and can't call it Green, you are probably heading towards Phase 3 


\section{Issues That Remain Pending}

- "Cross-cutting issues"

- We assume finding is tied to one (or more) fire areas

- Some findings cut across many fire areas

- The process works for these, but you need to select a representative set of fire areas to analyze risk change

- Area selection guidance has not been developed

- Examples:

- Broad performance issues for manual fire fighting

- Some circuit analysis issues

- Some manual actions issues

\section{Idaho National Laboratory}




\section{Issues That Remain Pending}

- Guidance for treatment of Main Control Room (MCR) fires and MCR abandonment is incomplete

- No explicit guidance in Phase 2 on how to assess conditional probability of MCR abandonment

- There are worksheets for alternate and remote shutdown

- MCR fire frequency is nominally covered, but guidance on partitioning is a bit weak

- Likelihood of a fire in a specific panel or cabinet

- MCR manual suppression is covered by a suppression curve, but key is failure of prompt suppression, and that guidance is still lacking

\section{Idaho National Laboratory}




\section{Issues That Remain Pending}

- Complex manual actions

- Worksheets are provided to assess manual actions but, due to simplified approach, won't give much credit to complex action sets

- Complex actions sets may require additional analysis (e.g., Phase 3) 


\section{Issues That Remain Pending}

- There are processes underway to address most of these issues - SDP will incorporate guidance as it develops:

- Manual fire-fighting

- Circuit analysis

- Manual actions 


\section{A Word About Complexity}

- The process looks complex, but hope to convince you it is really pretty straight-forward

- The systematic structure and supporting guidance should aid efficiency and effectiveness

- You may not be fully convinced this week, but hope you will come to see this as you become more experienced with the process

- Practice and regular use will be a key

- If you only do Fire SDP once a year, you may struggle

\section{Idaho National Laboratory}




\section{Example Problem}

- Go over background material for example problem 


\section{Module 2: Concepts, Terminology, and Fire Scenario Introduction}




\section{Concepts, Terminology, and Fire Scenario Introduction}

- Objectives:

- Outline the basic quantification process used in fire PRA

- Define the factors that go into quantification

- Define key terms

- Point out some "red flag" issues along the way

- Define fire scenarios and introduction of details

\section{Idaho National Laboratory}




\section{Why?}

- Why spend time here? Why not jump right into the SDP process?

- The fire SDP structure is the same as that used in a general fire PRA

- If you understand this basis, life will be much easier

- Lots of unique terminology

- Meanings need to be clear

- Allows us to look at the technical quantification process separate from the SDP regulatory decision-making process 


\section{Risk}

- Risk combines the likelihood that something undesirable will happen with the severity of resulting consequences

- From PRA Basics: Risk = Frequency $\times$ Consequences

- In context of NRC mission, risk is most correctly measured based on potential public health consequence:

- Atomic energy act empowers NRC to establish and enforce standards governing the commercial use of nuclear materials and facilities as "the Commission may deem necessary or desirable in order to protect health and safety and minimize danger to life or property."

- That implies risk measures such as acute and latent fatalities

- Probabilistic Safety Goals of 1986 established goals for acute and latent fatalities

- Primary measure of fire risk is Core Damage Frequency (CDF)

- CDF is a surrogate for public health consequence risk

- Large Early Release Frequency (LERF) not used for fire protection SDP 


\section{How We Estimate Fire CDF}

- We calculate fire CDF using four basic factors:

- Fire Frequency (F)

- Severity Factor (SF)

- Probability of Non-Suppression (PNS)

- Conditional Core Damage Probability (CCDP)

- Note that SF is often folded into fire PRA as a part of ' $F$ ' or 'PNS' depending on analyst preference - we'll call it out explicitly in Fire SDP

\section{Idaho National Laboratory}




\section{How We Estimate Fire CDF}

- For one fire scenario:

$-\mathrm{CDF}_{\mathrm{i}}=\mathrm{F}_{\mathrm{i}}{ }^{*} \mathrm{SF}_{\mathrm{i}}{ }^{*} \mathrm{PNS}_{\mathrm{i}}{ }^{*} \mathrm{CCDP}_{\mathrm{i}}$

- We do as many fire scenarios as we need to, add them up (carefully), and that is our fire CDF estimate

- We can roll up CDF values at different levels:

- One fire scenario

- One fire ignition source - multiple scenarios

- One fire area - multiple ignition sources

- One building - multiple fire areas

- Entire unit

- Entire plant site 


\section{How We Estimate Fire CDF}

- Fire SDP focuses on fire area roll-up

- Question: what is the risk increase caused by a specific performance deficiency?

- Deficiency is assumed to be tied to one or two fire areas

- We estimate risk for the impacted area(s)

- Remember that some issues cut across fire areas - examples:

- Post-fire manual actions

- Manual fire brigade

- Circuit analysis issues

- We don't do cross-cutting issues (yet)

- You have to tie your finding to one or more fire areas

- No guidance for picking areas for cross-cutting issue 


\section{Fire Frequency $(F)$ :}

- Definition: The rate at which fire occurs during some time period

- Time period is generally $\mathbf{1 2}$ months of at-power reactor operations

- One reactor-year ( ry )

- Estimated based on past experience

- A bunch of statistics that we won't go into

- Database used contains nearly 1,500 reported "fires"

- EPRI Fire Event Database updated through 2002

- Industry average capacity factors are used

- General units of measure:

- fires / ry 


\section{Pop Quiz - Who Is This?}

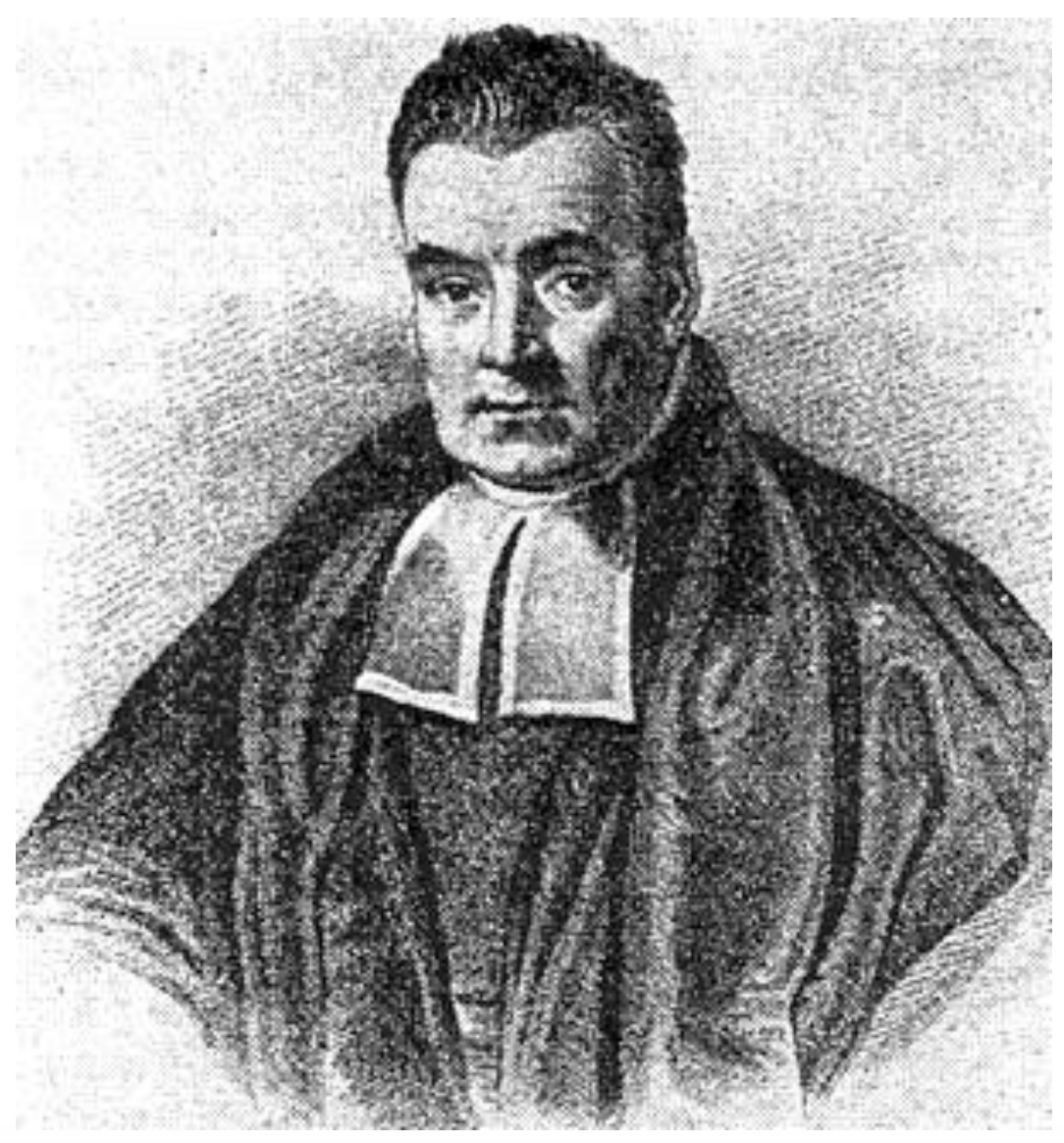

\section{Ti1. Idaho National Laboratory}




\section{Fire Frequency: $\mathbf{F}$}

- You often hear that not all events reported as a fire hold the potential to challenge nuclear safety - TRUE!

- We took care of this for you

- Events were "screened out" if there was no potential for a safety challenge

- Ignition frequencies provided for SDP should not be adjusted beyond the instructions provided - leave that to Phase 3

- In the end, we retained about $1 / 2$ of the fire "events" as potentially challenging

- Actual percentage retained depends on nature of fire source 


\section{Fire Frequency and Event Screening}

- Sounds easy, but you can really cause problems if you're not careful

- Important to maintain independence

- Other steps in analysis take credit for things you might be "counting" when you screen the events

- Basic assumptions tend to flow from the "event set" you choose as representing your fire frequency

- Be skeptical when someone argues that particular events are not relevant to fire risk

- They may be right, but their basis for rejecting an event cannot align with another factor credited elsewhere

\section{Idaho National Laboratory}




\section{Fire Frequency: $F$}

- Statistics give us the frequency of a fire somewhere, or involving something, in the plant

- Tied to either location or fire ignition source

- We assume this frequency is the same for all plants

- What we want is the frequency of a fire involving a specific ignition source in a specific location

- For most cases, component based fire frequencies do this directly - e.g., you get frequency for one motor

- In some cases we apply a partitioning factor to reflect a critical location out of all possible locations

- Area ratio factors - e.g., transients, welding

- Linear feet ratio factors - e.g., cable trays, control room panels 


\section{If We Need A Room Fire Frequency}

- We can use a generic area fire frequency based on average industry experience for similar fire areas

- SDP through step 2.3

OR

- We can add up the contributions from all the individual sources in that particular fire area

- SDP beginning with Step 2.4

- Don't expect to get the same answer either way

- For SDP, the generic values are intended to be slightly conservative - especially in Phase 1

- This won't be a universal truth, but differences should not be significant 


\section{Grouping Fire Ignition Sources}

- You can group some individual ignition sources, and treat the group rather than each individual

- Common example is electrical cabinets/panels

- Want all members of the group to be "the same"

- Fire characteristics

- Proximity to targets (damage) and secondary combustibles (fire spread)

- Frequency for group is sum of frequency of each individual source

- For group of 10 panels, fire frequency = 10 times frequency for a single panel

- More on grouping later

\section{Idaho National Laboratory}




\section{Severity Factor (SF)}

- General fire PRA definition: value between 0 and 1 reflecting fraction of all fires that are considered threatening in the context of a specific fire scenario 


\section{Severity Factor: Fire SDP}

- SDP approach ties SF to fire intensity

- Current PRA practice, but not same as typical IPEEE for fires

- Why tie SF to fire intensity?

- Burn an electrical panel 10 times, and you'll probably get 11 different burn profiles

- This reflects fact that fire intensity profile is inherently uncertain

- All things being equal, some fires will remain small, some will get big

- If it takes a big fire to cause problems (and it usually does) we reflect this through the severity factor

\section{Idaho National Laboratory}




\section{Severity Factor}

- SDP Definition: SF = the fraction of fires big enough to cause damage to at least one potential target and/or spread fire to secondary combustibles

- We calculate "big enough" on a case-specific basis

- How big is the fire [use peak heat release rate (HRR)]

- How close are the damage targets and secondary combustibles

- We use two HRR values for each fire ignition source

- Lower HRR represents $90 \%$ of all fires: $\mathrm{SF}=\mathbf{0 . 9}$

- Larger HRR represents worst $10 \%$ of fires: $\mathrm{SF}=0.1$

- In effect we split each fire ignition source into two possible fires - one big and one not so big

- If only the larger HRR leads to spread/damage, we end up with a net severity factor of 0.1

\section{Idaho National Laboratory}




\section{Illustration of SF Concept:}

-Even looking at a single fire ignition source, not all fires will be the same, some will be big, some not so big

-Fire intensity or heat release rate (HRR) is not a point value!

-We model uncertainty in peak HRR with a probability distribution

\section{Peak HRR Probability Distribution}

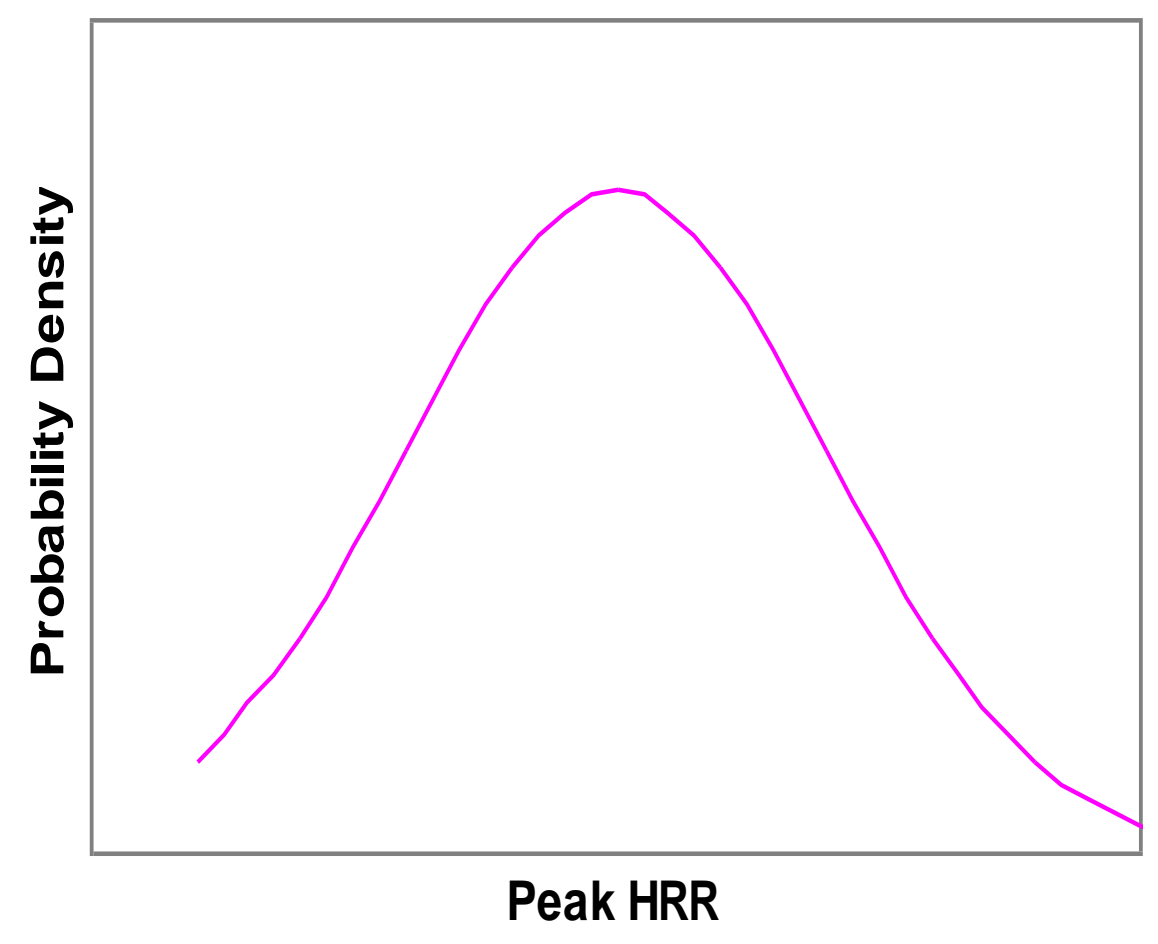

\section{Idaho National Laboratory}




\section{Illustration of SF Concept - General}

-We look for the smallest fire leading to fire damage and/or spread

-Fires that large or larger are the "risky" ones

-We tie SF to the fraction of fires that large or larger

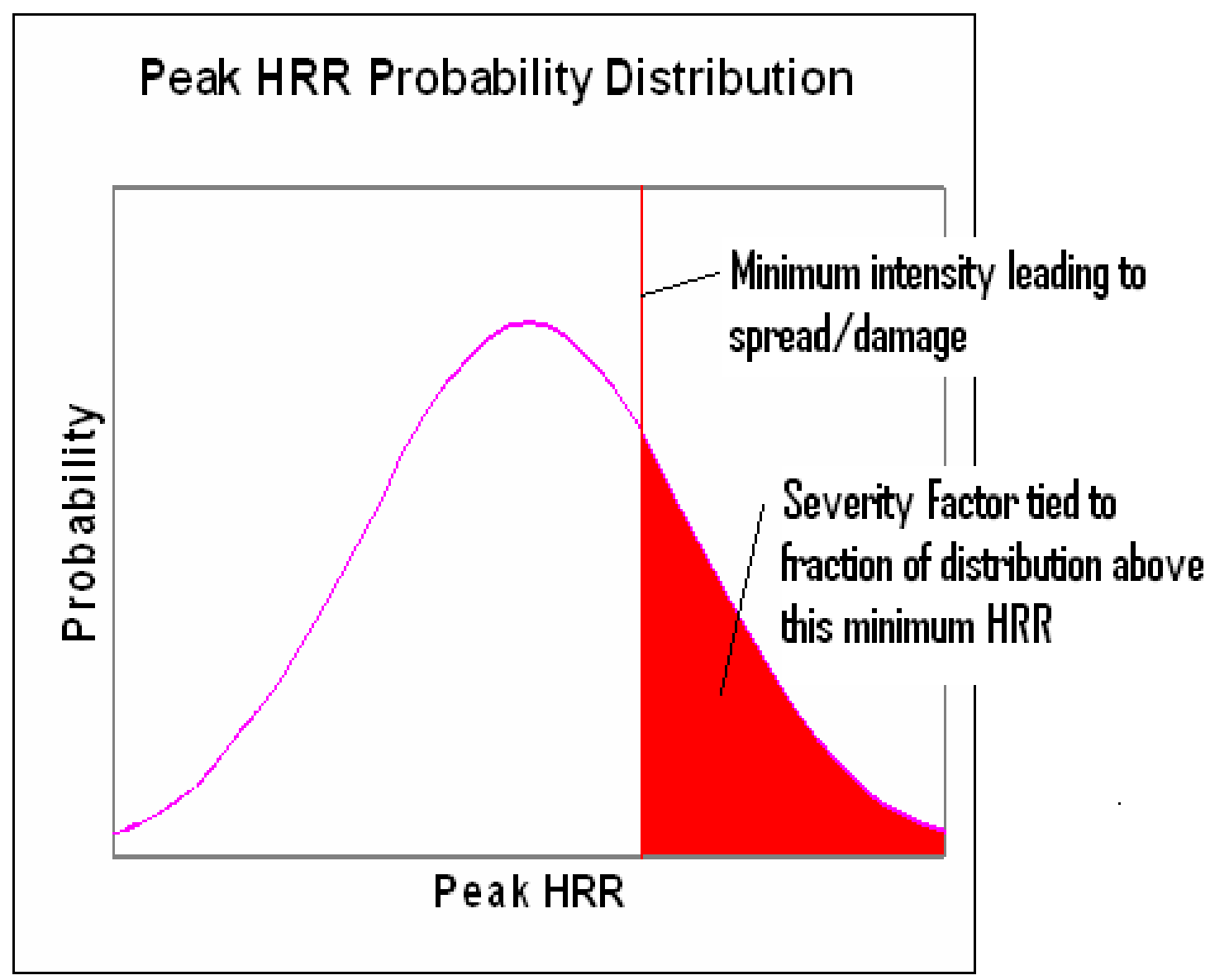

\section{Idaho National Laboratory}




\section{Illustration of SF Concept - SDP}

Peak HRR ProbabilityDistribution

- For SDP we use a simplified version

- Two fire HRR

values for each fire ignition source

- Expected value represents $90 \%$ of fires

- High confidence value represents $10 \%$ of fire

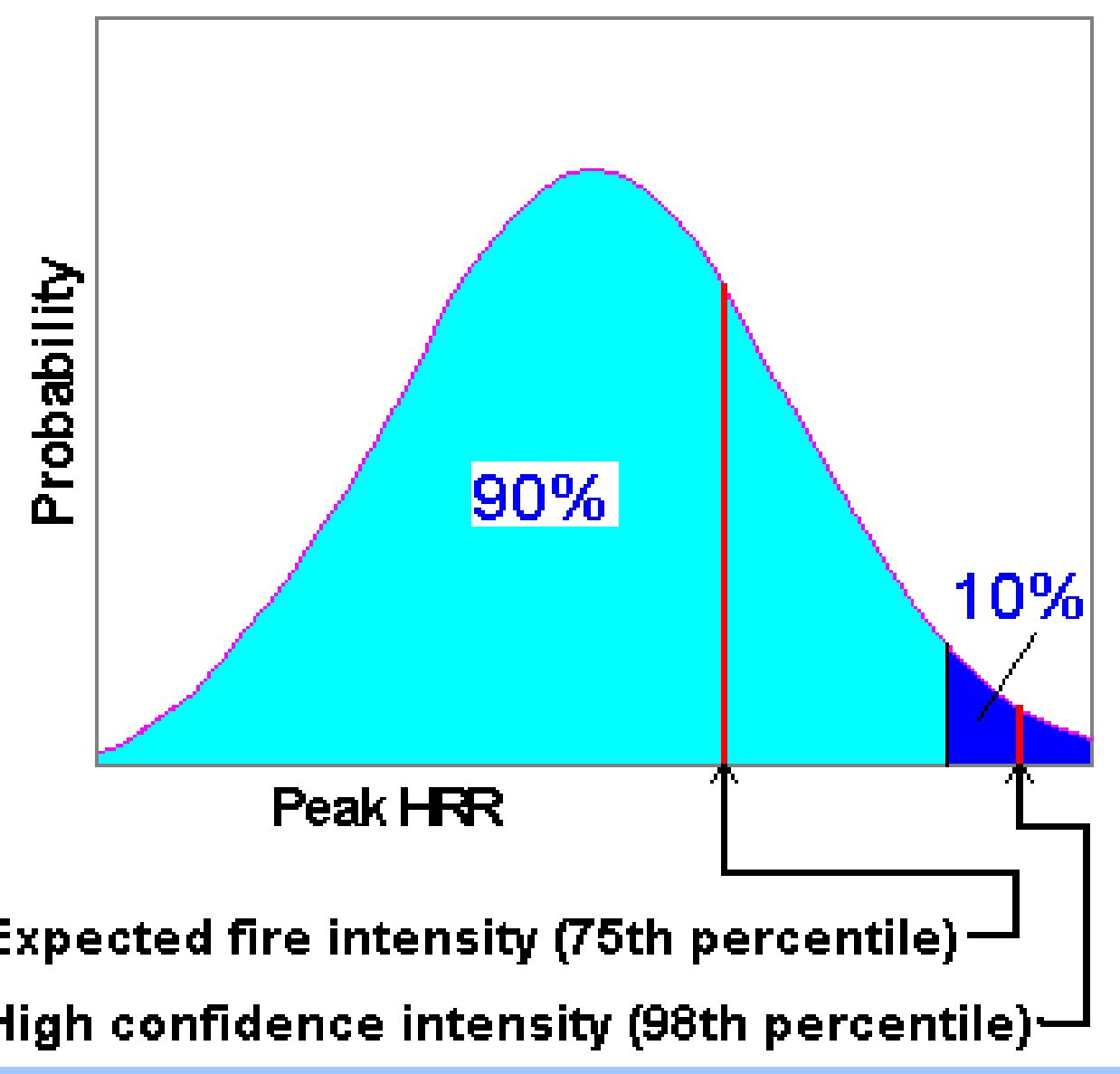

Idaho National Laboratory

High confidence intensity ( 98 th percentile) 


\section{SDP Approach - Quick Review}

- SDP uses simplified version of general approach

- Two fire intensity (HRR) values used represent the full distribution for each fire ignition source

- 'Expected' and 'High Confidence' or $75 \%$ and $98 \%$

- Words/numbers not important - it's the concept that counts

- Assigned SF of 0.9 and 0.1 respectively

- Assess the spread/damage potential for these two HRR values

- The final results combine these two cases using SF as, in effect, a weighting factor on fire frequency

- Net severity factor depends on whether each intensity value causes damage

\section{Idaho National Laboratory}




\section{Obtaining HRR Values}

- Discrete HRR values were suggested based on Fire Risk Requantification Study (FRRS)

- Review and discussion by SDP fire scenario team including NRC and Industry reps. - an expert panel

- Final values ultimately accepted for SDP

- Some adjustments made in FRRS approach to reflect SDP team/panel input

\section{Idaho National Laboratory}




\section{Severity Factor - Past Red Flag Issue for Fire PRA}

- One of the most widely and easily abused aspects of fire PRA

- Steve Nowlen's professional view

- Some cases of abusive application were seen in the IPEEEs, so take care when someone cites those to you

- You'll see severity factors crediting:

- Prompt suppression, self-extinguished fires, fires that caused no trip, fires that did not spread, fires that did not damage secondary components, fires in non-vital areas, and ... the kitchen sink

\section{Idaho National Laboratory}




\section{Severity Factor (Summary)}

- Before you buy, remember the three "Ds" of PRA:

- Dependency, dependency, dependency

- The same factors may be accounted for elsewhere in the PRA - either implicitly or explicitly

- When you see the use of one (or heaven forbid more than one) severity factor in quantification you have to ask if they are double counting somewhere 


\section{Probability of Non-Suppression (PNS)}

- Definition: PNS - The conditional probability that, given the fire, the fire will not be suppressed prior to the failure of a specific set of damage targets or ignition of secondary combustibles

- Key 1: Specific to a particular fire ignition source scenario

- May be a grouped set of fire ignition sources

- Key 2: Specific to a particular target set

- PNS is the conditional probability that, given the fire, these targets will fail or ignite

\section{Idaho National Laboratory}




\section{Target Set}

- A collection of components and/or cables that may be threatened by a postulated fire

- Target set could be anything from one cable to everything in the fire area 


\section{Target Set}

- The target set either survives or fails as a whole

- If you need to break down a target set, you really need to define more than one target set

- Target sets can be progressive if needed - one set represents expansion of another smaller set:

- Target Set $1=$ item 1 $\}$

- Target Set 2 = \{items 1,2,3\} ...

- Helpful if two trains are threatened but separated (for example)

- Different fire ignition sources may have the same target set or different target sets

\section{Idaho National Laboratory}




\section{Target Set}

- For any one fire ignition source:

- Most often one target set is enough

- You may define a series of expanding target sets, if necessary, to reflect growth and spread of the fire

- Don't go overboard - one, two, or at most three, should handle most situations 


\section{Target Set}

We'll come back to this a bit later, but...

- Poor cable routing data actually makes this step easier

- If you don't know where specific cables are, you basically have to assume the worst

- Good cable routing data can actually complicate the choice

- You may be tempted to define many target sets as each tray becomes involved

- Don't: keep it simple 


\section{Back to PNS...}

- PNS is a 'probabilistic' horse race: time to damage versus time to suppression

- Time to damage depends on:

- How close targets are to the fire

- Target failure threshold

- How big the fire is

- Possibly: How quickly fire spreads

- The plant's chances of putting the fire out within this time depend on:

- What sort of fixed fire suppression capability is available

- Timing of manual fire response (e.g., the brigade) 


\section{Time to Damage}

- We can predict time to damage in three steps:

- Set the damage threshold

- Targets are usually cables

- Two basic cable types:

- thermoset (robust)

- thermoplastic (wimpy)

- Note: KERITE cables are a special type of thermoset cable, and because of the nature of KERITE cables they use the target temperatures for thermoplastic cables in SDP.

- Predict the exposure conditions

- Plume, direct radiant heating, or hot gas layer

- Estimate temperature or heat flux at target location using Fire Dynamics Tools (FDTs)

- Convert exposure condition to damage time

- SDP uses look-up tables 


\section{Cable Insulation/Jacket Types}

- Thermoplastic

- Melt if heated, solidify if cooled

- Drip and burn as a liquid pool

- More wimpy

- Examples:

- Polyethylene (PE)

- Polyvinylchloride (PVC)

- *Thermoset KERITE cables use target temperature of thermoplastic cables in SDP
- Thermoset

- Don't melt

- Burn/char in place if heated enough

- More macho

- Examples:

- Cross-linked polyethylene (XLPE or XPE)

- Ethylene-Propylene rubber (EPR)

\section{Idaho National Laboratory}




\section{Damage Thresholds}

- Screening Criteria for Assessment of Ignition and Damage Potential of Electrical Cables

Cable Type:

Thermoplastic*

Heat Flux:

Temperature:
(Metric)

$6 \mathrm{~kW} / \mathrm{m}^{2}$

$205^{\circ} \mathrm{C}$
(English)

$0.5 \mathrm{BTU} / \mathrm{ft}^{2} \mathrm{~s}$

$400^{\circ} \mathrm{F}$

*Thermoset KERITE cables use target temperatures for thermoplastic cables in SDP

Thermoset

Heat Flux:

Temperature:
(Metric)

$11 \mathrm{~kW} / \mathrm{m}^{2}$

$330^{\circ} \mathrm{C}$
(English)

1.0 BTU/ft ${ }^{2} \mathrm{~s}$

$625^{\circ} \mathrm{F}$ 


\section{Damage Time Look-Up Table (Example*)}

${ }^{\star}$ Table A7.1 from IMC 0609, Appendix F, Attachment 7, 02/28/05

${ }^{*}$ Thermoset KERITE cables use target temperatures for thermoplastic cables in SDP

\begin{tabular}{|c|c|c|}
\hline \multicolumn{2}{|c|}{ Exposure Temperature } & \multirow{2}{*}{$\begin{array}{l}\text { Time to Failure } \\
\text { (minutes) }\end{array}$} \\
\hline${ }^{\circ} \mathrm{C}$ & ${ }^{\circ} \mathrm{F}$ & \\
\hline $330 \leq \mathrm{T}<335$ & $625 \leq \mathrm{T}<634$ & 28 \\
\hline $335 \leq \mathrm{T}<340$ & $634 \leq \mathrm{T}<642$ & 24 \\
\hline $340 \leq \mathrm{T}<345$ & $642 \leq \mathrm{T}<651$ & 20 \\
\hline $345 \leq \mathrm{T}<350$ & $651 \leq \mathrm{T}<660$ & 16 \\
\hline $350 \leq \mathrm{T}<360$ & $660 \leq T<680$ & 13 \\
\hline $360 \leq T<370$ & $680 \leq T<700$ & 10 \\
\hline $370 \leq \mathrm{T}<380$ & $700 \leq T<716$ & 9 \\
\hline $380 \leq T<390$ & $716 \leq \mathrm{T}<735$ & 8 \\
\hline $390 \leq \mathrm{T}<400$ & $735 \leq \mathrm{T}<752$ & 7 \\
\hline $400 \leq T<410$ & $752 \leq T<770$ & 6 \\
\hline $410 \leq T<430$ & $770 \leq \mathrm{T}<805$ & 5 \\
\hline $430 \leq T<450$ & $805 \leq T<840$ & 4 \\
\hline $450 \leq \mathrm{T}<470$ & $840 \leq T<880$ & 3 \\
\hline $470 \leq \mathrm{T}<490$ & $880 \leq T<915$ & 2 \\
\hline $\mathrm{T} \geq 490$ & $\mathrm{~T} \geq 915$ & 1 \\
\hline
\end{tabular}

Idaho National Laboratory 


\section{Damage Time Look-Up Table (Example*)}

*Table A7.2 from IMC 0609, Appendix F, Attachment 7, 02/28/05

*Thermoset KERITE cables use target temperatures for thermoplastic cables in SDP

\begin{tabular}{|c|c|c|}
\hline \multicolumn{2}{|c|}{ Table A7.2 - Failure Time-Temperature Relationship for Thermoplastic Cables } \\
\cline { 1 - 2 } Exposure Temperature & $\begin{array}{c}\text { Time to Failure } \\
\text { (minutes) }\end{array}$ \\
\hline${ }^{\circ} \mathrm{C}$ & ${ }^{\circ} \mathbf{F}$ & 30 \\
\hline $205 \leq \mathrm{T}<220$ & $400 \leq \mathrm{T}<425$ & 25 \\
\hline $220 \leq \mathrm{T}<230$ & $425 \leq \mathrm{T}<450$ & 20 \\
\hline $240 \leq \mathrm{T}<245$ & $450 \leq \mathrm{T}<475$ & 15 \\
\hline $245 \leq \mathrm{T}<260$ & $475 \leq \mathrm{T}<500$ & 10 \\
\hline $260 \leq \mathrm{T}<275$ & $500 \leq \mathrm{T}<525$ & 8 \\
\hline $275 \leq \mathrm{T}<290$ & $525 \leq \mathrm{T}<550$ & 7 \\
\hline $290 \leq \mathrm{T}<300$ & $550 \leq \mathrm{T}<575$ & 6 \\
\hline $300 \leq \mathrm{T}<315$ & $575 \leq \mathrm{T}<600$ & 5 \\
\hline $315 \leq \mathrm{T}<330$ & $600 \leq \mathrm{T}<625$ & 4 \\
\hline $330 \leq \mathrm{T}<345$ & $625 \leq \mathrm{T}<650$ & 3 \\
\hline $345 \leq \mathrm{T}<355$ & $650 \leq \mathrm{T}<675$ & 2 \\
\hline $355 \leq \mathrm{T}<370$ & $675 \leq \mathrm{T}<700$ & \\
\hline
\end{tabular}




\section{Automatic Suppression Time}

- We can predict the time to actuation for an automatic suppression system using a simple spreadsheet tool

- e.g., a sprinkler head looks just like a heat detector

- Fire Dynamics Tools (FDTs) from NRR

- This gives us a number

- $x$ :y minutes:seconds 


\section{PNS for Automatic Suppression}

- We don't want to do a straight yes/no comparison between damage time and suppression time - this can be very misleading

- Damage time $=10 \mathrm{~min}$

- Suppression time $=9 \mathrm{~min}, 30 \mathrm{sec}$.

- Nominally suppression wins, but what is your confidence in this answer?

- Is it really yes/no or fail/no fail?

- To acknowledge uncertainties in the time estimates, we use the margin between damage time and suppression time 


\section{Probability Table for Automatic Suppression}

Probability of Non-suppression for Fixed Fire Suppression Systems Based on the Absolute Difference Between Damage Time and Suppression Time

Time Delta: (tDarmage - tsuppress )

Negative Time up to 1 Minute

$>1$ Minute to 2 Minutes

$>2$ Minutes to 4 Minutes

$>4$ Minutes to 6 Minutes

$>6$ Minutes to 8 Minutes

> 8 Minutes to 10 Minutes

$>10$ Minutes
PNS

1.0

.95

.80

.5

.25

.1

0.0 


\section{PNS and Manual Suppression}

- PNS for manual suppression estimated from empirical fire duration curves

- The vast majority of fires are manually suppressed

- We get fire duration data for enough of the reported fires to develop a fire duration curve

- Pick the appropriate fire duration curve

- Estimate $\left(t_{\text {damage }}-t_{\text {detection }}\right)$

- Remember that detection triggers manual response, but damage time ( $\left.t_{\text {damage }}\right)$ is measured from time of ignition $(t=$ 0)

- Pick off PNS $_{\text {manual }}$

- Values also available in look-up table

\section{Idaho National Laboratory}




\section{Duration Curve Example:}

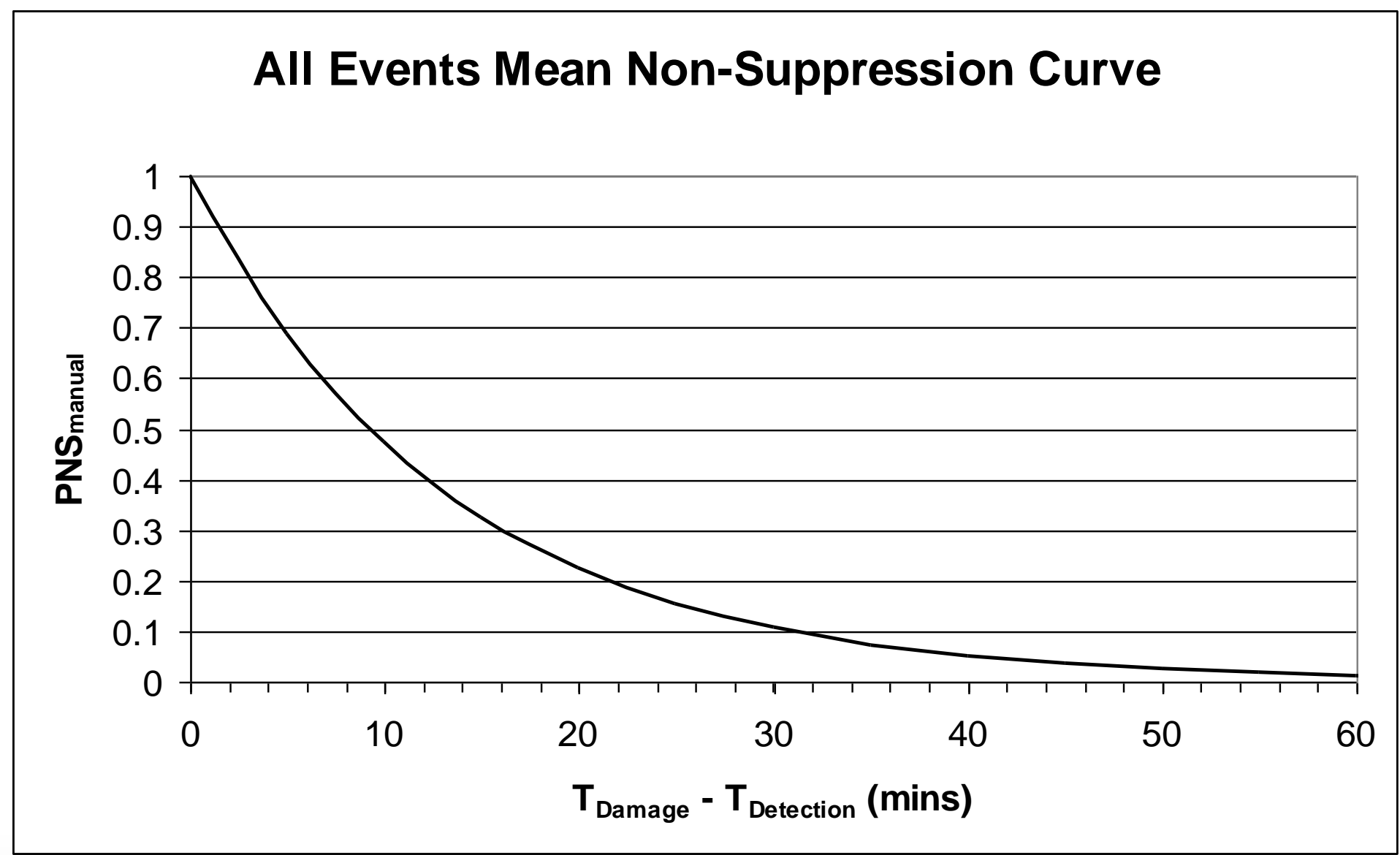

\section{Idaho National Laboratory}




\section{Auto vs. Manual Suppression}

- If auto is present, we assume it will be primary suppression means

- If auto fails, manual suppression is always the backup and we assume that;

- Water-based automatic suppression systems fail on demand $2 \%$ of the time

- Dry-pipe and Gaseous systems fail on demand $5 \%$ of the time

- If no auto system, then manual suppression is all there is

\section{Idaho National Laboratory}




\section{Manual Fixed Suppression}

- Fixed fire suppression systems that have no automatic actuation mechanism - human action is required

- No hard/fast rule possible - use following:

- Estimate detection time

- Estimate physical response time

- Review decision criteria and estimate decision-making time

- Nominal value is 2 minutes

- Increase if circumstances warrant

- Actuation time is sum of these three 


\section{Combining Manual and Auto- Suppression}

- If auto-suppression is present, it is assumed first line of defense

- Auto systems don't always work:

- Water based systems 2\% failure on demand

- Gaseous systems 5\% failure on demand

- Values reflect both reliability and availability (outof-service time)

- Manual is always available as a backup 


\section{Combining Manual and Auto- Suppression}

For Water-based systems:

$\mathrm{PNS}_{\text {scenario }}=\left(0.98 \times \mathrm{PNS}_{\text {fixed-scenario }}\right)+\left(0.02 \times \mathrm{PNS}_{\text {manual-scenario }}\right)$

For Dry-pipe and Gaseous systems:

$\mathrm{PNS}_{\text {scenario }}=\left(0.95 \times \mathrm{PNS}_{\text {fixed-scenario }}\right)+\left(0.05 \times \mathrm{PNS}_{\text {manual-scenario }}\right)$

$* * \mathrm{PNS}_{\text {scenario }} \leq \mathrm{PNS}_{\text {manual-scenario }}$ 


\section{Special Consideration For Degraded Gaseous System}

- If gaseous suppression system cannot maintain adequate suppressant concentration for sufficient time to assure fire extinguishment, then manual fire-fighting must do the final mop-up

- The degraded gaseous system cannot permanently extinguish the fire, but does buy the fire brigade some additional response time

- We assume that the fire will be held in check during the time that the fire suppressant concentration is maintained at design level

- Upon dissipation of suppressant fire will re-flash - we assume it will pick up right where it left off 


\section{Degraded Gaseous Systems}

- To get PNS we need to compare damage time to a suppression time-line with the following elements:

- Actuation time for gaseous system (manual or automatic as normally analyzed)

- The probability table that reflects our confidence that system actuation is timely compared to fire damage time

- Hold time / soak time for design concentration that system can deliver

- Manual response following loss of concentration

- Details in Module 5 


\section{Conditional Core Damage Probability (CCDP)}

- Definition: The conditional probability that, given fire-induced loss of a target set, safe shutdown efforts will fail to achieve a safe and stable state, thus resulting in core damage

- Safe and stable generally means hot shutdown

- Risk analyses don't generally look at ability to achieve cold shutdown 


\section{CCDP}

- CCDP is calculated using a post-fire safe shutdown plant response model

- Screening estimates may only credit the designated post-fire safe shutdown path

- For more detail, we use a broader plant response model that may credit components and systems beyond Appendix R

- SDP originally used the plant notebooks and presolved worksheets 


\section{CCDP}

- We won't go into depth on this topic, but some high level rules:

- To credit a system or function, you must have reasonable assurance that it will not be damaged by the fire - your judgment counts

- We do credit manual actions - guidance is provided - but complex sets of actions will likely get little credit in Phase 2

- Spurious operations may be a part of CCDP calculation - you may need help here

\section{Idaho National Laboratory}




\section{That's pretty much it.}

$\mathrm{CDF}_{\mathrm{i}}=\mathrm{F}_{\mathrm{i}}{ }^{*} \mathrm{SF}_{\mathrm{i}}{ }^{*} \mathrm{PNS}_{\mathrm{i}}{ }^{*} \mathrm{CCDP}_{\mathrm{i}}$

Of course, the devil's in the details...

\section{Idaho National Laboratory}




\section{More On Fire Scenarios}

- Definition: A fire scenario is a postulated sequence of events starting with the ignition of a fire and ending either in plant safe shutdown or core damage. 


\section{Fire Scenario}

- What is a Fire Scenario:

(Fire Scenario $)=($ fire ignition source scenario $)$ and (fire growth and damage scenario) and (fire suppression scenario) and (plant SSD response scenario)

Change any element and you have a new fire scenario! 


\section{Fire Ignition Source Scenario}

- Definition: Defines the physical characteristics of the fire that will develop for a particular fire ignition source - key factors:

- Placement of fire "origin" - how close is origin to targets

- Heat release rate (HRR)

- SDP bins fire sources by type, and ties characteristics to each type

- Five HRR values used to characterize all (simple) fires 
Table 2.3.1 - Mapping of General Fire Scenario Characterization Type Bins to Fire Intensity Characteristics

\begin{tabular}{|c|l|l|l|l|l|l|}
\hline \multirow{2}{*}{$\begin{array}{c}\text { Fire Size } \\
\text { Bins }\end{array}$} & \multicolumn{5}{|c|}{ Generic Fire Type Bins with Simple Predefined Fire Characteristics } \\
\cline { 2 - 7 } & $\begin{array}{l}\text { Small } \\
\text { Electrical } \\
\text { Fire }\end{array}$ & $\begin{array}{l}\text { Large } \\
\text { Electrical } \\
\text { Fire }\end{array}$ & $\begin{array}{l}\text { Indoor Oil- } \\
\text { Filled } \\
\text { Transformers }\end{array}$ & $\begin{array}{l}\text { Very } \\
\text { Large Fire } \\
\text { Sources }\end{array}$ & $\begin{array}{l}\text { Engines } \\
\text { and } \\
\text { Heaters }\end{array}$ & $\begin{array}{l}\text { Solid and } \\
\text { Transient } \\
\text { Combustibles }\end{array}$ \\
\hline $70 \mathrm{~kW}$ & $\begin{array}{l}75^{\text {th }} \\
\text { Percentile } \\
\text { Fire }\end{array}$ & & & & $\begin{array}{l}75^{\text {th }} \\
\text { Percentile } \\
\text { Fire }\end{array}$ & $\begin{array}{l}75^{\text {th }} \text { Percentile } \\
\text { Fire }\end{array}$ \\
\hline $200 \mathrm{~kW}$ & $\begin{array}{l}98^{\text {th }} \\
\text { Percentile } \\
\text { Fire }\end{array}$ & $\begin{array}{l}75^{\text {th }} \\
\text { Percentile } \\
\text { Fire }\end{array}$ & & & $\begin{array}{l}98^{\text {th }} \\
\text { Percentile } \\
\text { Fire }\end{array}$ & $\begin{array}{l}98^{\text {th }} \text { Percentile } \\
\text { Fire }\end{array}$ \\
\hline $650 \mathrm{~kW}$ & & $\begin{array}{l}98^{\text {th }} \\
\text { Percentile } \\
\text { Fire }\end{array}$ & $\begin{array}{l}75^{\text {th }} \text { Percentile } \\
\text { Fire }\end{array}$ & $\begin{array}{l}75^{\text {th }} \\
\text { Percentile } \\
\text { Fire }\end{array}$ & & \\
\hline $2 \mathrm{MW}$ & & & $98^{\text {th }}$ Percentile & & & \\
\hline $10 \mathrm{MW}$ & & & & $\begin{array}{l}98^{\text {th }} \\
\text { Percentile } \\
\text { Fire }\end{array}$ & & \\
& & & & & \\
\end{tabular}




\section{Fire Origin}

- The fire origin is a conceptual point at which we will assume the fire originates.

- Horizontal placement determines what is overhead and therefore within the fire plume

- Vertical placement will affect plume temperature for exposure of overhead targets

- Choice depends on the nature of the fire source

- We'll come back to this later 


\section{Heat Release Rate (HRR)}

- HRR characterizes the fire intensity or the amount of heat generated by a fire per unit time

- Typical units are either KW or BTU/hr

- This is generally the most critical of all fire characterization input values

- Remember - SDP ties fire intensity to severity factor 


\section{Convective / Radiative Fractions}

- Heat transfer from fire is via two primary mechanisms:

- Convective transfer - The mixing of hot fire products with ambient air resulting in direct heating of the surrounding air that in turn causes buoyancy and fire plume behaviors

- Radiative transfer - the luminosity of a fire's flame zone results in direct radiant heating of opaque targets (including soot-laden air)

- Recommended split fractions are:

0.7 convective, 0.3 radiative

- Paired values should add to $\mathbf{1 . 0}$ 


\section{Fire Growth and Damage Scenario}

- Definition: characteristics of fire spread to secondary combustibles if such occurs, and the behaviors leading to failure of an identified thermal damage target set

- You must define a target set - we already covered this

- Damaging conditions may be created either due to burning of the ignition source alone, or due to fire spread

- If fire ignition source alone is not enough, and fire cannot spread, then damage is not possible 


\section{SDP Fire Damage States (FDS)}

- FDS0 - loss of only the fire ignition source

- Not analyzed as a contributor to increase in CDF (screen to Green)

- FDS1 - localized damage near (especially directly above) the fire ignition source

- Keys factors: plume heating, upward spread of fire, and direct radiant heating

- FDS2 - widespread damage within a single fire area

- Key factors: horizontal fire spread, hot gas layer, and failure of degraded raceway fire barriers

- FDS3 - fire damage impacting two (or more) fire areas (room-to-room)

- Key factor: failure of an inter-compartment fire barrier element

\section{Idaho National Laboratory}




\section{Fire Detection and Suppression}

- We credit all available means of fire detection and suppression

- Detection is important mainly because it triggers the manual response

- Plant personnel become aware of the fire

- Fire procedures may kick in (check plant process for when this really happens)

- The fire brigade is activated

- Fixed automatic suppression systems require no prior detection signal, but usually are tied to alarm circuits 


\section{Fire Suppression}

- Remember, in SDP it's a horse race

- Question is not so much "does suppression fail?"

- But rather, "does suppression fail to put out the fire before damage occurs?"

- All fires are put out (or go out) eventually - we want to know if suppression is timely in the context of our specific target set 


\section{CCDP}

- CCDP characterized plant/operator response to the fire

- Objective is safe shutdown (hot shutdown)

- This part can be complex - you will likely want to get your SRA involved to support this effort 


\section{Developing a Fire Time Line}

- Key events on the time line

- Fire ignites ( define this as time $=0$ )

- Fire is detected ( $t_{\text {detection }}$ )

- Manual/operator response begins

- Fire brigade is activated

- Target set fails ( $t_{\text {damage }}$ )

- Remember: $t_{\text {damage }}$ measured from $t=0$

- Automatic suppression activates ( $t_{\text {supp_auto }}$ )

- Manual suppression is successful ( $t_{\text {supp_man }}$ )

- Order of these events is TBD! 


\section{Page Intentionally Left Blank}




\section{Module 3: Process Overview}




\section{Process Overview}

- A quick once-through - flow chart style

- Objective: familiarize you with the process

- Its structure

- Steps and tasks

- How the pieces fit together 


\section{Ground Rules For This Section}

- Process questions are OK

- Please hold questions on Step/Task details

- We'll come back and cover the details of both Phase 1 and Phase 2

- There will be plenty of time for questions on the details 


\section{Process Overview - Scope}

- We are talking about Phase 1 and 2 only

- Phase 3 is still out there

- Anything goes for Phase 3 - that's not our job! 


\section{Phase 1 - Objective and Basis}

- Phase 1 objective: identify findings that can be categorized as Green without detailed analysis

- Phase 1 basis: combines concepts of "qualitative screening" and very preliminary "quantitative screening" from fire PRA 


\section{Figure F.1 - Phase 1 Flow Chart}

Step 1.1 - Provide

Statement of Fire Finding
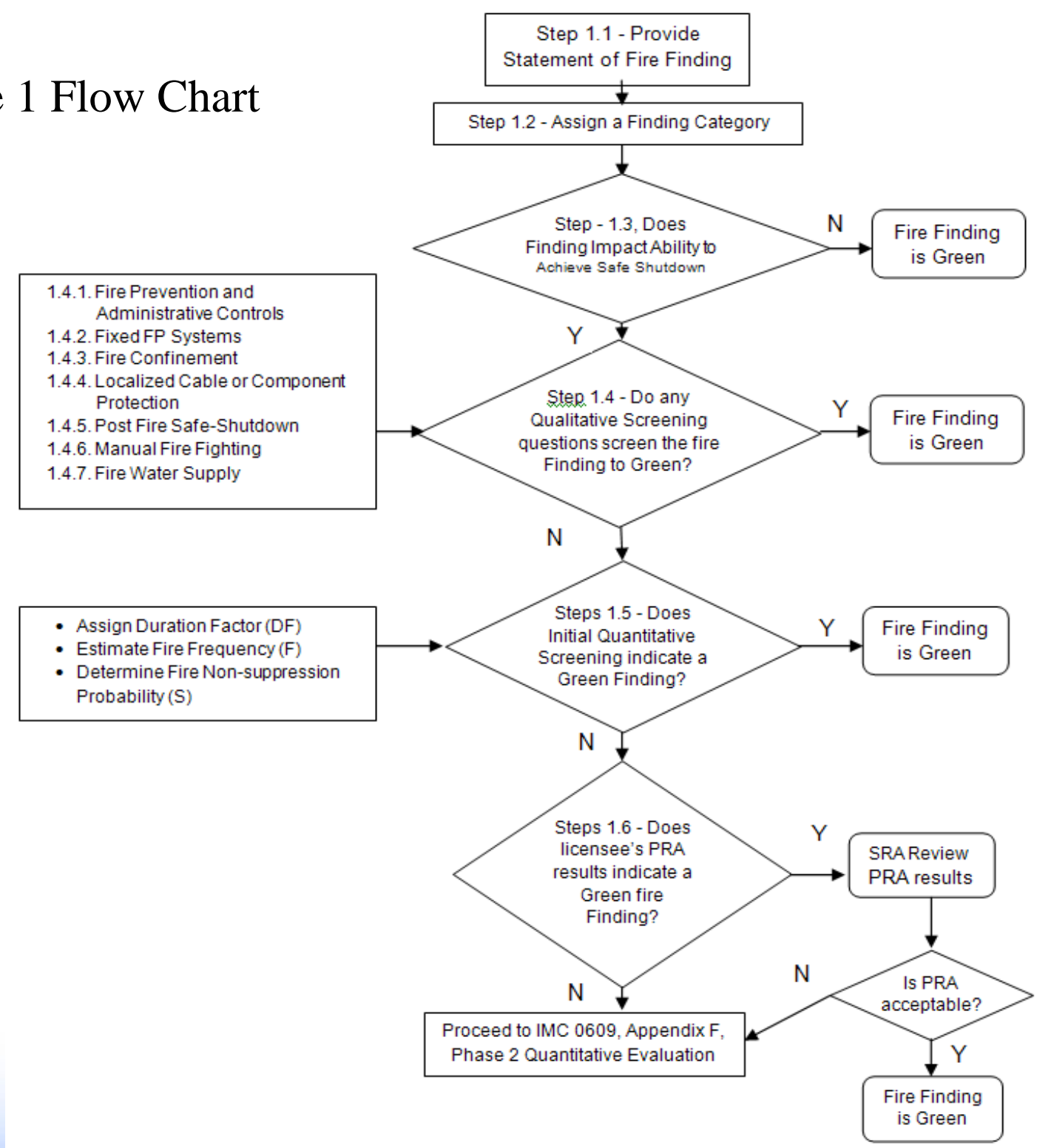

- Assign Duration Factor (DF)

- Estimate Fire Frequency (F)

- Determine Fire Non-suppression Probability (S)

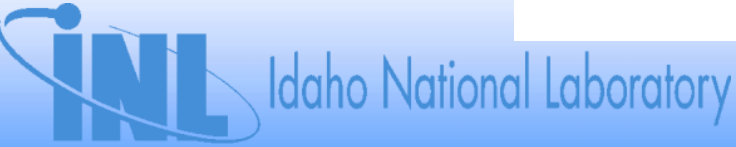




\section{Phase 2 - Objective and Basis}

- Objective: Estimate the increase in CDF due to a finding

- Basis: Simplified versions of current fire PRA methods - we borrow:

- Structure

- Assumptions

- Numerical values

- Analysis Tools

- Quantification approach 


\section{Figure F. 2 - Phase 2 Flow Chart}

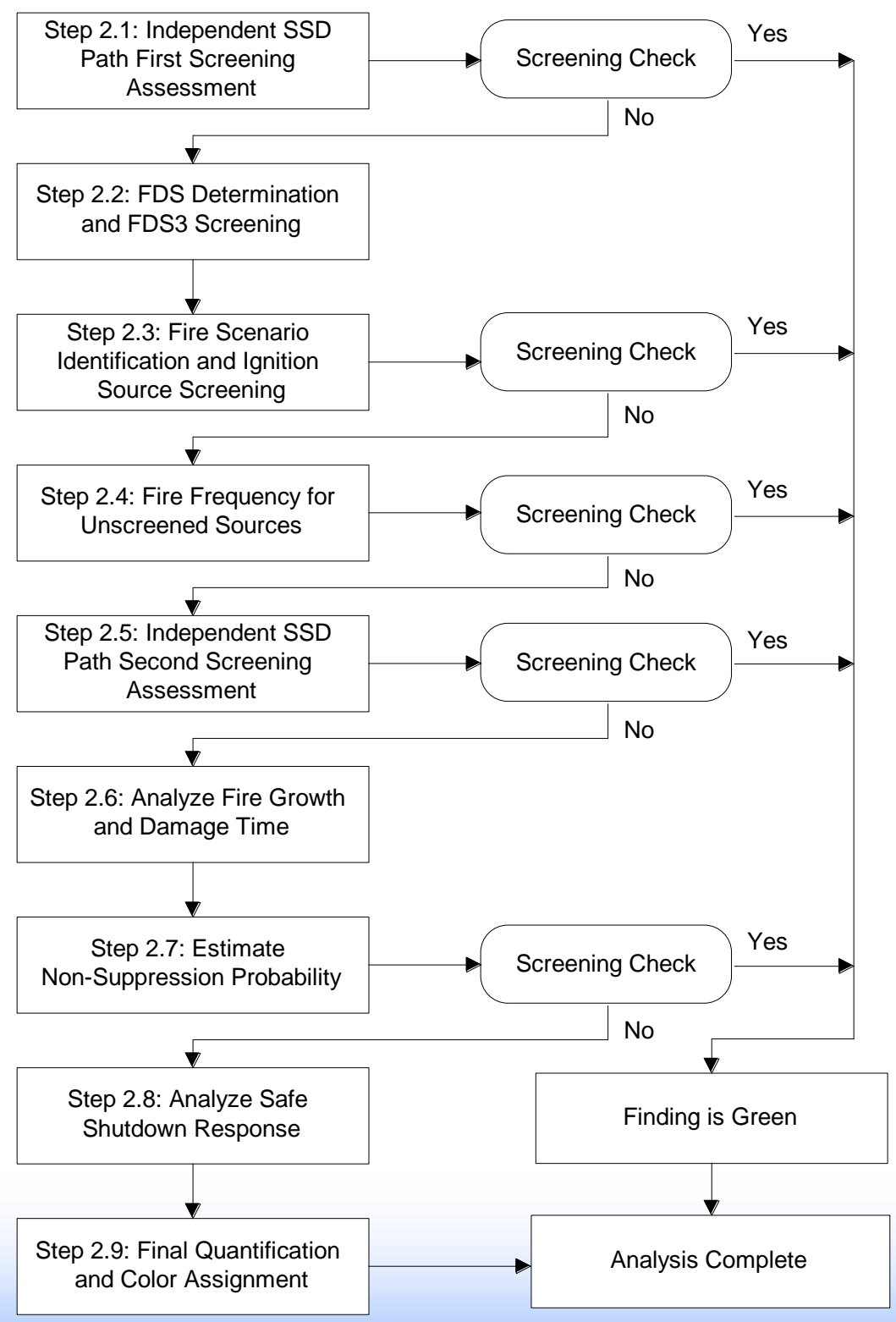

\section{TII. Idaho National Lobocatory}




\section{Assumptions and Limitations}

- This approach is a simplified tool that provides a slightly conservative, nominally order-of-magnitude assessment of the risk significance of inspection findings related to the fire protection program.

- The Fire Protection SDP is a tool that NRC inspectors can easily use to obtain an assessment of the risk significance of a finding.

- The Fire Protection SDP approach has a number of inherent assumptions and limitations. A more detail discussion of these assumptions and limitations is contained in the Supplemental Guidance/Technical Basis for Appendix F (IMC 0308, Attachment 3 of Appendix F).

\section{Idaho National Laboratory}




\section{Assumptions and Limitations (cont.)}

- The Fire Protection SDP assesses the change in CDF, rather than LERF, as a measure of risk significance.

- The quantification approach and analysis methods used in this Fire Protection SDP are largely based on existing fire PRA analysis methods. As such, the methods are also limited by the current state of the art in fire PRA methodology.

- The Fire Protection SDP focuses on risks due to degraded conditions of the fire protection program during full power operation of a nuclear power plant. This tool does not address the potential risk significance of fire protection inspection findings in the context of other modes of plant operation (i.e., low power or shutdown).

\section{Idaho National Laboratory}




\section{Assumptions and Limitations (cont.)}

- In the process of simplifying existing fire PRA methods for the purposes of the Phase 2 Fire Protection SDP analysis, compromises in analysis complexity have been made. The process strives to achieve order of magnitude estimates of risk significance. However, it is recognized that fire PRA methods in general retain considerable uncertainty. The Fire Protection SDP strives to minimize the occurrence of false-negative findings.

- The Fire Protection SDP excludes findings associated with the performance of the on-site manual fire brigade or fire department.

- The Fire Protection SDP Phase 2 quantitative screening method includes an approach for incorporating known fire-induced circuit failure modes and effects issues into an SDP analysis. However, the SDP approach is intended to support the assessment of known issues only in the context of an individual fire area. A systematic plant-wide search and assessment effort is beyond the intended scope of the fire protection SDP.

\section{Idaho National Laboratory}




\section{Assumptions and Limitations (cont.)}

- This document does not currently include explicit treatment of fires in the main control room. The Phase 2 process can be utilized in the treatment main control room fires, but it is recommended that additional guidance be sought in the conduct of such an analysis.

- This document does not currently include explicit treatment of fires leading to main control room abandonment, either due to fire in the main control room or due to fires in other fire areas. The Phase 2 process can address such scenarios, but it is recommended that additional guidance be sought in the conduct of such an analysis.

\section{Idaho National Laboratory}




\section{Module 4: Phase 1 Details}




\section{Phase 1 Details}

- We will cover each step and task in Phase 1:

- Purpose/objective

- What, why, how

- Input/output

- Supporting guidance 


\section{Phase 1- Step 1.1}

- Provide Statement of Fire Inspection Finding

- Provide a clear statement of fire inspection finding and the non-compliance

- IMC 0609 Appendix F Attachment 1: Fire Protection Significance Determination Process Worksheet 


\section{Phase 1- Step 1.2}

- Assign a finding category

- A convenient way to bin (classify) findings

- Later decisions will depend on the assigned category:

- Degradation ratings

- Quantitative screening criteria

- Types of fire scenarios that are relevant

- Look for underlying issue leading to a finding and assign category accordingly 
The Finding Categories Are... (as shown in 0609, App F, Att 1,Table 1)

- Fire Prevention and Administrative Controls

- Fixed Fire Protection Systems

- Fire Confinement

- Localized Cable or Component Protection

- Post-Fire Safe Shutdown (SSD)

- Manual Firefighting

- Fire Water Supply 


\section{Fire Prevention and Administrative Controls}

- Findings relating to combustible control programs, training, permit processes, activity specific fire watches, etc.

- Examples:

- Violation of combustible control limits

- Failure to follow hot work permitting requirements

- Failure to properly execute hot work fire watches

- Deficiencies in fire-protection related training

- Records keeping issues 


\section{Fixed Fire Protection Systems}

- Findings related to:

- Fixed fire detection

- Fixed fire suppression (automatic or manual)

- Fire watches posted as a compensatory measure for a fixed fire protection system outage or degradation

- Examples: Sprinklers, deluge, room flooding gas systems, smoke or heat detectors, etc.

- Excludes fire separation features

- Passive features such as fire barriers, doors, dampers, seals, wraps

- Water curtains (as a fire barrier element)

\section{Idaho National Laboratory}




\section{Fire Confinement}

- Findings related to fire barriers and barrier elements that separate fire areas

- Walls/floors/ceilings

- Penetration seals

- Water curtains when used as a separation element

- Fire and/or smoke dampers

- Fire doors

- Definition of fire area: portion of building or plant that is separated from other areas by rated fire barriers adequate for the fire hazard (R.G. 1.189). 


\section{Localized Cable or Component}

Protection

- Passive fire protection features meant to protect cables and/or components from fire damage given fires within the same fire area

- Cable and raceway fire wraps

- Radiant heat shields

- Spatial separation (e.g., per Appendix R Section III.G.2)

- Fire barriers between fire zones within a fire area 


\section{Post-Fire Safe Shutdown (SSD)}

- Findings that directly impact systems or functions identified in the post-fire SSD analysis or systems or functions relied upon for post-fire SSD

- Completeness of the

- Post-fire SSD component list

- Post-fire SSD analysis

- Post-fire plant response procedures

- Alternate shutdown (e.g., manual actions)

- Remote shutdown and control room abandonment

- Circuit-analysis-related issues (e.g., spurious operation) 


\section{Manual Firefighting}

- Findings that directly impact manual firefighting capabilities

- Hose Station

- Fire Extinguishers

- Fire Pre-Plans 


\section{Fire Water Supply}

- Findings that directly impact fire water supply availability

- Fire Pumps

- Yard Loop Piping

- Water Sources 


\section{Fire Barriers vs. Safe Shutdown}

- Example: A hole in a raceway fire barrier (made during maintenance) was not properly sealed upon completion of maintenance activities. The barrier protects a cable associated with the designated post-fire SSD path.

- This one may be obvious - a localized cable or component protection issue 


\section{Fire Barriers vs. Safe Shutdown}

- Example 2: The licensee committed to providing fire wraps for certain post-fire SSD cables. In one case, the wrong cable tray was wrapped, and the correct tray was left unprotected

- This is a Localized Fire Barrier issue

- The underlying issue is failure to provide the barrier that was committed to

- Treat as highly degraded raceway fire barrier 


\section{Fire Barriers vs. Safe Shutdown}

- Example 3: A cable associated with the designated post-fire SSD path is found to be exposed (with no fire wrap) in a fire area where it is required to support safe shutdown. Further review reveals that the licensee failed to identify the cable as a required component.

- This is a Safe Shutdown Finding - failure to identify a required component is the underlying issue. 


\section{Fire Barriers vs. Safe Shutdown}

- Example 4: It is determined that spurious operation of a particular circuit could compromise the designated post-fire SSD path (open a diversion path) for the area being inspected. A cable that could cause spurious operation is found to be exposed (with no fire wrap) in the fire area being inspected. The licensee did not identify the circuit as an associated circuit; hence, the cable is not on the post-fire SSD component list.

- This is a Safe Shutdown Finding - failure to identify an associated circuit is the underlying issue.

\section{Idaho National Laboratory}




\section{Relationship of Finding Categories to SDP Process}

- Category assigned 'maps' to elements of the analysis process:

- Fire prevention and administrative controls

- Increases fire frequency

- Fixed Fire Protection

- Increases time to suppression

- Fire Confinement

- Focus placed on FDS3 Scenarios

- Localized Cable or Component Protection

- Focus placed on scenarios that damage protected compohent

- Post-Fire Safe Shutdown

- Increases CCDP

- Manual Firefighting

- Increases time to suppression

- Fire Water Supply

- Increases time to suppression 


\section{Finding Categories - A Final Note}

- Once assigned, category does not change 


\section{Phase 1 - Step 1.3}

- Screen Fire Finding for Ability to Achieve Safe Shutdown

- 1.3.1-A Question: Is the reactor able to reach and maintain safe shutdown (either hot or cold) condition?

- Yes - Screens to Green, no further analysis required.

- No - Continue to next question.

- 1.3.1-B Question: Based on the criteria in Appendix $F$, Attachment 2, is the finding assigned a "Low" degradation rating?

- Yes - Screens to Green, no further analysis required.

- No - Continue to question below. 


\section{Phase 1 - Step 1.3 - Degradation}

\section{Rating}

- Assign a degradation rating

- In general pick one: High - Moderate - Low

- Exceptions:

- No Moderate rating for Fire Prevention and Administrative Controls (call it either High or Low)

- For Fire Confinement and Localized Cable and Component Protection (fire barriers) Moderate rating is split into "Moderate A" and "Moderate B"

- Degradation rating criteria depend on finding category (from Step 1.2)

- See IMC 0609, Appendix F, Attachment 2 for Degradation Rating Guidance

\section{Idaho National Laboratory}




\section{Questions On Degradation Rating Guidance?}

- Don't intend to cover Attachment 2 guidance in detail, but open to questions and/or discussion

- Time for reading IMC 0609 will be provided in afternoon sessions 


\section{Degradation Rating - Final Note:}

- Once set, degradation rating doesn't change 


\section{Phase 1 - Step 1.4}

- Initial Qualitative Screening

- Based on a series of yes/no questions

- Answer leads to

- Screen to Green

- Go to SDP Phase 2 Quantitative Screening Approach in IMC 0609, Appendix F.

- Continue to next question

- Continue to Step 1.5 - Initial Quantitative Screening

- Questions are specific to the Finding Category Assigned in Step $\mathbf{1 . 2}$

- Seven finding categories to chose from

- Only one assigned finding category 


\section{Phase 1 - Step 1.4 (cont.)}

- Task1.4.1: Fire Prevention and Administrative Controls (10 questions)

- 1.4.1-A Question: Would the impact of the fire finding be limited to equipment which is not important to safety?

- Yes - Screen to Green, no further analysis required.

- No - Continue to next question.

- 1.4.1-B Question: Would the impact of the fire finding be limited to no more than one train/division of equipment important to safety?

- Yes - Screen to Green, no further analysis required.

- No - Continue to next question.

- 1.4.1-C Question: If the fire finding is associated with the presence of transient combustibles, were there sufficient transient combustibles such that they could challenge either a fire barrier or a safe shutdown analysis boundary?

- Yes - Continue to SDP Phase 2 Quantitative Screening Approach in IMC 0609, Appendix F.

- No - Continue to next question. 


\section{Phase 1 - Step 1.4 (cont.)}

- Task1.4.1: Fire Prevention and Administrative Controls (cont.)

- 1.4.1-D Question: If the fire finding is associated with the presence of transient combustibles, did the transient combustibles involve selfigniting materials (e.g., oily rags)?

- Yes - Continue to SDP Phase 2 Quantitative Screening Approach in IMC 0609, Appendix F.

- No - Continue to next question.

- 1.4.1-E Question: If the fire finding is associated with the presence of transient combustibles, did the transient combustibles involve a gallon or more of low flashpoint (having a flashpoint less than $200^{\circ} \mathrm{F}$ ) flammable or combustible liquids in a non-approved container?

- Yes - Continue to SDP Phase 2 Quantitative Screening Approach in IMC 0609, Appendix F.

- No - Continue to next question.

- 1.4.1-F Question: If the fire finding is associated with the presence of transient combustibles, did the transient combustibles involve in excess of $1 \mathrm{lb}$ of a flammable gas?

- Yes - Continue to SDP Phase 2 Quantitative Screening Approach in IMC 0609, Appendix F.

- No - Continue to next question. 


\section{Phase 1 - Step 1.4 (cont.)}

- Task1.4.1: Fire Prevention and Administrative Controls (cont.)

- 1.4.1-G Question: Is the fire finding associated with the presence of an ignition source (e.g., evidence of portable heater)?

- Yes - Continue to SDP Phase 2 Quantitative Screening Approach in IMC 0609, Appendix F.

- No - Continue to next question.

- 1.4.1-H Question: Is the fire finding associated with the presence of an ignition source (e.g., evidence of recent cigarette smoking)?

- Yes - Continue to SDP Phase 2 Quantitative Screening Approach in IMC 0609, Appendix F.

- No - Continue to next question.

- 1.4.1-I Question: Is the fire finding associated with a failure to implement a hot work fire watch capable of suppressing a fire from hot work which could impact equipment important to săfety?

- Yes - Continue to SDP Phase 2 Quantitative Screening Approach in IMC 0609, Appendix F.

- No - Continue to Step 1.5. 


\section{Phase 1 - Step 1.4 (cont.)}

- Remaining Finding Category Qualitative Screening Questions found in IMC 0609, Appendix F 


\section{Fire Confinement - A Note On Terminology}

- PRA practice is a bit loose here with respect to terminology

- You may see reference to:

- Inter-area fires, inter-compartment fires, room-to-room fires, multi-room fires

- They all mean basically the same thing

- Watch "fire area" versus "fire compartment" definitions

- With respect to SDP usage of "fire area", we mean the Appendix $R$ context ( $R G$ 1.189):

- The term "fire area" as used in Appendix R means an area sufficiently bounded to withstand the hazards associated with the area and, as necessary, to protect important equipment within the area from a fire outside the area..

- For SDP, Fire Confinement relates only to the fire barriers that separate one fire area from another

\section{Idaho National Laboratory}




\section{Exposing vs. Exposed Compartment}

- Remember: Fire Confinement findings always involve two fire areas

- "Exposing compartment" is fire area where you will assume that fire starts

- "Exposed compartment" is the fire area on the other side of the degraded fire barrier

- Remember to look both ways...

- You will pick one orientation for actual analysis

- Generally pick orientation where fire in exposing compartment will create greatest challenge to the degraded fire barrier

\section{Idaho National Laboratory}




\section{Exposing vs. Exposed Compartment}

- Indicators for choosing exposing compartment:

- More challenging fire ignition sources

- Higher intensity (e.g., a source of big oil fires is an obvious choice)

- Fire ignition sources adjacent to degraded barrier

- Lacks automatic fire suppression coverage

- Point is that you need to develop a fire scenario leading to spread through a degraded barrier, so you need a significant fire source in the exposing compartment, with no potential for rapid suppression

\section{Idaho National Laboratory}




\section{Phase 1 - Step 1.5}

- Initial Quantitative Screening

- Three quantitative factors considered:

- Duration factor (DF)

- Fire frequency for the fire area $\left(F_{\text {area }}\right)$

- Probability of non-suppression for a fire (S)

- If product of these three factors are "low enough" (i.e., less than 1E-6), screen to Green

- In practice, this is unlikely to happen

- Fire area fire frequencies are pretty conservative

- Screening criteria are still pretty stringent

- We'll need DF and $F_{\text {area }}$ for Phase 2, so do this step anyway, just don't expect to screen

- Step had more meaning in previous versions of the SDP, may come back into play in the future 


\section{Task 1.5.1 - Assign a Duration Factor (DF)}

Duration of the Degradation

$<3$ days

3 - 30 days

$>30$ days
Duration Factor (DF)

0.01

0.1

1.0

\section{Idaho National Laboratory}




\section{Task 1.5.2 - Fire Frequency for the Fire Area}

- $F_{\text {area }}$ from look-up table - IMC 0609, App F, Table 1.5.2

- Intended to be somewhat conservative, but this won't be universally true

- If fire area contains more than the average number of fire ignition sources, the component-based fire frequency for the full fire area as calculated in Phase 2 may be higher!

- Differences should be minor

- You need to cross an order of magnitude boundary for difference to be significant

- You may use the Phase 2 approach if table value does not fit your case - use your judgment

\section{Idaho National Laboratory}




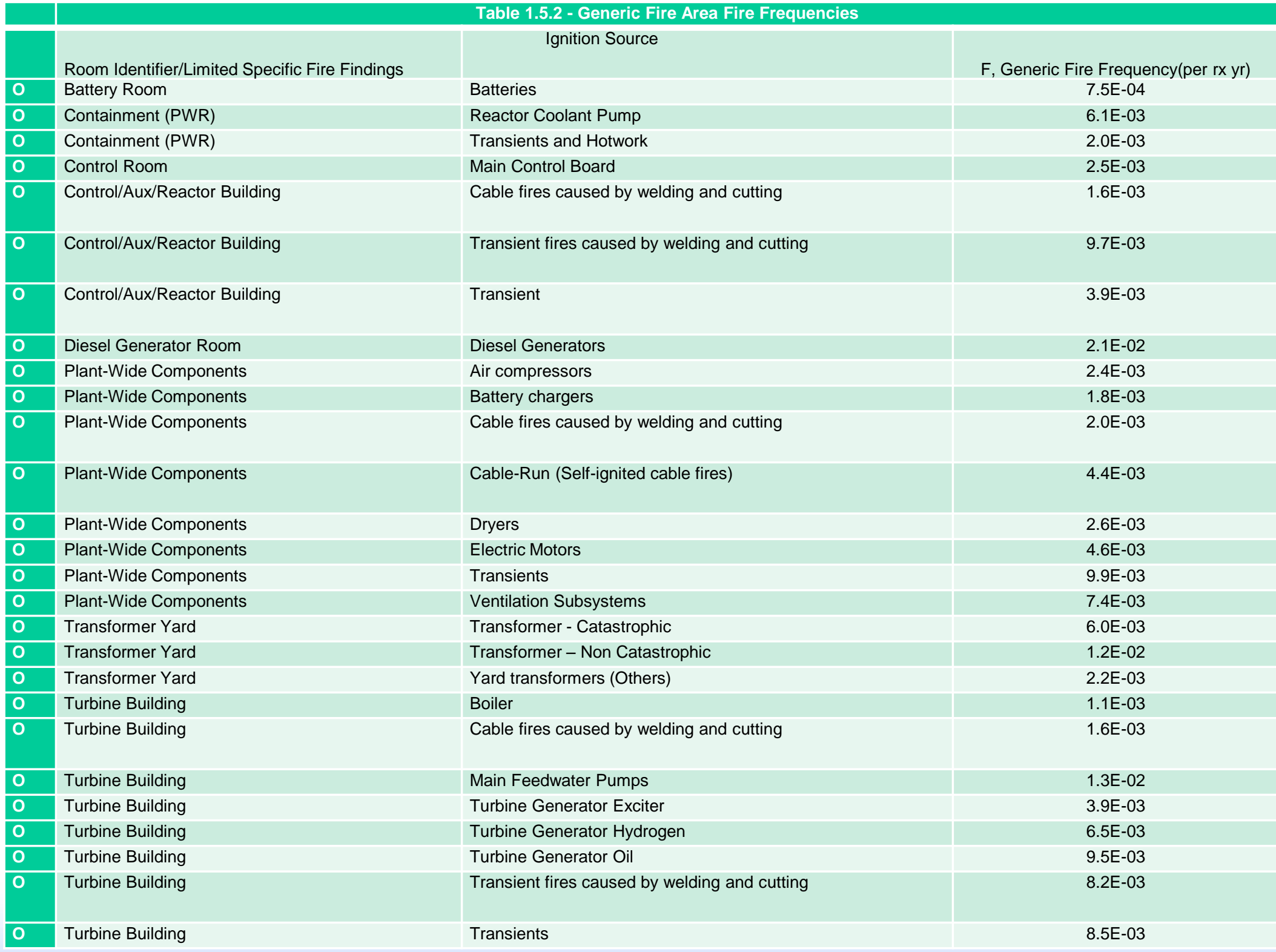




\section{Task 1.5.3 - Fire Non-Supression Probability (S)}

- Fire Non-Suppression Probability(S) is the likelihood that a fire would not be suppressed before potential damage is done to safe shutdown cables, safety-related cables, or safety-related equipment located in the fire area.

- The selection of $\mathbf{S}$ is based on the Non-Suppression decision tree and engineering judgment.

- The $S$ value for a fire finding is determined by following the decision path in Figure F.3 based on the selected characteristics from Table 1.5.3 that best describes the fire finding. 


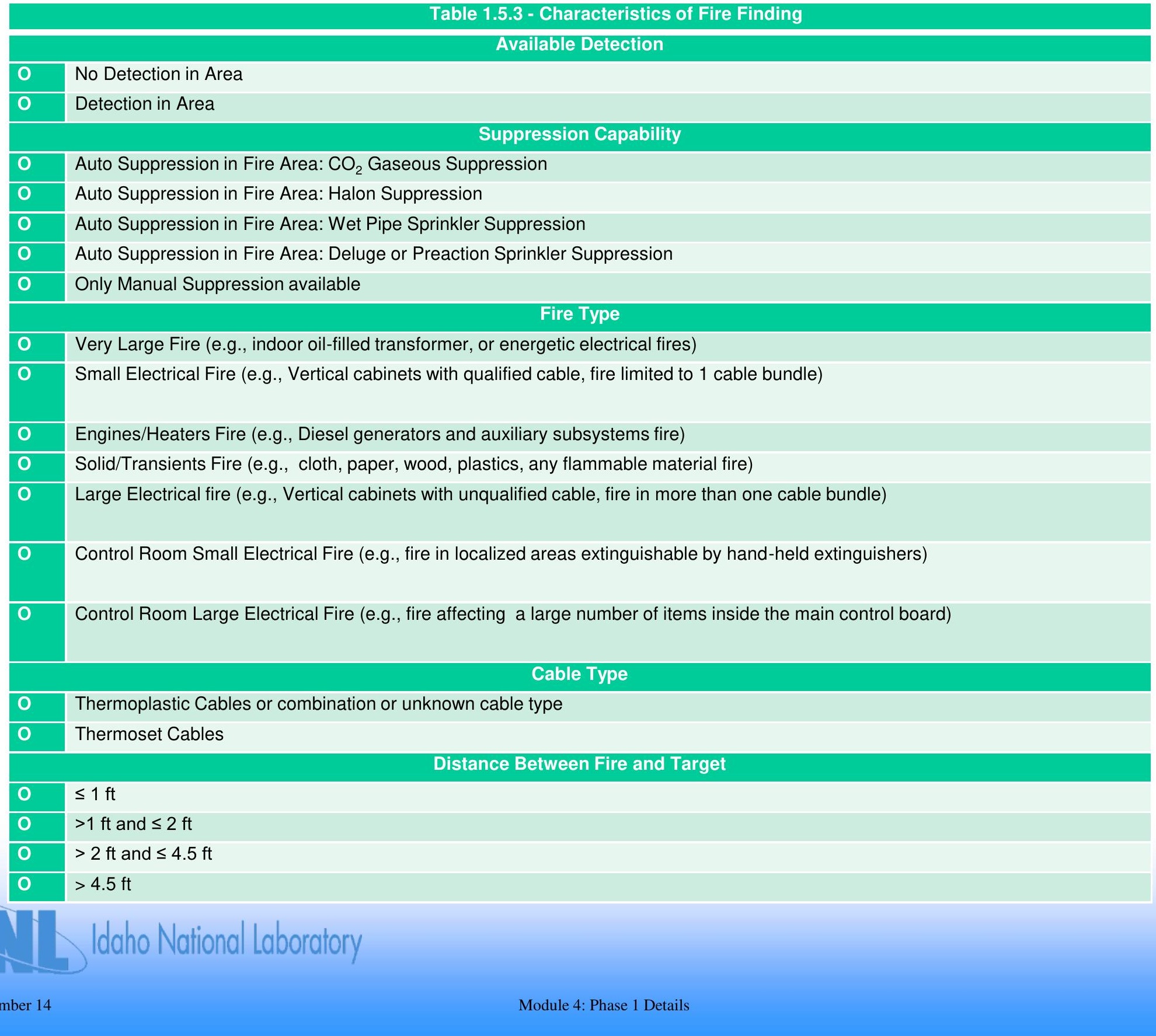


Figure 3 - Non-Suppression

Probability Decision Tree

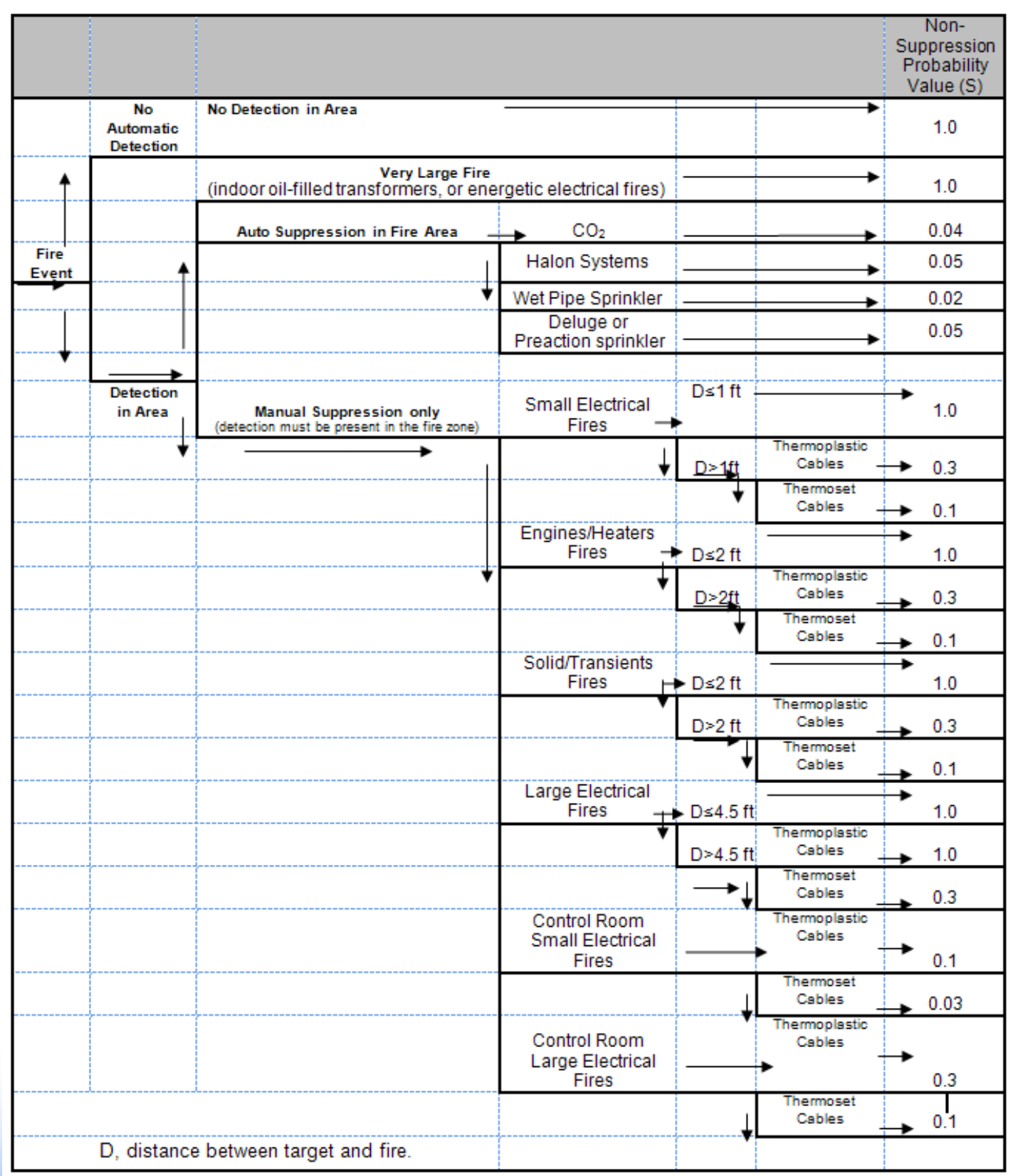




\section{Task 1.5.4 - Screening Check}

- Task 1.5.4 sets Phase 1 quantitative screening criteria

- If the finding impacts multiple fire areas, then initial Phase 1 screening CDF value is based on the sum of the fire frequencies for all impacted fire areas, see Table 1.5.4 Change in Core Damage Frequency

- Screening criteria imply an implicit level of risk credit for non-impacted DID elements

- Conditional Core Damage Probability (CCDP) has not yet been considered, and is assumed to be 1.0 for this screening check

- Remember, if you ever get below 1E-6, fire finding screens to Green

\section{Idaho National Laboratory}




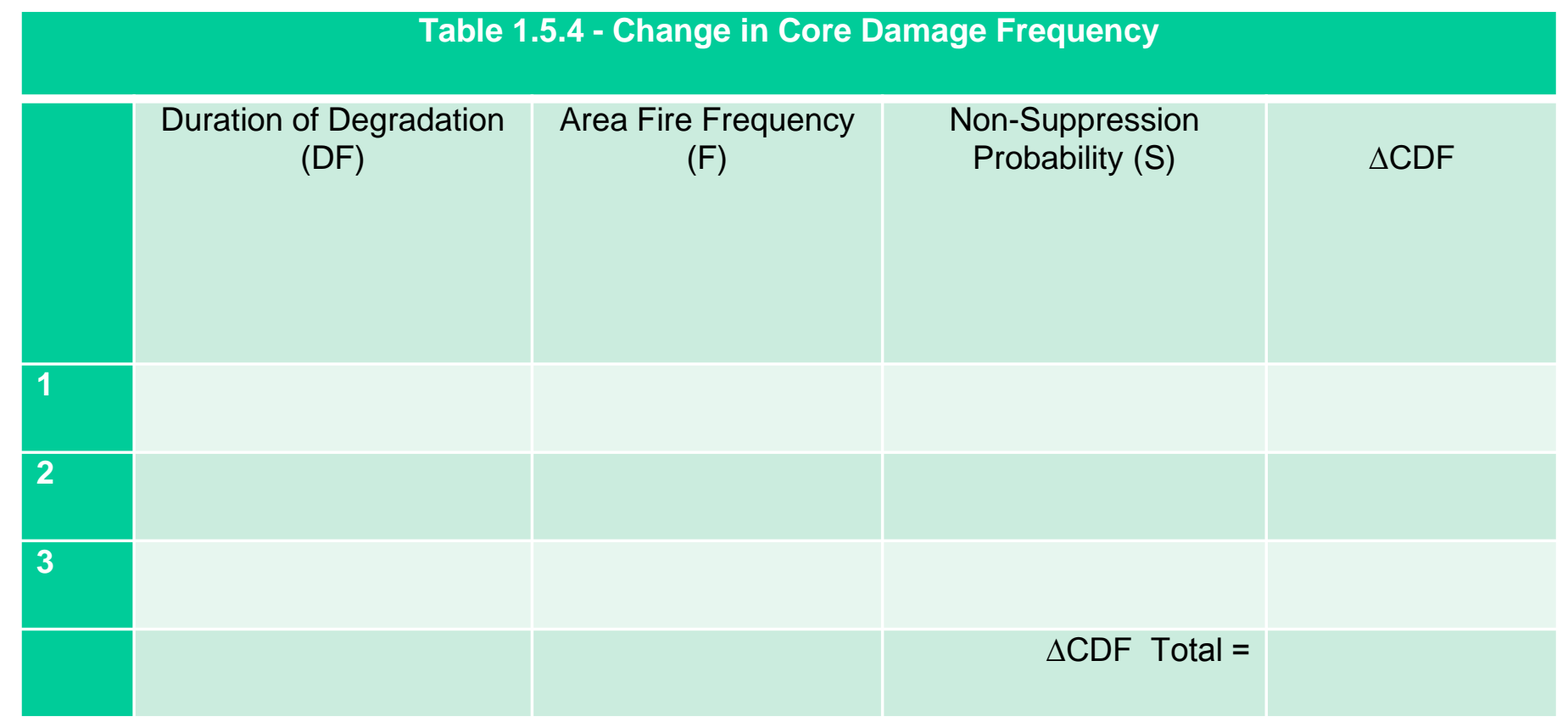

If $\triangle \mathrm{CDF}$ is less than $1 \mathrm{E}-06$, the fire finding screens to Green and the analysis is complete, and no further analysis is required.

If $\triangle \mathrm{CDF}$ is greater than or equal to $1 \mathrm{E}-06$, then the fire finding does not screen to Green. The finding then has to be evaluated by the SDP Phase 2 Quantitative Screening Approach in IMC 0609, Appendix F.

\section{SII. Idaho National Laboratory}




\section{Task 1.6 - Screen by Licensee Fire}

\section{PRA Results}

- For plants with an approved fire PRA, the results of the licensee's PRA-based safety evaluation can serve as the basis for screening a finding to Green.

- For this process the licensee has to provide a risk evaluation based on an approved fire PRA (typically one that meets the relevant supporting requirements at the Capability Category II Level of the Fire PRA Standard, as clarified/qualified via RG 1.200).

- The licensee must also provide the dominant cut sets and information on how the deficiency is modeled.

- With this information, the SDP can then proceed directly to a Phase 3 evaluation, where a SRA will conduct a detailed risk assessment and determine whether the licensee's evaluation is acceptable. 
Task 1.6 - Screen by Licensee Fire PRA Results (cont.)

- Based on results from licensee's PRA evaluation, a determination can be made on if the finding is of very low risk significance.

- 1.6-A Question: If there is an approved fire PRA for this plant, does the licensee's risk-based evaluation for this fire finding indicate a $\triangle C D F$ of less than $1 \mathrm{E}-6$, and is the evaluation result accepted by a US NRC SRA?

- Yes - Screen to Green, no further analysis required

- No - Continue to Phase 3 evaluation 


\section{Example Problem - Phase 1}

- Fill out Attachment 1 to IMC 0609, App. F for the example problem 


\section{Module 5: Phase 2 Details}




\section{Module 5: Phase 2 Details}

- We will cover each step and task in Phase 2:

- Purpose/objective

- What, why, how

- Input/output

- Supporting guidance

- Some examples - focus on a step/task 


\section{Step 2.1: Independent SSD Path First Screening Assessment}

- This step involves a coarse assessment of the designated post-fire SSD path

- Can we credit SSD path prior to development of detailed scenarios

- If so, what is appropriate screening CCDP value

- If we can show that the path is independent of any fire scenarios we might develop, we will credit that path right away for all scenarios

- Often, we may "attack" the redundant SSD path in one or more scenarios, so we won't give credit yet

- SSD credit/analysis gets refined after development of scenarios in Step 2.4 and again in Step 2.8

- This is just a first rough cut 


\section{Task 2.1.1: Identify the Designated Post-}

Fire SSD Path

- The SSD Path must meet all of the following criteria:

- Must be identified as the designated post-fire SSD path in the plant's fire protection program

- Must be supported by a documented post-fire SSD analysis consistent with regulatory requirements

- Must be documented and included in the plant operating procedures

- BTW: If the answer to any one of these is "No," then you may well have an SSD finding to deal with

\section{Idaho National Laboratory}




\section{Task 2.1.2 - SSD Nominal Unavailability}

- SSD path is assigned a nominal unavailability factor

- Possible values are limited to:

- $1.0,0.1$, or 0.01

- 1.0 means no credit - appropriate if there are questions as to adequacy of SSD

- For example, given an SSD finding

- Note: "unavailability" = CCDP in the equation 


\section{Unavailability Factors}

Table 2.1.1 - Total Unavailability Values for SSD Path Based Screening CCDP

Type of Remaining Mitigation Capability

Screening Unavailability

Factor

1 Automatic Steam-Driven (ASD) Train: A collection of associated equipment that includes a single turbine-driven component to provide $100 \%$ of a specified safety function. The probability of such a train being unavailable due to failure, test, or maintenance is assumed to be approximately 0.1 when credited as "Remaining Mitigation Capability."

1 Train: A collection of associated equipment (e.g., pumps, valves, breakers, etc.) that together can provide $100 \%$ of a specified safety function. The probability of this equipment being unavailable due to failure, test, or maintenance is approximately $1 \mathrm{E}-2$ when credited as "Remaining Mitigation Capability."

Operator Action Credit:: Major actions performed by operators during accident scenarios (e.g., primary heat removal using bleed and feed, etc.). These actions are credited using three categories of human error probabilities (HEPs). These categories are Operator Action $=1.0$ which represents no credit given, Operator Action $=0.1$ which represents a failure probability between $5 \mathrm{E}-2$ and 0.5 , Operator Action $=0.01$ which represents a failure probability between $5 \mathrm{E}-3$ and $5 \mathrm{E}-2$. Credit is based upon the following criteria being satisfied: (1) sufficient time is available; (2) environmental conditions allow access, where needed; (3) procedures describing the appropriate operator actions exist; (4) training is conducted on the existing procedures under similar conditions; and (5) any equipment needed to perform these actions is available and readv for use. 


\section{Task 2.1.3 - SSD Path Independence}

- Independence has special context here:

- SSD path should not be challenged in any of the fire scenarios we might later develop

- SSD path components/cables are not included in the target set for any of our possible fire scenarios

- Fire scenario definition comes later, so this requires a bit of foresight

- If path might be compromised in any potential fire scenario, we don't credit the path yet

- We still want unavailability, because later we may credit the SSD path in those scenarios where the path does survive

- SSD Path Independence Check Criteria listed in IMC 0609, App F, Table 2.1.2 


\section{Independence Criteria:}

- These should be assured by virtue of Appendix R compliance:

- The licensee has identified and analyzed the SSD SSCs required to support successful operation of the SSD path.

- The licensee has identified and analyzed SSCs that may cause mal-operation of the SSD path (e.g., the required and associated circuits).

- The licensee has evaluated any manual actions required to support successful operation of the SSD path and has determined that the actions are feasible. 


\section{Independence Criterion - Manual Actions}

- This criterion might be an issue for plants taking credit for long term actions after the fire is out:

- All manual actions take place outside the fire area under analysis

- Implication of this criterion:

- No operator actions that take place within the fire-affected area will be credited in Phase 2

- Feasibility of actions will be reconsidered during Phase 3 so make a note of these in your documentation 


\section{Independence Criteria - Circuit Analysis}

- These three relate to circuit analysis:

- The licensee has conducted an acceptable circuit analysis

- Should be a given

- Any known unresolved circuit analysis issues that could adversely impact the operability of the designated SSD path are identified.

- No known circuit analysis issues (e.g., a known spurious operation issue) for exposed cables should hold the potential to compromise operability of the identified SSD path. 


\section{Independence Criteria - Exposed Cables}

- "Exposed cables" guidance:

- Cables within the fire area under analysis are not considered exposed if

- they are protected by a non-degraded raceway fire barrier with a minimum 3-hour fire endurance rating.

OR

- they are protected by a raceway fire barrier with a minimum one-hour fire endurance rating, and the area is provided with automatic detection and suppression capability, and none of these elements is found to be degraded. 


\section{Independence Criteria - Exposed Cables}

- “Exposed cables" guidance (cont.)

- Cables in an adjoining fire area are not considered exposed if the fire barrier separating adjoining fire area from the fire area under analysis is not degraded.

- If the finding category assigned in Step 1.1 was "Fire Confinement," cables located in the adjacent fire area are considered exposed unless they are protected by a nondegraded localized fire barrier with a minimum 1-hour fire endurance rating. 


\section{Independence Criteria}

- Features discussed in previous two slides relate directly to Appendix R, III.G.2 separation strategies

- Basically, when we decide if cables are exposed or not exposed for purposes of SDP fire scenarios:

- We do credit 3-hour separation as long as barrier is not degraded

- We do credit 1-hour separation with auto detection and suppression as long as these features/systems are not degraded

- We do not credit spatial separation within the same fire area

- We do not credit exemptions or remote shutdown at this stage of analysis 


\section{Task 2.1.4 - Screening Check}

- $\Delta \mathrm{CDF}_{2.1}=\mathrm{DF} \times\left(\mathrm{F}_{\text {Area }}\right) \times \mathrm{CCDP}_{2.1}$

\begin{tabular}{|c|c|c|}
\hline \multirow[b]{2}{*}{ Assigned Finding Category (from Step 1.1): } & \multicolumn{2}{|c|}{$\Delta \mathrm{CDF}_{2.1}$ Screening Value } \\
\hline & $\begin{array}{c}\text { Moderate } \\
\text { Degradation }\end{array}$ & $\begin{array}{c}\text { High } \\
\text { Degradation }\end{array}$ \\
\hline Fire Prevention and Administrative Controls & $\mathrm{N} / \mathrm{A}$ & \multirow{5}{*}{$1 \mathrm{E}-6$} \\
\hline Fixed Fire Protection Systems & $1 \mathrm{E}-5$ & \\
\hline Fire Confinement & $1 \mathrm{E}-5$ & \\
\hline Localized Cable or Component Protection & $1 \mathrm{E}-5$ & \\
\hline Post-fire SSD & $1 \mathrm{E}-6$ & \\
\hline
\end{tabular}

- $\quad \Delta \mathrm{CDF}_{2.1}$ is lower than the corresponding value in Table A1.2 - the finding screens to Green and the analysis is complete.

- $\quad \Delta \mathrm{CDF}_{2.1}$ is greater than or equal to the corresponding value in Table A1.2. The analysis continues to Step 2.2 


\section{Example Problem - Step 2.1}

- Do Step 2.1 for the example problem 


\section{Step 2.2 - Fire Damage State (FDS) Determination}

- The nature of the finding determines which types of fire scenarios MAY be relevant to risk increase

- If nothing about a scenario changes as a result of the degradation, then the scenario is not relevant

- This step is a quick decision process to decide which FDSs need to be considered as you develop fire scenarios

- The most complex part of this step is Task 2.2.2, FDS3 screening

\section{Idaho National Laboratory}




\section{Task 2.2.1: Initial FDS Assignment}

- Simple look up table:

\begin{tabular}{|l|c|c|c|}
\hline \multicolumn{4}{|c|}{ Table 2.2.1 - FDS/Finding Category Matrix } \\
\hline Finding Type or Category: & FDS1 & FDS2 & FDS3 \\
\hline Fire Prevention and Administrative Controls & Retain & Retain & Retain \\
\hline Fixed Fire Protection Systems & Retain & Retain & Retain \\
\hline Fire Confinement & N/A & N/A & Retain \\
\hline $\begin{array}{l}\text { Localized Cable or Component Protection } \\
\text { Given a High degradation } \\
\text { Given a Moderate degradation }\end{array}$ & $\begin{array}{c}\text { Retain } \\
\text { N/A }\end{array}$ & $\begin{array}{l}\text { Retain } \\
\text { Retain }\end{array}$ & $\begin{array}{l}\text { Retain } \\
\text { Retain }\end{array}$ \\
\hline Post-fire SSD & Retain & Retain & Retain \\
\hline
\end{tabular}

Note 1: For a highly degraded local barrier, the protected components/cables are treated as fully exposed and may be assumed damaged in FDS1 scenarios, depending on their proximity to the fire ignition source.

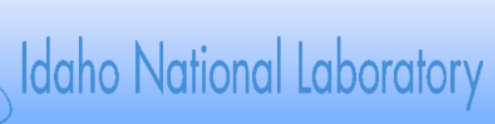




\section{Task 2.2.2 - FDS3 Screening}

- We would really like to drop FDS3 if we can - most of the time you will

- Multi-area scenarios are rarely risk significant as long as the barriers are intact

- If the inter-area barrier is degraded, you're stuck with FDS3

- This screening task only applies to findings that are not in the Fire Confinement category

- We already did an equivalent screening for Fire Confinement findings in Phase 1 (Step 1.3.2) so we do not repeat 


\section{FDS3 Screening: Exposing and Exposed Areas}

- Given that the finding category is anything other than Fire Confinement, the fire area you are inspecting is always the exposing fire area

- The fire always starts somewhere in the exposing fire area

- The exposed fire area may be any adjacent fire area - up, down, sideways

- You will be evaluating the potential risk due to fire spread to an exposed fire area

- You are going to look for a fire in the exposing fire area that is substantial enough to challenge the fire area boundaries and spread to the exposed fire area, causing additional unique damage there

\section{Idaho National Laboratory}




\section{FDS3 Screening: How It Works}

- Series of yes/no questions

- Start in the exposing fire area - where the finding is

- Apply the questions to each adjacent fire area as a potential exposed fire area

- Look for any one exposing/exposed area pair that might give you a credible scenario

- If FDS3 scenarios do not screen out you will ultimately identify one area to act as the representative exposed fire area

- Pick the worst case and go with it - usually based on interesting targets (e.g., redundant SSD path)

- You won't analyze all combinations in detail

- Questions are virtually identical to those in Task 1.3.2

- Same general intent and basis

- Only difference is we assume the barrier between the fire areas is not degraded

- Words relating to fire endurance rating of the barrier "in its degraded condition" are dropped 


\section{Drop FDS3 If:}

- Fire area boundaries for the exposing fire area have minimum 2-hour endurance rating

- May have a mixed bag of barriers - some 2-hour, some not

- Drop any room combinations that are separated by a 2-hour barrier

- For the rest of the questions, focus only on those combinations that don't have 2-hour separation

- The exposing fire area has:

- Non-degraded gaseous suppression, OR

- No more than moderately degraded full-coverage water suppression, OR

- Partial coverage water system that covers all fixed fire ignition sources

- Meeting any one of these conditions is enough

\section{Idaho National Laboratory}




\section{Drop FDS3 If:}

- For these three conditions, remember to focus on specific combinations of fire areas that lack 2-hour separation:

- There are no unique targets in any exposed compartment, OR

- Targets in any exposed compartment are at least 20 feet from the separating fire barrier and/or have passive protection with a one-hour fire endurance rating, OR

- The fire barrier between fire areas has at least 20 minutes fire endurance, AND fixed ignition sources won't subject barrier to direct flame impingement

- Fire ignition sources are well away from the barrier

- (Meeting any one of these conditions is enough)

\section{Idaho National Laboratory}




\section{To Retain FDS3 You Must Have Found All of the Following:}

- A somewhat weak barrier to at least one adjacent fire area (less than 2 hours endurance rating)

- Questionable or non-existent fixed suppression capability in exposing compartment

- Unique and exposed targets in the adjoining exposed fire area

- The potential for fire that can directly challenge that fire barrier element

It's not hard to develop an inter-area fire scenario out of that situation! 


\section{Step 2.2 - Summary}

- At the end of this step you will be left with one, two, or three FDSs to consider in the development of fire scenarios

- We still need to develop credible fire scenarios, but this step says we will at least look for scenarios corresponding to each retained FDS

- If you drop one or more FDSs, they never come back 


\section{Step 2.2 - One Last Point}

- Step 2.2 only tells you that you need to consider the possibility of one or more fire scenarios for each FDS retained

- It does NOT say you MUST develop at least one fire scenario for each FDS

- Some FDS states may simply not be credible

- FDS2 in a fire area with inadequate combustibles to create a hot gas layer

- It also does not say every fire ignition source will lead to at least one scenario for each FDS retained

- Some fire ignition sources might contribute to only one FDS and not to other FDSs even though the other FDSs were retained

\section{Idaho National Laboratory}




\section{Illustrative Example}

Finding: A cable tray associated with the designated Train B SSD path should have been wrapped but was not (licensee wrapped the wrong tray)

- Finding Category: Localized Cable and Component Protection

- Degradation: High

- Task 2.2.1 says nominally retain FDS1, FDS2, FDS3

- To complete example, let's assume:

- We know exactly where the train $B$ tray is

- The train B tray is routed in the first (lowest) tray among a stack of trays directly above a bank of electrical panels

- There are various other panels and equipment in the fire area, and many train A cable trays

- FDS3 screened out in 2.2.2 


\section{Illustrative Example}

So let's develop scenarios!

- General Observations: Fire Sources

- We have several fire sources around the room

- The row of electrical panels directly below the train B tray is of particular interest, but other more remote sources may also be important 


\section{Illustrative Example - Sources Near Train B}

Scenario development:

- Second key factor in scenario development is target sets:

- Targets of interest are:

- Train A cables throughout the room

- Specifics lacking so we must assume they are everywhere

- Loss of any exposed tray causes loss of Train A

- The cables in the unwrapped Train B tray

- Can cause loss of post-fire SSD capability

- Implies we might have two target sets:

- Target set 1: Loss of Train A cables only

- Target set 2: Loss of both Train A and Train B cables

- Why not target set 3: Train B only? 


\section{Illustrative Example - Sources Near Train B}

- For the bank of electrical panels directly below the unwrapped Train B tray:

- First exposed cable tray has Train B

- Loss of any tray assumed to cause loss of Train A

- FDS1 scenarios get us loss of both Train A and B - Target set 2

- Do we need FDS2?? Answer: NO

- FDS2 scenarios can't add anything new

- We already lost both trains, including the SSD train

- For these sources, FDS1 scenarios are enough to characterize the risk change - Target set 2 applies

\section{Idaho National Laboratory}




\section{Illustrative Example - Remote Sources}

- What about fire sources remote from unwrapped tray?

- FDS1 scenarios for remote sources will not damage train $B$ cables - Target set 1 applies - Train A only

- Question to ask yourself: Does the lack of a wrap on the train B cable tray change these remote-source FDS1 scenarios in any way?

- Answer in this case: NO - FDS1 is not attacking the train B tray, so lack of thermal protection is irrelevant.

- Result: Fires from remote sources leading to loss of train A only are not relevant to the finding against the train B wrap - FDS1 scenarios need not be pursued for these remote fire ignition sources 


\section{Illustrative Example - Remote Sources}

- FDS2 scenarios - fire spreads to overhead cables causing a damaging hot gas layer

- These scenarios can damage both the Train A and Train B cables

- Are these scenarios relevant?? ASOLUTELY!

- For the remote fire ignition sources the FDS2 scenarios characterize risk increase relevant to the finding

- We don't need to analyze the FDS1 scenarios in detail for the remote fire ignition sources 


\section{Illustrative Example}

- To summarize:

- Risk increase will be characterized by a combination of FDS1 and FDS2 scenarios

- For the panels directly under the train B tray, we analyze FDS1 scenarios only

- For the other remote fire ignition sources, we analyze FDS2 scenarios only

- For this case, we probably can characterize risk with just two fire scenarios by appropriately grouping the fire ignition sources!

\section{Idaho National Laboratory}




\section{Summary of Illustrative Example}

- Electrical panels directly below unwrapped Train B cables:

- FDS1

- Sources remote from unwrapped Train B cables:

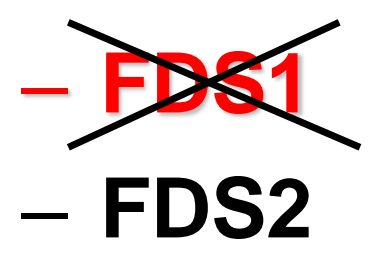

-Target Set 1: Train A cables only

-Target Set 2: Train A and Train B cables

- Target Set 3: Train B cables only

\section{Idaho National Laboratory}




\section{Example Problem - Step 2.2}

- Do Step 2.2 for the example problem 


\section{Step 2.3 - Scenarios and Ignition}

Sources

- Purpose of this step is to begin defining fire scenarios

- That last illustrative example started us on this path!

- First point of focus is to identify fire ignition sources to be retained for further analysis

- Identify and count fire ignition sources

- Screen out non-threatening fire ignition sources

- Revise room fire frequency based on retained fire ignition sources

- Screening check using new room fire frequency 


\section{Task 2.3.1 - Count Sources}

- For most cases, we use a component-based fire frequency, so first task is to count fire ignition sources

- If you use spreadsheet, entering counting results automatically updates the fire frequency

- For transients, cables, and hot work fires, the area is ranked as High - Medium - Low

- There is ranking guidance provided

- Intent is to do a relative ranking - how does this fire area compare to other fire areas in the plant?

- Any questions on counting/ranking guidance??

\section{Idaho National Laboratory}




\section{There Will Be Counting Challenges}

- How many "distinct vertical sections" do you see?

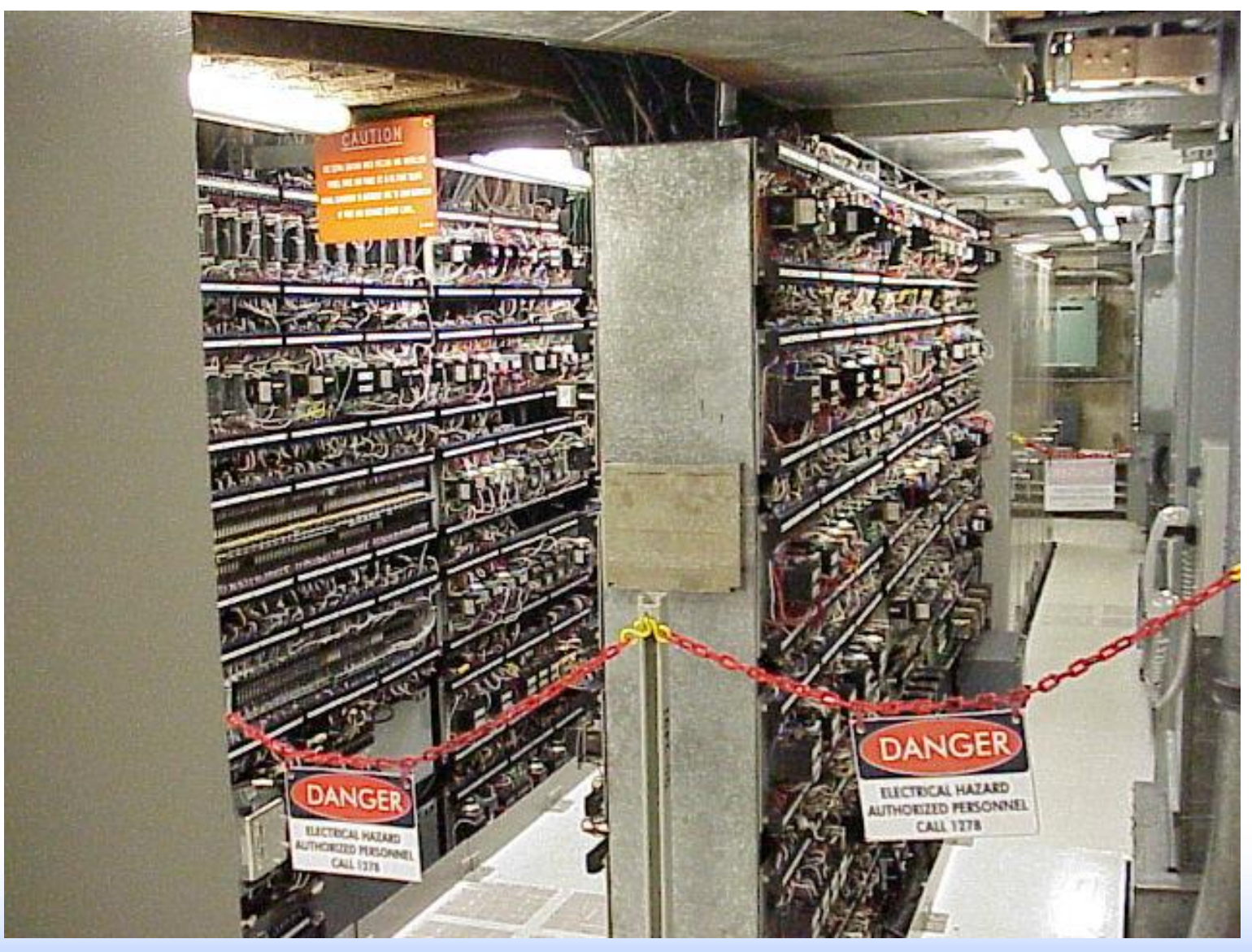

Idaho National Laboratory 


\section{Counting}

- Use your judgment!

- Goal is to get a reasonable estimate of the fire frequency

- Avoid optimism but also avoid gross conservatism

- For the illustrated relay racks, two possible options are:

- There are some distinct visible divisions between sections that could be counted as panel dividers

- Q: How would this weigh against general plant practice and other electrical panels? Does it seem reasonable?

- You could assume a "typical" vertical section is about 3 feet wide, and assign the relay racks a frequency based on the total linear feet of racks 


\section{Task 2.3.1 - Special Cases}

- For some findings, only a specific subset of potential fire ignition sources is considered

- High-degradation finding against combustible material controls - only transient fire ignition sources are relevant

- High-degradation finding against hot work fire watch - only hot work fires are relevant 


\section{Focus On What Changes}

- You want to focus on fire ignition sources where the finding causes a scenario to change, for example:

- If a portion of a fire sprinkler system is out of service, focus on sources that would normally be covered but now are not

- Given a lack of detection within a beam pocket, focus on fire ignition sources that are also within/under that same beam pocket

- Use your judgment and limit your search as appropriate

- No different than what you are already doing 


\section{Focus On What Might Prove To Be Credible}

- Don't waste time worrying about fire ignition sources that will clearly not yield a credible fire scenario:

- If you have an issue in one corner of a reactor building, and there is a small fire source isolated at the opposite end of the building, Don't waste time worrying about that source

- If it's obvious that the fire cannot spread enough to create a damaging hot gas layer, then you have no FDS2 and the scenario is not going to be credible

- Document your logic and move on. 


\section{Task 2.3.2: Characterize Sources}

- We talk about simple and non-simple fire ignition sources

- Simple: panels, other electrical fires, transformers, engines, heaters, transients

- Non-simple: self-ignited cable fires, energetic arcing faults, transients that exceed nominal size, hot work fires, flammable liquids, hydrogen

- We are going to talk about simple sources now, we will cover non-simple sources in Module 6 (with examples)

\section{Idaho National Laboratory}




\section{Task 2.3.2 - Simple sources}

- For simple sources, pull HRR values from the lookup table for each fire ignition source

- Two values for each source:

- Lower value represents $90 \%$ of fires - the "expected value" or $75^{\text {th }}$ percentile

- Higher value represents upper $10 \%$ of fires - the "high confidence value" or $98^{\text {th }}$ percentile

\section{Idaho National Laboratory}




\section{Fire Characteristics Table}

Table 2.3.1 - Mapping of General Fire Scenario Characterization Type Bins to Fire Intensity Characteristics

\begin{tabular}{|c|c|c|c|c|c|c|}
\hline \multirow{2}{*}{$\begin{array}{c}\text { Fire Size } \\
\text { Bins }\end{array}$} & \multicolumn{6}{|c|}{ Generic Fire Type Bins with Simple Predefined Fire Characteristics } \\
\hline & $\begin{array}{l}\text { Small } \\
\text { Electrical } \\
\text { Fire }\end{array}$ & $\begin{array}{l}\text { Large } \\
\text { Electrical } \\
\text { Fire }\end{array}$ & $\begin{array}{l}\text { Indoor Oil- } \\
\text { Filled } \\
\text { Transformers }\end{array}$ & $\begin{array}{l}\text { Very } \\
\text { Large Fire } \\
\text { Sources }\end{array}$ & $\begin{array}{l}\text { Engines } \\
\text { and } \\
\text { Heaters }\end{array}$ & $\begin{array}{l}\text { Solid and } \\
\text { Transient } \\
\text { Combustibles }\end{array}$ \\
\hline $70 \mathrm{~kW}$ & $\begin{array}{l}75^{\text {th }} \\
\text { Percentile } \\
\text { Fire }\end{array}$ & & & & $\begin{array}{l}75^{\text {th }} \\
\text { Percentile } \\
\text { Fire }\end{array}$ & $\begin{array}{l}75^{\text {th }} \text { Percentile } \\
\text { Fire }\end{array}$ \\
\hline $200 \mathrm{~kW}$ & $\begin{array}{l}98^{\text {th }} \\
\text { Percentile } \\
\text { Fire }\end{array}$ & $\begin{array}{l}75^{\text {th }} \\
\text { Percentile } \\
\text { Fire }\end{array}$ & & & $\begin{array}{l}98^{\text {th }} \\
\text { Percentile } \\
\text { Fire }\end{array}$ & $\begin{array}{l}98^{\text {th }} \text { Percentile } \\
\text { Fire }\end{array}$ \\
\hline $650 \mathrm{~kW}$ & & $\begin{array}{l}98^{\text {th }} \\
\text { Percentile } \\
\text { Fire }\end{array}$ & $\begin{array}{l}75^{\text {th }} \text { Percentile } \\
\text { Fire }\end{array}$ & $\begin{array}{l}75^{\text {th }} \\
\text { Percentile } \\
\text { Fire }\end{array}$ & & \\
\hline $2 \mathrm{MW}$ & & & $\begin{array}{l}98^{\text {th }} \text { Percentile } \\
\text { Fire }\end{array}$ & & & \\
\hline $10 \mathrm{MW}$ & & & & $\begin{array}{l}98^{\text {th }} \\
\text { Percentile } \\
\text { Fire }\end{array}$ & & \\
\hline
\end{tabular}




\section{Task 2.3.2 - Simple Sources}

- Assign a location for the fire origin

- For general fire ignition sources, place origin on top of the fire source

- Motor, transformer, etc.

- Exceptions:

- Electrical cabinets/panels: 1 foot below the top of the panel

- Transients: 2 feet above the floor at desired location 


\section{Tasks 2.3.3 and 2.3.4 - Screening Ignition Sources}

- We need to screen ignition sources:

- If we can damage or ignite any target, we keep the ignition source

- If we cannot damage/ignite nearest target, we drop that ignition source

- Three considerations for damage/ignition:

- Plume exposure

- Radiant heating

- Hot gas layer

- Screening is done in two tasks... 


\section{Task 2.3.3 - Nearest Target}

- In this task you identify the nearest and/or most vulnerable target to each fire source

- Don't need to define a full target set (yet), just find the one most likely to fail/ignite

- Target can be either a damage or ignition target - it's all the same for this step

- Target's function does not matter - does not need to be an SSD component, for example

- For now, we just want to know if the fire ignition source is capable of either damaging one or more potential targets OR spreading fire to secondary combustibles

\section{Idaho National Laboratory}




\section{Task 2.3.3 - Nearest Target}

- Look for targets directly above fire

- Plume heating

- Look for targets off to the side

- Radiant heating

- If nothing else, you will have some target for hot gas layer exposure

- If you can't find a target, you should not be in that room 


\section{Task 2.3.3 - Nearest Target}

- Note target location relative to fire ignition source

- Height above source

- Horizontal distance from source

- Targets are almost always cables

- For most equipment, cables are the weak spot

- Motor will likely fail because fire damages its power and/or control cables, not because fire overheats the motor itself

- Find out if you are dealing with thermoplastic or thermoset cables

- Integrated circuit components also valid targets

- IC components are weaker than their cables 


\section{Task 2.3.4 - Screening Sources}

- This task decides if a given fire ignition source can damage the most vulnerable target and/or spread the fire

- We do two types of check:

1. Zone of Influence (aka Ball and Column)

- Column = Plume heating

- Ball = Radiant heating

2. Hot gas layer temperature 


\section{Fire Ignition Sources and HRR}

- You must consider both the expected and high-confidence HRR values for each source

- Check the expected HRR (lower) value first

- If you retain a source at the expected value, then you clearly keep it at the high-confidence value also!

- If expected value is not enough to retain, then check the highconfidence HRR (higher) value

- If a fire ignition source screens at both HRR values, then it drops out of the analysis entirely

- No need to track this fire ignition source any further

- You may retain a source at its high confidence HRR, and screen it out at its expected value

- That's OK (more later) and probably will be pretty common 


\section{Zone of Influence Chart}

- Graphical zone of influence chart

- Height $(\mathrm{H})$ and radius

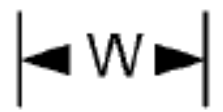
(R) are from look-up tables

- Width (W) corresponds to footprint of the source

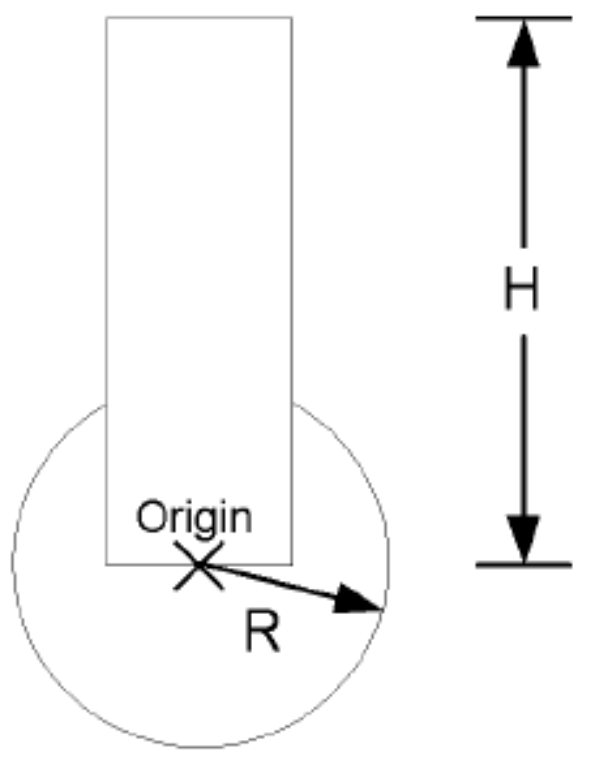

\section{Idaho National Laboratory}




\section{Zone of Influence - Typical Look-up Table}

For fires in an open area away from walls or corners:

\begin{tabular}{|c|c|c|c|c|}
\hline \multicolumn{4}{|c|}{$\begin{array}{c}\text { Calculated Values (in feet) for Use in the Ball and Column Zone of } \\
\text { Influence Chart for Fires in an Open Location Away from Walls }\end{array}$} \\
\hline \multirow{2}{*}{ Fire HRR } & Thermoplastic Cables & \multicolumn{2}{c|}{ Thermoset Cables } \\
\cline { 2 - 5 } & H & R & H & R \\
\hline $70 \mathrm{~kW}$ & 4.8 & 1.8 & 3.5 & 1.3 \\
\hline $200 \mathrm{~kW}$ & 7.3 & 3.0 & 5.3 & 2.1 \\
\hline $650 \mathrm{~kW}$ & 11.6 & 5.4 & 8.5 & 3.8 \\
\hline $2 \mathrm{MW}$ & 18.2 & 9.5 & 13.3 & 6.7 \\
\hline $10 \mathrm{MW}$ & 34.7 & 21.3 & 25.3 & 15.0 \\
\hline
\end{tabular}

Calculations are based on the following damage criteria:

Thermoplastic Cables: $400^{\circ} \mathrm{F}\left(325^{\circ} \mathrm{F}\right.$ rise above ambient $)$ and $0.5 \mathrm{BTU} / \mathrm{ft}^{2} \mathrm{sec}$

Thermoset Cables: $625^{\circ} \mathrm{F}\left(550^{\circ} \mathrm{F}\right.$ rise above ambient $)$ and $1 \mathrm{BTU} / \mathrm{ft}^{2} \mathrm{sec}$

\section{Idaho National Laboratory}




\section{Zone of Influence - Fire Location}

- Fire location can make a difference -3 cases:

- Fires in the open (away from walls)

- Fires near a wall

- Fires near a corner

- What do we mean by "near"?

- Near = within 2 feet of the wall

- Near a corner = within 2 feet of both walls

-When near a wall or corner, plume effect is "magnified" (2 for a wall, 4 for a corner)

- Separate H and R look-up tables for these two cases 


\section{Zone of Influence}

- If there is at least one target within the zone of influence, then:

- We have the potential for fire spread and/or damage due to plume and radiant heating effects

- The fire ignition source is retained

- If there are no targets within the zone of influence, then:

- Fire cannot spread from that particular ignition source to any secondary fuels

- Plume and radiant heating cannot damage any of the potential targets in the room

- Need to check hot gas layer to determine if source must be retained 


\section{Zone of Influence}

- Essentially, the zone of influence chart is a visual check

- Have your HRR and H-R look-up tables handy when you do your walkdown

- You can quickly perform this screening check for most of the sources in the room

- Ballpark distances are OK

- If it looks really close, assume you are right at the threshold and go from there 


\section{Zone of Influence}

- If you are dealing with an HRR value not included in the tables (i.e., any one of the standard values) you will have to calculate the $H$ and $R$ values for your fire

- FDT spreadsheets can do this

- For $\mathrm{H}$ - use plume correlation and look for height where plume temperature equals damage threshold

- Unless it's a pool fire, use a standard fire surface area of 6 square feet

- For $\mathbf{R}$ - use radiant heating correlation and look for distance where flux equals damage threshold

- Recommend you seek guidance if you are not sure 


\section{Task 2.3.4 - Hot Gas Layer}

- If a fire source was retained based on the zone of influence, it is retained - period

- Only need to meet one condition in order to retain

- If a source is already retained, don't bother checking hot gas layer for that source

- Could save you some time

- Won't hurt if you check anyway, but it's not necessary at this point

- If you did not retain based on zone of influence, have to check HGL temperature for that source 


\section{Hot Gas Layer}

- Check the hot gas layer temperature for any fire ignition sources that had no targets within their zone of influence

- Nothing in the zone of influence means no spread of fire beyond the fire ignition source

- For damage, that means fire source in and of itself has to be enough to create damaging hot gas layer

- If such sources can create a hot gas layer temperature above the failure threshold of the weakest target, the source is retained

- This will be rare!

- Need a pretty big source in a pretty small room 


\section{Hot Gas Layer: Process}

- The hot gas layer check requires use of the FDT spreadsheet tool

- Recommendation: Use the natural ventilation spreadsheet and assume an open door (standard commercial door is 36 " $x$ 84")

- Warning: Do not run a zero ventilation case using either natural or forced ventilation spreadsheet - the correlations don't work unless there is some substantial ventilation assumed

- Required inputs:

- Room dimensions (L-W-H); ventilation conditions; fire HRR

- Record the hot gas layer temperature at $\mathbf{3 0}$ minutes

- Compare HGL temperature to target damage threshold

- Fire ignition source screens out if HGL temperature is less than damage threshold

\section{Idaho National Laboratory}




\section{Hot Gas Layer}

- Fire location makes no difference for hot gas layer

- That means you don't have to repeat the HGL calculation for each and every fire ignition source

- Do the HGL calculation once for each unique HRR

- The answer is the same for all fires sources at that particular HRR 


\section{Task 2.3.4 - Summary}

- You end up with a screening result for each fire ignition source - three outcomes possible:

- Source may be retained at both the expected and high-confidence HRR values

- Source may be retained only at the highconfidence HRR value

- Source may screen out

- Note that if the source is retained at the expected HRR value, it is also retained (by definition) at its high confidence HRR value

\section{Idaho National Laboratory}




\section{Task 2.3.5 - Screening Check}

- If no fire ignition sources were retained, then you failed to identify a credible fire scenario

- In this case you are done - finding is Green

- This requires that all sources screened out at both their expected and high-confidence HRR values

- If even one source at one HRR value is retained, you continue to next step 


\section{Example Problem - Step 2.3}

- Do Step 2.3 for the example problem 


\section{Step 2.4 - Refined Fire Frequency}

- In this step a refined fire frequency for the fire area is calculated

- We remove the contribution associated with fire ignition sources that screened out in Step 2.3

- We apply a severity factor of 0.1 for those sources retained only at their high-confidence HRR value

- Using the refined fire frequency, the quantitative screening check is repeated

- New information (better fire frequency) may be enough to call a finding Green 


\section{Task 2.4.1 - Nominal Fire Frequency}

- Enter the results of Task 2.3 into a fire frequency worksheet (or spreadsheet)

- Count results for retained (unscreened) fire ignition sources

- Apply severity factors as necessary

- Sources retained only at high-confidence HRR value get a severity factor of 0.1

- Sources retained at both the expected and highconfidence values get severity factor of 1.0 (no severity factor reduction)

- Sources screened out in Step 2.3 are not included in the refined fire frequency

- Kind of like a severity factor of 0.0

\section{Idaho National Laboratory}




\section{Task 2.4.2 - Findings Quantified Based}

on Increase in Fire Frequency

- If finding category assigned is anything other than "Fire Prevention and Administrative Controls," no adjustment made to nominal fire frequency

- Within "Fire Prevention and Administrative Controls" findings, the following fire protection DID elements will result in an increase in the fire frequency

- Combustible Controls programs

- For Low or Medium likelihood rating for transient fires, raise the likelíhood rating one level

- For High likelihood rating for transient fires, multiply the likelihood by a factor of 3

- Hot-work-permitting and/or hot work fire watch provisions

- Fire area hot work fire likelihood is set to high and the hot work fire frequency for High likelihood is multiplied by a factor of 3

\section{Idaho National Laboratory}




\section{Task 2.4.3 - Credit for Compensatory Measures that Reduce Fire Frequency}

- If compensatory measures are in place and credited with reducing the frequency of transient combustible or hot work fires, assign a compensatory measures adjustment factor of 0.0 to the appropriate fire ignition source scenarios:

- Transient combustible fire frequency

- There are frequent surveillance patrols (at least once per shift) and review of surveillance reports shows no discovery of improperly stored combustibles.

- If finding is against the combustible controls program this provision will not apply - do not reduce fire frequency

- Hot work fire frequency

- Area has not been used for hot work as verified through a review of hot work permits issued.

- If finding is against hot work control requirements (e.g., fire watch) this provision will not apply - do not reduce fire frequency 


\section{Task 2.4.4 - Update Fire Frequency and Do Screening Check}

- The fire frequency for the fire area is revised considering

- Elimination of fire ignition sources that were not retained in Step 2.3

- Application of severity factors for ignition sources retained only at their high-confidence HRR value

- Adjustment factors as applicable for transients and hot work fires

- May be done using hand worksheet or electronic spreadsheet

- Screening check is essentially identical to that from Step 2.1, but the updated fire frequency is used

\section{Idaho National Laboratory}




\section{Screening Criteria for Step 2.4}

- $\Delta \mathrm{CDF}_{2.4}=\mathrm{DF} \times\left(\mathrm{F}_{\text {Area2.4 }}\right) \times \mathrm{CCDP}_{2.1}$

\begin{tabular}{|c|c|c|}
\hline \multirow[b]{2}{*}{ Assigned Finding Category (from Step 1.1): } & \multicolumn{2}{|c|}{$\Delta \mathrm{CDF}_{2.4}$ screening value } \\
\hline & $\begin{array}{c}\text { Moderate } \\
\text { Degradation }\end{array}$ & $\begin{array}{c}\text { High } \\
\text { Degradation }\end{array}$ \\
\hline Fire Prevention and Administrative Controls & $\mathrm{N} / \mathrm{A}$ & \multirow{5}{*}{$1 E-6$} \\
\hline Fixed Fire Protection Systems & $1 \mathrm{E}-5$ & \\
\hline Fire Confinement & $1 E-5^{1}$ & \\
\hline Localized Cable or Component Protection & $1 E-5^{1}$ & \\
\hline Post-fire SSD & $1 \mathrm{E}-6$ & \\
\hline
\end{tabular}

${ }^{1}$ This entry applies to both 'Moderate A' and 'Moderate B' findings against a fire barrier.

- $\Delta \mathrm{CDF}_{2.4}$ is lower than the corresponding value in Table A1.6 - the finding screens to Green and the analysis is complete.

- $\Delta \mathrm{CDF}_{2.4}$ is greater than or equal to the corresponding value in Table A1.6. The analysis continues to Step 2.5 


\section{Example Problem - Step 2.4}

- Do Step 2.4 for the example problem 


\section{Step 2.5 - Fire Growth and Damage Scenarios and $2^{\text {nd }}$ Check on SSD}

- In this step the process of defining specific fire scenarios continues

- Fire growth and damage scenarios are defined for each combination of fire ignition source and FDS that we are retaining

- This step includes identification of scenario-specific target sets

- Once fire growth and damage scenarios are defined, we re-assess survival of the designated SSD path in the context of each fire ignition source

\section{Idaho National Laboratory}




\section{Step 2.5 - Targets and Target Sets}

- We need to identify targets by both location and function

- We want to know where important targets are with as much accuracy as possible

- Don't start routing cables, but do use routing information made available by licensee

- We are going to group individual targets into target sets

- Target sets correspond to fire ignition source/FDS combinations 


\section{Step 2.5 - Target Sets}

- We would like to know what function is lost given failure of each target

- If possible, tie specific targets to specific functions

- As a minimum it is sufficient to know what functions are lost given loss of the entire target set

- In practice, this is how we use information

- The greater level of detail is still good information to record as available 


\section{Step 2.5 - Target Sets}

- If location information is lacking or uncertain, targets are placed in worst plausible location

- Lacking any other information, assume all target cables are in the tray right above the source

- Some rules of thumb may be applied

- Power cables tend to be routed in upper trays

- Control cables are often in lower or mid-level trays

- Instrument cables usually in the lowest trays

- When uncertain, err towards conservatism, but use available information 
Task 2.5.1 - Fire Growth And Damage Scenarios

- Define fire growth and damage scenarios for each combination of an unscreened fire source and FDS

- Define the fire ignition source

- Define a logical path for fire growth for each applicable FDS

- Define the associated target set 


\section{Defining FDS1 Scenarios}

Start with a fire ignition source and ask yourself:

- Q: Was this fire ignition source retained based on targets within the zone of influence?

- If yes then we may have an FDS1 scenario to consider

- Or Q: Was this fire ignition source retained based only on potential for hot gas layer damage (not plume/radiant heating damage)?

- If yes, then there will be no FDS1 for that source - might still have FDS2 or FDS3 


\section{Defining FDS1 Scenarios}

- FDS1 involves localized damage near the fire source

- Focus especially on vertical fire spread/damage (within the fire plume)

- Define logical path of fire spread if one exists

- Allow fire to grow vertically (i.e., through a stack of cable trays or up a vertical cable riser)

- Do not postulate substantial horizontal spread - that is for FDS2

- Note: we will cover specifics on cable fire spread rules in Module 6 


\section{Defining FDS1 Scenarios}

- FDS1 target set can include any of the following:

- Targets within zone of influence for radiant heating

- The ball in the ball and column

- Targets above the fire source (convective heating zone of influence)

- Targets within the column in the ball and column

- Targets within the range of upward fire spread

- Lowest tray in a stack may be within zone of influence, but target may be a tray ignited due to additional fire spread

- Unprotected cables and components

- Cable and components "protected" by a highly degraded localized fire barrier system

- Non-functional or missing cable wrap 


\section{Defining FDS2 Fire Scenarios}

Start with a fire ignition source:

- Define fire spread path if needed

- If fire source alone is enough to cause damaging hot gas layer, then fire spread is moot - just worry about the source

- If fire ignition source is not enough to cause hot gas layer damage without fire spreading, then you must postulate a path of fire spread

- This time we allow for more extensive horizontal fire spread

- Define in particular, maximum extent of fire possible 


\section{Defining FDS2 Scenarios}

- Define the fire damage target set

- FDS2 involves widespread damage within the fire area

- Look for HGL potential and timing

- If HGL not reasonable or simply takes too long to be risk significant (i.e., high likelihood of suppression), then FDS2 target set may be limited by extent of direct fire spread

- If HGL is possible in reasonable time, any and all exposed cables and components anywhere in the room may be damaged

- Note: anything damaged in the corresponding FDS1 scenario for the same fire source (if you developed one) is also included in the FDS2 target set 


\section{Defining FDS2 Scenarios}

- Cables protected by a moderately degraded localized cable or component fire barrier element are also damaged in FDS2

- These targets will likely drive the overall damage time

- Cables and components protected by a one-hour fire barrier wrap may be damaged in FDS2 even if wrap is not degraded

- Recall - we did not credit a one-hour wrap alone in Step 2.1 as meeting independence criteria!

- Any scenario that requires one hour is likely to be relatively low risk, so a "scoping" calculation may be appropriate:

- Check product of refined fire frequency and manual nonsuppression probability at one hour

- If non-degraded automatic fire suppression system is present, don't chase these scenarios - they will be low risk

- Don't try to fail a non-degraded three-hour fire wrap 


\section{Defining FDS3 Scenarios}

- The FDS3 scenarios depend a bit on what your finding is - two cases:

- Finding is not Fire Confinement

- Finding is Fire Confinement 


\section{FDS3 - Finding Is Not Fire Confinement}

- The inspected area is always the exposing fire area, an adjacent area is the exposed area

- For this case, something in the fire area you are inspecting is degraded, but it is not the fire area boundaries

- In developing FDS3 scenarios, we are presuming that a fire in the inspected compartment might be more likely to spread to an adjacent compartment

- Example: It might go unsuppressed for a longer time than one would normally expect 


\section{If Step 2.2 Didn't Drop FDS3 You Must Have Found All of the Following:}

- A somewhat weak barrier to at least one adjacent fire area

- Questionable or non-existent fixed suppression capability in exposing compartment

- Unique and exposed targets in at least one adjoining room

- The potential for fire that can directly challenge the fire barrier

It's not hard to develop an FDS3 scenario out of that situation! 


\section{FDS3 - Finding Is Fire Confinement}

- In this case you have a degraded fire barrier between two fire areas

- Fire spreading through the degraded barrier IS the scenario

- Fire might go in either direction, so you may have two scenarios

- Hopefully the screening question would eliminate fire in one direction or the other

- If one fire area has a non-degraded fire sprinkler system, that should not be the exposing fire area 


\section{For Both Cases: Defining The FDS3 Scenarios}

- Focus only on fire getting through the barrier(s) that did not meet the screening rules

- The degraded barrier or the one that didn't give at least 2 hours endurance

- If endurance rating is greater than 20 minutes, but less than 2 hours, your targets in the exposed room should be right near the barrier

- If it's less than 20 minutes or barrier is degraded, targets could be anywhere in the exposed room

- Focus on fire ignition sources that could challenge the fire barrier

- High hazard

- Near barrier

- Direct path for fire spread through the barrier 


\section{Defining FDS3 Scenarios}

- Again, start with a fire ignition source

- Pick the worst one and let it represent the whole set

- You want one that can spread fire or fire effects into the adjacent area

- If you applied the screening rules in Step 2.2 correctly, then you should have verified at least one such source existed

- Characterize the conditions that lead to fire spread into the adjacent fire area

- Fire spread along cable trays that penetrate the barrier is typical

- If you have a high-hazard fire source (e.g., oil-filled transformer or other large oil source), source of spread could be hot gas layer impacting both fire areas 


\section{Defining FDS3 Scenarios}

- Target set should be pretty obvious

- Minimum set:

- Everything within reach of your ignition source (zone of influence)

- Everything in the path of fire spread

- The unique targets in the exposed fire area

- Maximum:

- Everything in both fire areas

- Use your judgment, pick a target set 


\section{Task 2.5.2 - Plant Damage State}

- For each fire growth and damage scenario determine what failure of the target set means in the context of plant SSD response

- What functions/systems are lost

- What is the nature of the failure

- Loss of function, spurious operation, operable but with loss of indication....

- What is function/system state given failure

- System may be running

- Valve may be open or closed...

- Recall - it is enough to know this answer for the set as a whole, but nice if you can tie functions to specific targets 


\section{Plant Damage State}

- Also define what survives

- What functions/systems can be credited for safe shutdown

- Assume system is lost unless it can be verified with reasonable confidence that the system will survive

- Identify any manual actions needed to support safe shutdown

- Focus on actions outside the main control room or complex actions within the main control room 


\section{Task 2.5.3 - Re-Check SSD Path Independence}

- In this task the independence of the designated SSD path is reassessed based on the specific plant damage state

- Plant damage state will define whether or not the SSD path is available - no more rules/questions needed

- You look at the worst case target set for each fire ignition source

- If the SSD path survives in this worst case, the CCDP from Step 2.1 (e.g., 0.1) can be applied to all scenarios for that fire ignition source 


\section{Step 2.5.4 - Screening Check}

- In this step, the SSD path is credited, or not credited, for each fire ignition source

- CCDP for each ignition source is either 1.0 or $\mathrm{CCDP}_{2.1}$ depending on results of Step 2.5.3

- If the SSD path is lost for at least one fire scenario for each fire ignition source, then this step is skipped

- You can only improve screening result if you are going to credit the SSD path for at least one fire ignition source

- If you decided earlier that $\mathrm{CCDP}_{2.1}$ applied in general, then there is no benefit to be gained 


\section{Step 2.5.5 - Screening Check}

\section{$\Delta \mathrm{CDF}_{2.5}=\mathrm{DF} X \sum\left\{\left(\mathrm{F}_{\text {source }}\right)_{\mathrm{i}} \mathrm{X}\left(\mathrm{CCDP}_{2.1}\right)_{\mathrm{i}}\right\}$}

- Sum over all fire ignition sources ( $i=1$ to $n$ )

\begin{tabular}{|l|c|c|}
\hline \multicolumn{2}{|c|}{ Table A1.8 - Phase 2, Screening Step 5 Quantitative Screening Criteria } \\
\hline \multirow{2}{*}{ Assigned Finding Category (from Step 1.1): } & \multicolumn{2}{|c|}{$\Delta \mathrm{CDF}_{2.5}$ screening value } \\
\cline { 2 - 2 } & $\begin{array}{c}\text { Moderate } \\
\text { Degradation }\end{array}$ & $\begin{array}{c}\text { High } \\
\text { Degradation }\end{array}$ \\
\hline Fire Prevention and Administrative Controls & $\mathrm{N} / \mathrm{A}$ & \\
\hline Fixed Fire Protection Systems & $1 \mathrm{E}-5$ & \multirow{2}{*}{$1 \mathrm{E}-6$} \\
\hline Fire Confinement & $1 \mathrm{E}-5^{1}$ & \\
\hline Localized Cable or Component Protection & $1 \mathrm{E}-5^{1}$ & \\
\hline Post-fire SSD & $1 \mathrm{E}-6$ & \\
\hline
\end{tabular}

${ }^{1}$ This entry applies to both 'Moderate A' and 'Moderate B' findings against a fire barrier.

$\mathrm{O}$ The value of $\triangle \mathrm{CDF}_{2.5}$ is lower than the corresponding value in Table A1.8. The finding Screens to Green, and the analysis is complete.

$0 \quad$ The value of $\triangle C D_{2.5}$ exceeds the corresponding value in Table A1.8. The analysis continues to Step 2.6. 


\section{Example Problem - Step 2.5}

- Do Step 2.5 for the example problem 


\section{Step 2.6: Damage Time}

- Estimate fire growth and damage time for each fire scenario

- There are separate "rules" for FDS1, FDS2, and FDS3

- Task 2.6.1 - FDS1

- Task 2.6.2 - FDS2

- Task 2.6.3 - FDS3

- FDS1 and FDS2 require use of FDTs (plume, radiant heating, hot gas layer)

- Fire spread rules also apply 


\section{Task 2.6.1: FDS1}

- If all elements of the target set are within the zone of influence then plume/radiant heating is enough - don't need fire spread

- Calculate plume temperature or radiant heat flux level at target location

- Pick damage time off the look-up table

- If target tray is outside the zone of influence, fire spread upwards through the cable tray stack is needed

- Use the cable tray fire growth rules

- Details in Attachment 3 


\section{Fire Spread In A Tray Stack:}

- If first tray is within zone of influence it can be ignited and fire will spread

- Fire spreads according to the following rules:

- Time to ignition of first tray: use plume temperature at height of tray and time to damage/ignition table

- Call this $\mathrm{t}_{1}$

- Note: Early versions of guidance said to use five minutes but this was an error and has been corrected in current version

- Second tray 4 minutes later (elapsed time $t_{1}+4$ min.)

- Third tray 3 minutes later (elapsed time $t_{1}+7$ min.)

- Fourth tray 2 minutes later (elapsed time $t_{1}+9$ min.)

- Fifth tray 1 minute later (elapsed time $t_{1}+10$ min.)

- Higher trays 1 minute later (elapsed time $t_{1}+11$ min.)

- Cables assumed to fail when tray ignites

\section{Idaho National Laboratory}




\section{Task 2.6.2 - FDS2 Damage Time}

- Begin with corresponding FDS1 damage time if there is one for the fire ignition source

- FDS2 damage time cannot be any earlier

- Then you need to go after the hot gas layer, and consider time to damage for degraded raceway fire barriers 


\section{FDS2 Damage Time}

- Targets with no fire barrier protection are damaged based on exposure temperature and time-to-damage table

- If FDS2 target sets include cables or components within a moderately degraded local fire barrier system, add in the remaining performance time of the barrier, given the degradation, to get total time to damage 


\section{HGL Damage}

Check the HGL temperature for the fire ignition source alone (using FDTs) - if this is enough:

- If HGL temperature reaches damage threshold in less than $\mathbf{3 0}$ minutes, then ignition source alone is enough to cause damage

- You may have checked this during screening back in Step 2.4

- First check HGL temperature at 10 minutes

- If this value exceeds the damage threshold, record the value, use the look-up table to get damage time at this temperature

- Total damage time is $\mathbf{1 0}$ minutes plus time to damage from look-up table

- If HGL temperature reaches damage threshold in greater than 10 minutes:

- Damage time is time to reach damage threshold plus damage time from look-up table at the threshold temperature (e.g., 28 minutes) 


\section{HGL Damage}

If fire spread to cables is needed to get damaging HGL, process requires use of both FDTs and Cable Tray Fire Spread spreadsheets:

- FDT HGL tool: Determine HRR needed to get damaging HGL in the room of interest

- Input room parameters (dimensions, ventilation)

- Adjust HRR for the fire

- Look at HGL temperature at 10 minutes

- Compare to damage threshold temperature

- Iterate until HGL temperature equals or exceeds damage 


\section{HGL Damage}

- Fire ignition source contributes to total HRR, so subtract that out from required HRR

- The HRR difference needs to come from the cables

- Have to figure out time for fire to spread far enough to create a fire this big:

- Cable trays are assumed to burn at $400 \mathrm{~kW} / \mathrm{m}^{2}$

- Calculate square feet of tray required to get required HRR

- Determine if there are enough trays in the area to get a fire this big

- If no, then FDS2 scenario is not credible

- If yes, need to estimate time for fire to grow this far using cable tray fire spread rules

- Spreadsheet provided for this case 


\section{HGL Damage}

- If there are enough trays, use the Cable Tray Fire Spread spreadsheet ("Time to HGL From Fire Spread_Locked.xls"):

- Calculate time to ignition of first tray

- Using plume temperature at tray and damage time look-up table (as in a FDS1 scenario)

- Spreadsheet input: total HRR needed, ignition source HRR, time to ignition of first tray, characteristics of cable trays

- Manipulate "time of interest" until damaging HGL is indicated

- That puts us at the damage threshold

- Assume pre-heating of exposed cables during time of fire growth so no additional time to damage

- Time to develop damaging HGL is taken as time to damage exposed cables for fire propagation scenarios

- Cables with fire barrier wrapping get additional time

- Nominal fire barrier rating (after applying penalty for any degradation)

- Plus $1 / 2$ of time to damage for cable at threshold condition 


\section{HGL Damage}

- Don't try to get too fine an answer:

- HRR steps of $50 \mathrm{~kW}$

- Time steps of integer minutes 


\section{Task 2.6.3: FDS3 Scenarios}

- If you have a highly degraded fire barrier as the finding, combine the two areas and treat just like FDS2

- Inter-area barrier gets no credit

- Credit only one fire suppression system if more than one exists (i.e., you might have had some coverage in both rooms 


\section{Task 2.6.3 - FDS3 Scenarios}

- If you have a moderately degraded barrier or a finding that is not Fire Confinement

- Use one scenario to estimate time for direct fire spread to and through the fire barrier

- Estimate time for fire to spread to the barrier

- Use one scenario (same or other) to try to get a damaging hot gas layer

- Use FDS2 approach to estimate time to reach a damaging hot gas layer in the exposing fire area

- Pick the shorter time from these two cases to represent all FDS3 fires

- This is the fire growth time 


\section{Task 2.6.3 - FDS3 Scenarios}

- Moderate degradation Fire Confinement or non-confinement finding (cont.)

- Add in the fire endurance time allowed for the degraded barrier [e.g., $65 \%$ (Moderate A) or $35 \%$ (Moderate B) of nominal if barrier is degraded or full credit if not]

- If targets in exposed fire area have raceway fire barrier protection, add in the fire endurance rating of this protection

Total fire damage time $=($ fire growth time $)+($ endurance of degraded barrier) + (endurance of raceway barriers is present in exposed compartment) 


\section{Example Problem - Step 2.6}

- Do Step 2.6 for the example problem 


\section{Step 2.7 - PNS Analysis}

- This step estimates the probability that suppression fails at extinguishing fire before target set is damaged

- Credit is given to both fixed and manual fire suppression

- For the fire brigade, we also need the detection time

- Detection activates the human response including the fire fighting response 


\section{Task 2.7.1 - Fire Detection Time}

Detection time is a race - shortest time wins:

- Fixed fire detection is estimated using FDT spreadsheet

- Other means of detection

- Continuous fire watch: $t_{\text {detection }}=\mathbf{0}$

- Roving fire watch: $t_{\text {detection }}=1 / 2$ the duration of roving patrol

- General plant personnel:

- $t_{\text {detection }}=5$ minutes if continuously manned

- $t_{\text {detection }}=15$ if not manned

- Maximum detection time is 15 minutes 


\section{Task 2.7.2 - Fixed Fire Suppression}

- Activation of fixed fire suppression system that is considered effective against the fire ignition source is assumed to end the fire scenario

- Inspector decides on suppression system effectiveness

- Timing needs to be determined

- Skip this task if no fixed suppression exists or installed system is highly degraded 


\section{Task 2.7.2 - Fixed Fire Suppression}

- Use the fire detector spreadsheet in FDTs to estimate actuation time

- Sprinkler head is just a fancy heat detector

- Watch for cross-zoned actuation logic

- Common for auto gas systems and deluge systems

- Need to ensure both zones actuate, so analyze detector that is farthest from the fire source

- Add discharge delay time for gaseous systems

- Minimum of 30 seconds, 1-2 minutes is typical 


\section{Task 2.7.2 - Fixed Fire Suppression}

- If fixed suppression system is moderately degraded:

- If issue is head spacing - model as found

- If some subset of discharge heads are degraded then assume nearest head won't work, second closest head is modeled

- If system does not provide adequate coverage to some fire ignition sources, credit only for those sources that are covered 


\section{Task 2.7.2 - Fixed Fire Suppression}

- If fixed system is manually actuated

- Estimate the fire brigade response time

- If fire brigade members have full decision-making authority to actuate system, allow additional 2 minutes for situation assessment and decisionmaking

- If fire brigade must get authorization (e.g., from MCR, shift supervisor, plant manager) you must assess the time required for such authorization

- Don't forget delay time for gaseous system discharge applies even when manually actuated

\section{Idaho National Laboratory}




\section{Task 2.7.2 - PNS $_{\text {fixed }}$}

- Now that you have time to actuation and time to damage, the two are compared in order to assess the value of PNS $_{\text {fixed }}$

- Take the difference:

- $t_{\text {damage }}-t_{\text {supp_fixed }}$

- Refer to lookup table for PNS

- Both times have uncertainty

- If difference is small, we don't allow as much credit as when difference is large 


\section{The PNS $_{\text {fixed }}$ lookup table}

\begin{tabular}{|c|c|}
\hline $\begin{array}{c}\text { Probability of Non-suppression for Fixed Fire Suppression } \\
\text { Systems Based on the Absolute Difference Between } \\
\text { Damage Time and Suppression Time }\end{array}$ \\
\hline Time Delta: $\left.\mathbf{t}_{\text {Damage }}-\mathbf{t}_{\text {suppress }}\right)$ & PNS $_{\text {Fixed }}$ \\
\hline Negative Time up to 1 Minute & 1.0 \\
\hline$>1$ Minute to 2 Minutes & .95 \\
\hline$>2$ Minutes to 4 Minutes & .80 \\
\hline$>4$ Minutes to 6 Minutes & .5 \\
\hline$>6$ Minutes to 8 Minutes & .25 \\
\hline$>8$ Minutes to 10 Minutes & .1 \\
\hline$>10$ Minutes & 0.0 \\
\hline
\end{tabular}

\section{Idaho National Laboratory}




\section{Task 2.7.3 - Manual Suppression}

- Manual suppression is based on empirically fire duration curves

- Analysis of historical events

- Based on total fire duration so we don't do brigade response time - built into curves

- Different curves for different fire ignition sources

- Pick the curve that applies to your ignition source

- Example: If fire spreads from a panel to cable trays, the ignition source was the panel, use the electrical fire curve rather than the cable fire curve 


\section{Task 2.7.3 - Manual Suppression}

- "Curves" are available in three forms

- Graphical

- Look-up table

- Equation:

$$
P N S_{\text {manual }}=\exp [-\lambda \times t]
$$

- Values of suppression rate constant $(\lambda)$ are in lookup table

- $t$ is fire duration (time to damage minus time of detection) 


\section{Degraded Gaseous System PNS Analysis}

First calculate PNS for manual response as if gaseous system were not in place (or were to fail):

- Select appropriate fire duration curve, based on ignition source

- Estimate fire detection time in the usual manner

- Assume a valid actuation signal for gaseous system will trigger fire detection signal as well

- Calculate $t_{\text {damage }}{ }^{-t_{\text {detection }}}$

- Estimate PNS $_{\text {manual }}$ in the usual manner 


\section{Degraded Gaseous System PNS Analysis}

Next look at timeliness of system discharge:

- Estimate discharge/actuation time ( $t_{\text {suppress }}$ ) as you would for any fixed system

- Could be automatic or manual actuation of fixed system

- Calculate time margin ("Time Delta") between actuation time and fire damage time in the normal manner:

- Time Delta $=\left(t_{\text {damage }}-t_{\text {suppress }}\right)$

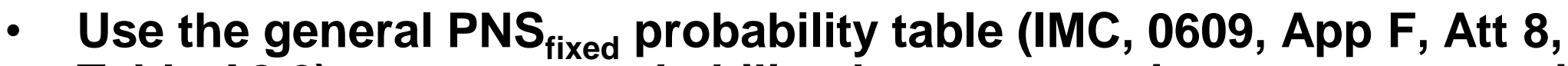
Table A8.2) to assess probability that suppression system actuation is timely in relation to estimated fire damage time. 


\section{Degraded Gaseous System PNS Analysis}

Based on PNS $_{\text {fixed }}$ decide whether to credit gaseous system:

- If $\mathrm{PNS}_{\text {fixed }}$ is 1.0, then gaseous system will not be credited.

- Use PNS $_{\text {scenario }}=$ PNS $_{\text {manual }}$

- Analysis is complete.

- If PNS $_{\text {fixed }}$ is less than 1.0, then gaseous system will be credited.

- Continue this analysis to estimate PNS $_{\text {scenario* }}$ 


\section{Degraded Gaseous System PNS Analysis}

Now do the case where system buys some added time for fire brigade response:

- Calculate modified fire damage time as follows:

$t_{\text {damage_new }}=t_{\text {damage }}+t_{\text {maintain_gas }}$

where $t_{\text {maintain_gas }}$ is the time suppressant concentration can be maintained

- Calculate modified time available for manual suppression:

[ $\left.t_{\text {damage_new }}-t_{\text {detection }}\right]$

- Estimate PNS $_{\text {gas_manual }}$ in the manner normally applied to PNS $_{\text {manual }}$

- Use appropriate fire duration curve with the modified time available 


\section{Degraded Gaseous System PNS Analysis}

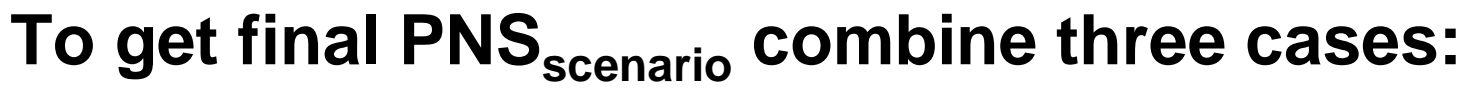

- Case 1: Suppression system works (0.95 - no random failure), the actuation is timely (1- PNS $_{\text {fixed }}$ ), and fire brigade fails to respond with extra time available ( PNS $_{\text {gas_manual }}$ )

- Case 2: Suppression system works (0.95 - no random failure), but discharge of the fire suppression system is not timely $\left(\right.$ PNS $\left._{\text {fixed }}\right)$, manual brigade must respond within original fire damage time (no extra time available - PNS $_{\text {manual }}$ )

- Case 3: Gaseous suppression system suffers random failure on demand (0.05), fire brigade must respond within the originally estimated fire damage time $\left(\right.$ PNS $\left._{\text {manual }}\right)$ 


\section{Degraded Gaseous System PNS Analysis}

- And the final reduced equation is...

PNS $_{\text {scenario }}=0.95 \times\left(1-\right.$ PNS $\left._{\text {fixed }}\right) \times$ PNS $_{\text {gas_manual }}$

$$
+\left[\left(0.95 \times \text { PNS }_{\text {fixed }}\right)+0.05\right] \times \text { PNS }_{\text {manual }}
$$

- Verify that $\left(\mathrm{PNS}_{\text {scenario }} \leq \mathrm{PNS}_{\text {manual }}\right)$

- As in other cases, the manual brigade response given the original fire damage time is the minimum credit given to fire suppression for any scenario

- If $\left(\right.$ PNS $_{\text {scenario }}>$ PNS $\left._{\text {manual }}\right)$ reset $\left(\right.$ PNS $\left._{\text {scenario }}=\mathbf{P N S}_{\text {manual }}\right)$ 


\title{
Task 2.7.4: Final combined PNS
}

For water-based systems:

$\mathrm{PNS}_{\text {scenario }}=\left(0.98 \times \mathrm{PNS}_{\text {fixed-scenario }}\right)+\left(0.02 \times \mathrm{PNS}_{\text {manual-scenario }}\right)$

\section{For Gaseous systems:}

$\mathrm{PNS}_{\text {scenario }}=\left(0.95 \times \mathrm{PNS}_{\text {fixed-scenario }}\right)+\left(0.05 \times \mathrm{PNS}_{\text {manual-scenario }}\right)$

\author{
$* * \mathrm{PNS}_{\text {scenario }} \leq \mathrm{PNS}_{\text {manual-scenario }}$
}




\title{
And The Degraded Gaseous System - Inadequate Soak Time Case
}

\author{
PNS $_{\text {scenario }}=0.95 \times\left(1-\right.$ PNS $\left._{\text {fixed }}\right) \times$ PNS $_{\text {gas_manual }}$ \\ $+\left[\left(0.95 \times\right.\right.$ PNS $\left.\left._{\text {fixed }}\right)+0.05\right] \times$ PNS $_{\text {manual }}$
}




\section{Step 2.7.5 - Screening Check}

- We now have scenario-specific PNS

- Combine with duration factor, scenario-specific frequency, and scenario-specific credit for SSD path to get new screening result

- Screen to Green if increase in CDF is less than 1E-6 


\section{Example Problem - Step 2.7}

- Do Step 2.7 for the example problem 


\section{Step 2.8 - SSD / CCDP Analysis}

- Won't go into detail

- Task 2.8.1 - Select appropriate plant initiating event worksheet (guidance on p. F-40)

- Task 2.8.2 - Identify credited systems and functions

- Task 2.8.3 - Identify ex-control room actions

- Task 2.8.4 - Assess failure probability of manual actions

- Task 2.8.5 - Assess CCDP 


\section{Step 2.9 - Final Quantification}

- In this step you use all your best information, which now includes a specific CCDP for each individual scenario

- Run these values through the risk equation

- Sum scenario frequencies

- Assign a preliminary color

\begin{tabular}{|c|c|}
\hline \multicolumn{2}{|c|}{ Table 2.9.1- Risk Significance Based on $\Delta$ CDF } \\
\hline Frequency Range/ry & SDP Based on $\Delta$ CDF \\
\hline$\geq 10^{-4}$ & Red \\
\hline$<10^{-4}-10^{-5}$ & Yellow \\
\hline$<10^{-5}-10^{-6}$ & White \\
\hline$<10^{-6}$ & Green \\
\hline
\end{tabular}




\section{Page Intentionally Left Blank}




\section{Module 6: Special Topics}




\section{Module 6A - High Energy Arcing Faults In Electrical Distribution And Switching Equipment}




\section{High Energy Arcing Faults}

- Arcing faults are not your typical fire

- High energy discharge at the outset - essentially a small explosive discharge

- Usually started due to either phase-to-phase or phase-toground shorts and arcing

- Often following a maintenance activity

- Electrical energy is converted to heat - lots of heat - for a very short time

- Copper electrical contacts get vaporized

- Arcs can burn through steel in very short order 


\section{Our Prototypical Event}

- San Onofre, Unit 3, Feb. 3, 2001

- Discussion based largely on presentation by Bob Richter at 10/01 NEI FP Forum

- Additional information in App. $\mathrm{H}$ of NUREG-1824

- Picture at right shows panel after the fire

- Some damage was done during fire fighting (large mass bottom center pulled free of panel)

- Note extensive burn marks

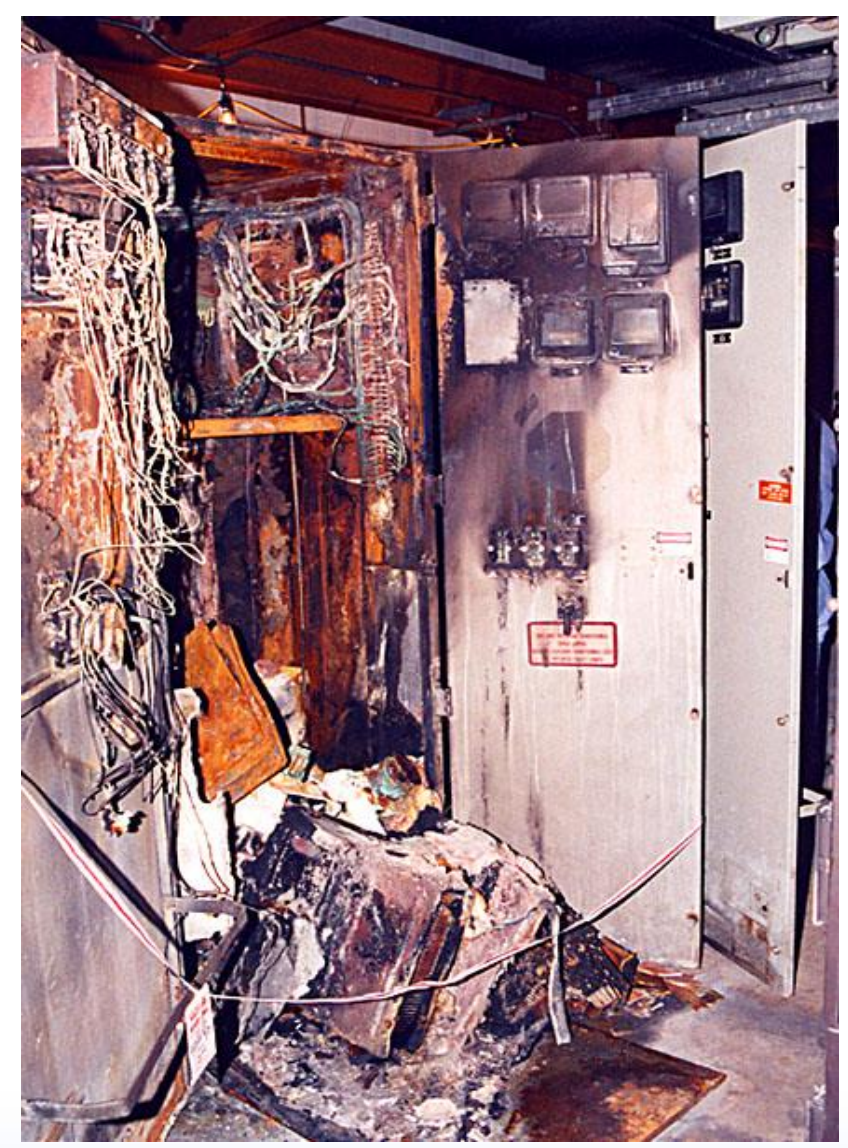

\section{Idaho National Laboratory}




\section{What Happened}

- While "racking in" one of the two main input breakers for one train of switchgear, the "stabs" for one phase did not make proper/full contact

- Arcing vaporized the copper contacts

- Arcing burned a hole through the side of the panel

- The ionized smoke and copper plasma propagated to the second main input breaker in an adjoining panel

- Arcing in the second breaker cubicle caused a catastrophic arcing fault and explosion 


\section{What Happened}

- The door to the second panel was blown open

- The ensuing fire caused loss of overhead cable trays, adjoining switchgear breaker cubicles, and panels located across the aisle from the initially faulting switchgear

- Total fire duration was over one hour

- Numerous attempts to extinguish fire with dry chemical were unsuccessful; water required to put out deep-seated fire 


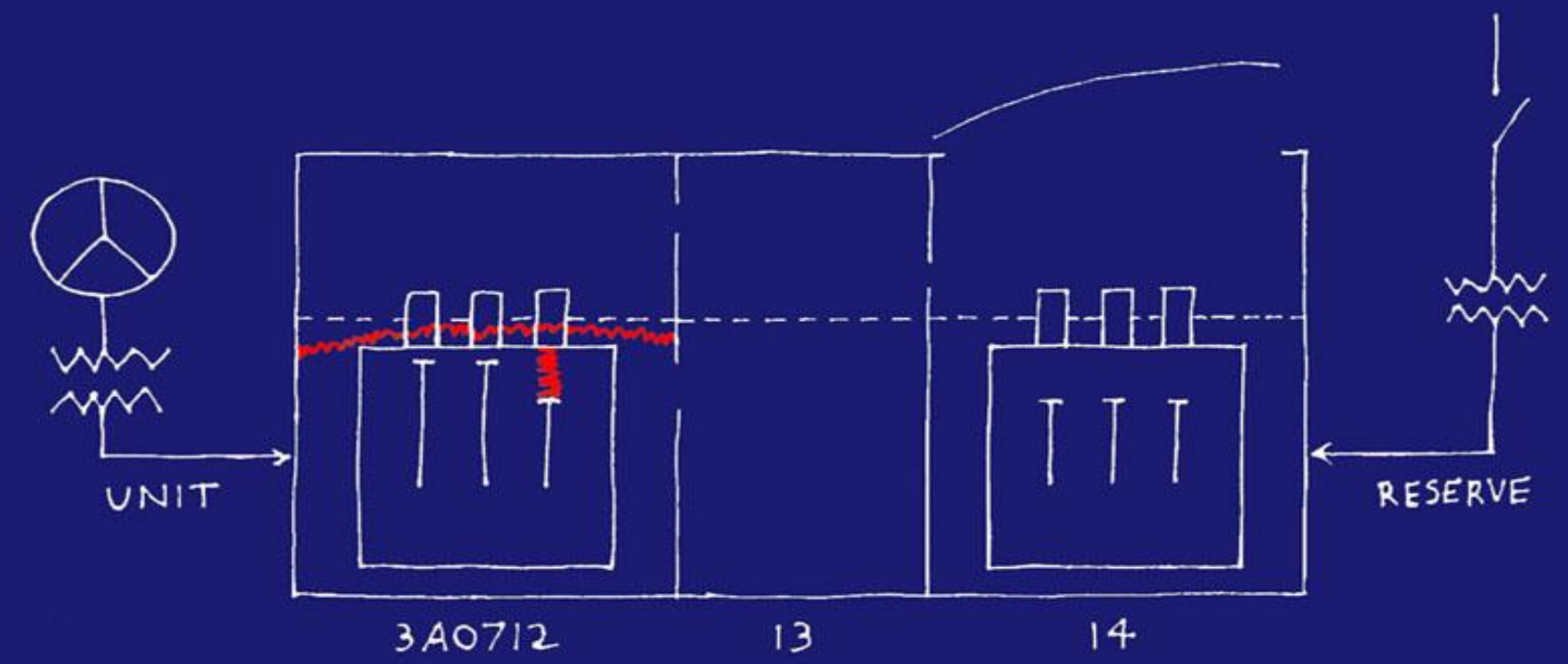

Sketch 1: C Contact arcing and Phase to Phase to ground arcing in Cabinet 3A0712.

\section{Idaho National Laboratory}




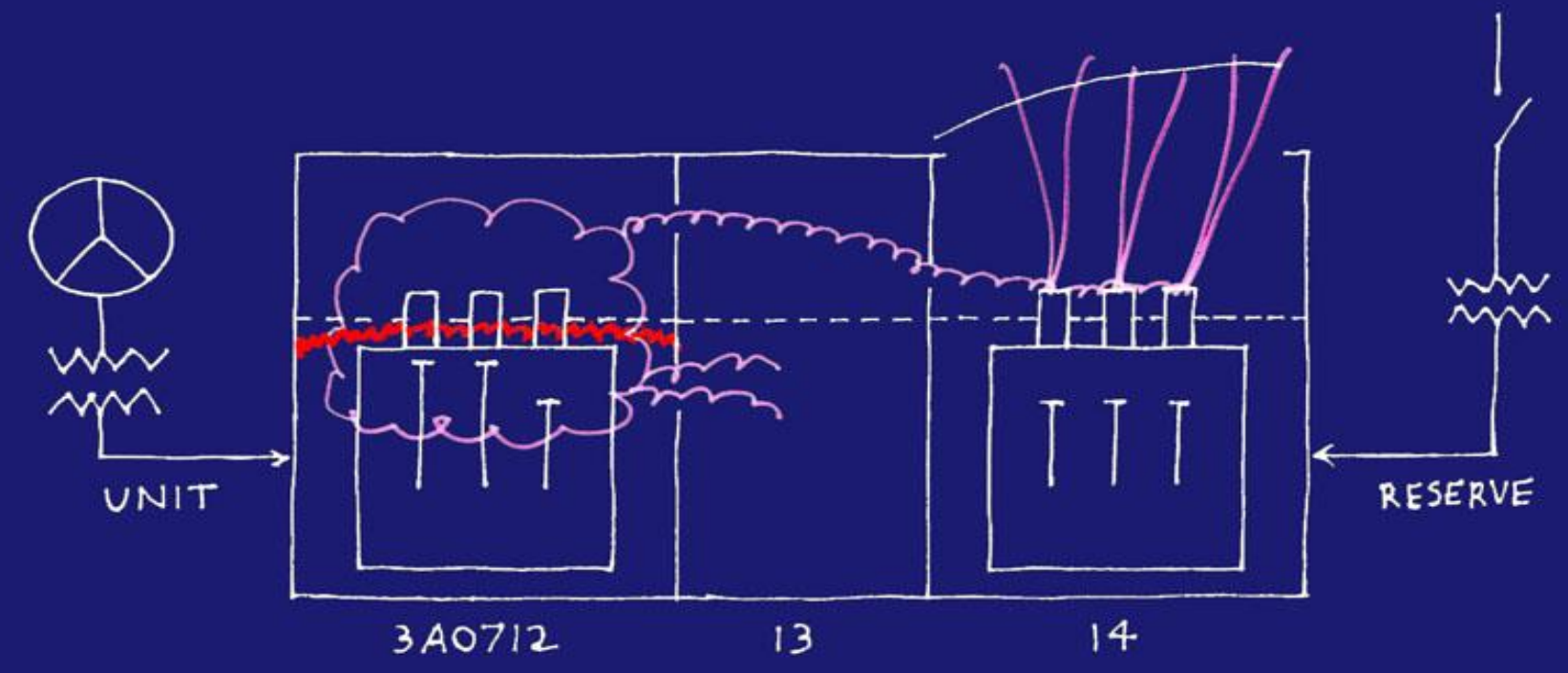

Sketch 2: lonized gas transits from 12 to 14 and into 13. Conductive bridge across 14 Reserve stabs causes flash.

\section{Idaho National Laboratory}




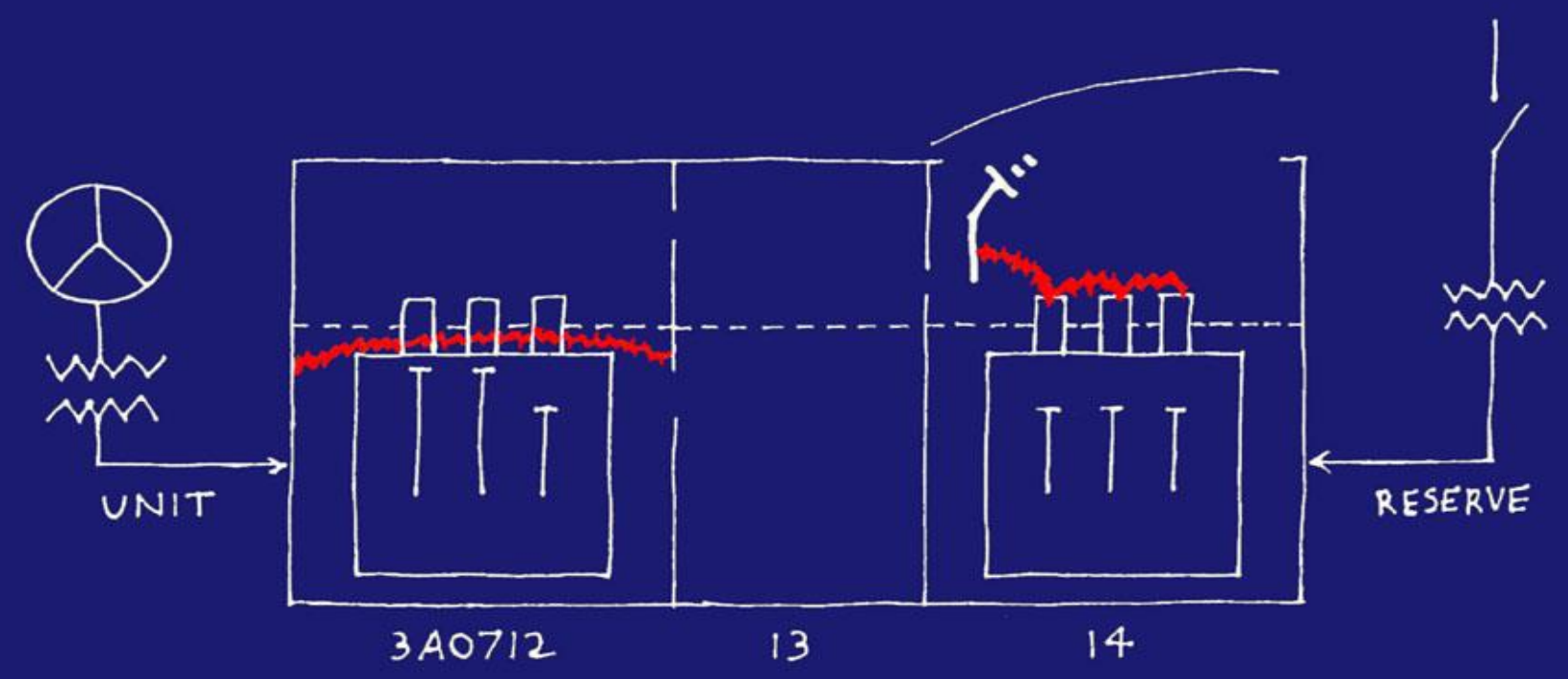

Sketch 3: $\quad$ Main Generator continues to feed A-B-C-Ground arcing in 12. A-phase arcs to ground in 14 causing Differential trip.

\section{Idaho National Laboratory}




\section{Assessment Of Causes}

- Most Likely Causes For A07 Fire

- 1. Mispositioning of stud-to-pushrod interface among the 3 phases.

- 2. Improper bridge pivot joint pressure

- 3. Arc chute degradation leading to foreign material between breaker contacts 


\section{U3 A07 30' Switchgear Room Bus \& Cable Tray}

Arrangement

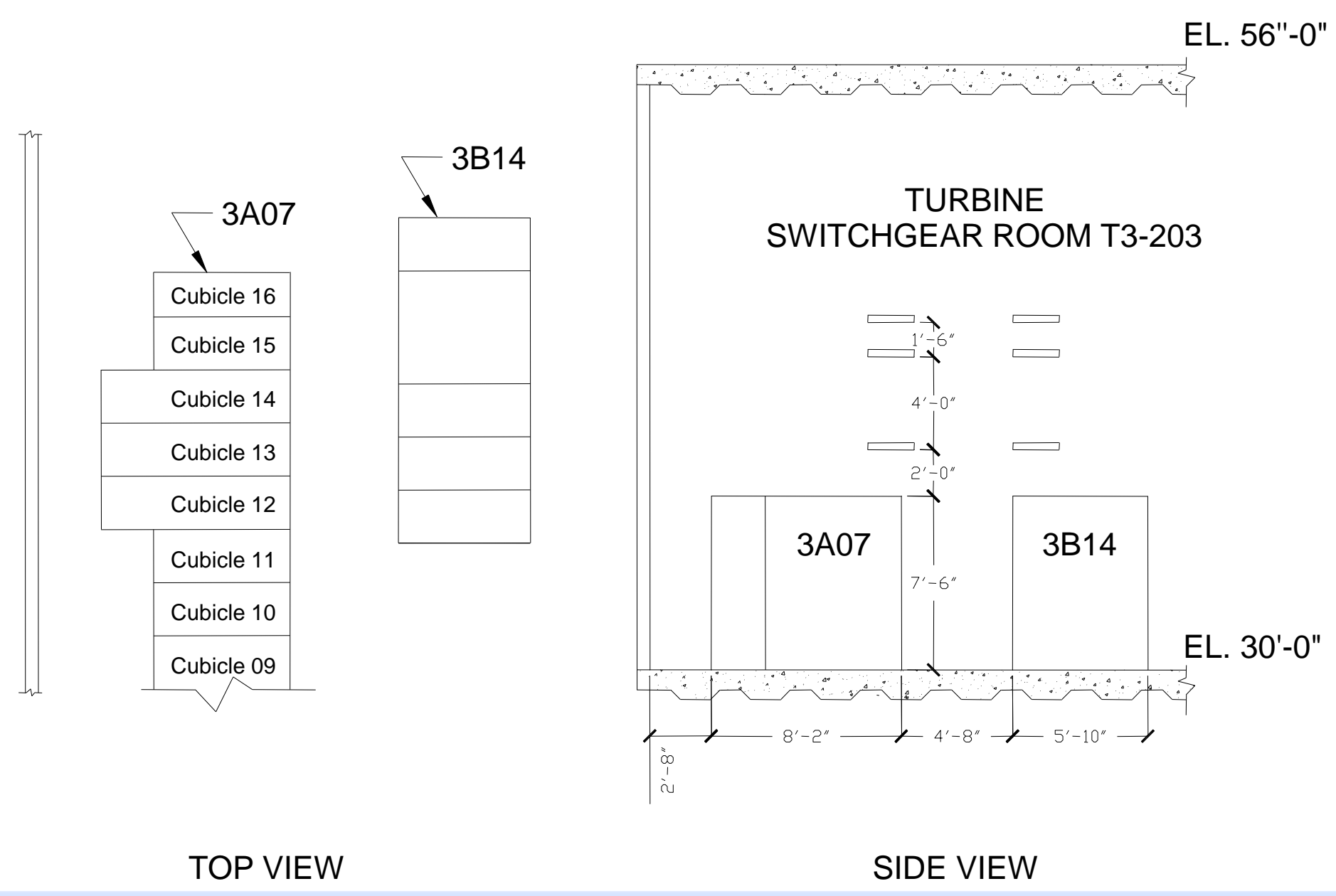




\section{U3 A07 30' Switchgear Room Cable Trays}

Cable

Tray

Directly

Above

Bus

A07

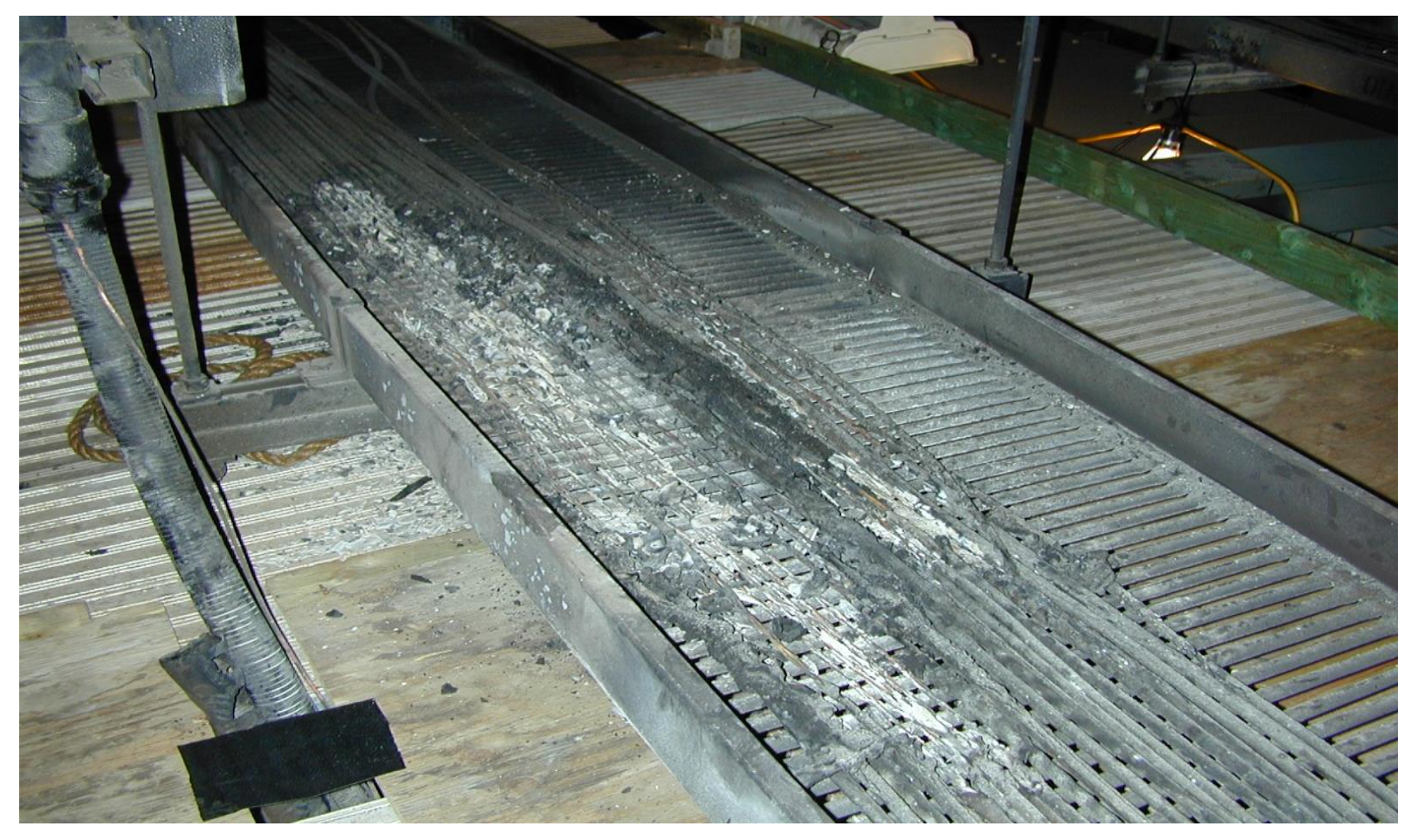

\section{Idaho National Laboratory}




\section{U3 AO7 30' Switchgear Room Cable Trays}

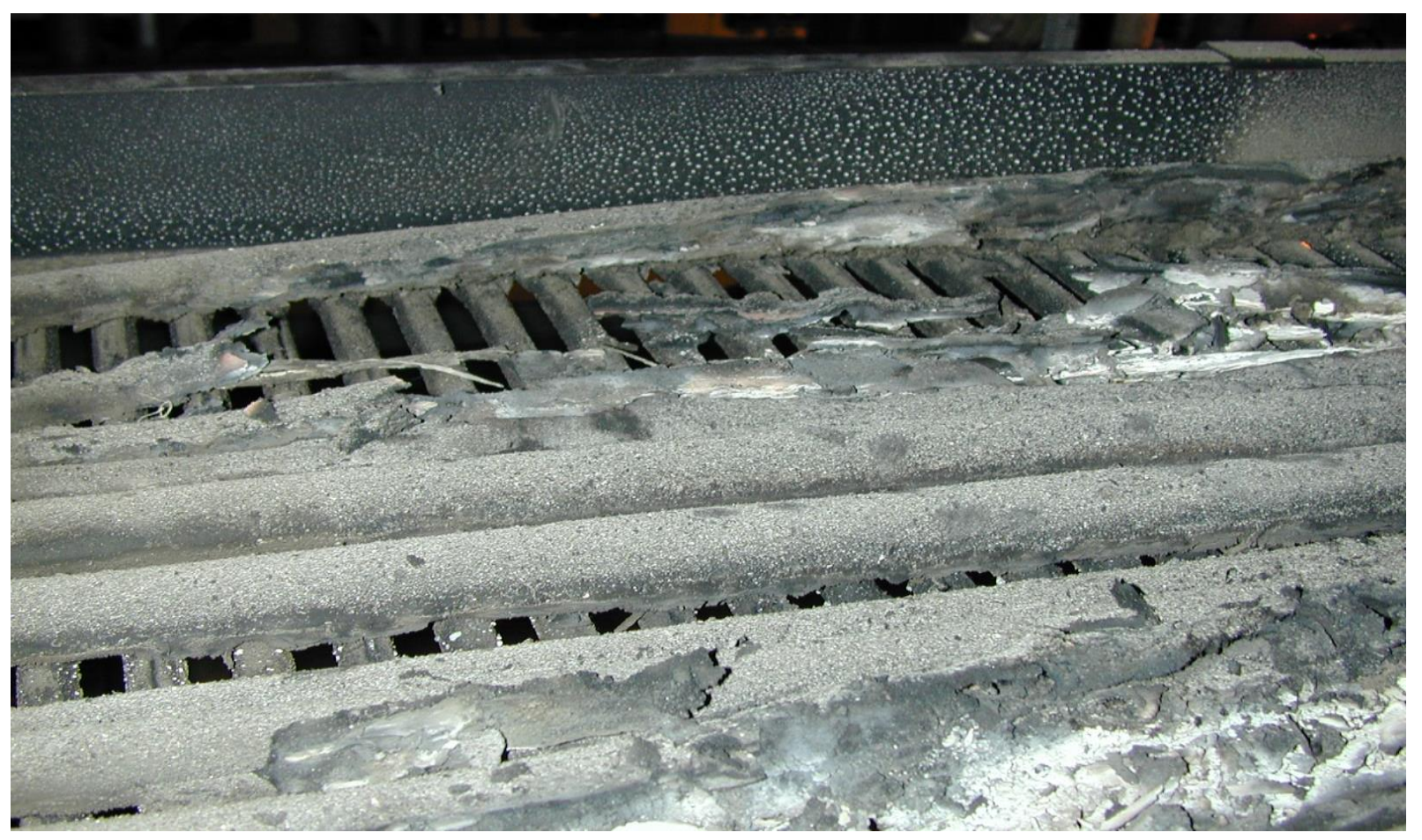

Cable Tray Directly Above Bus A07

\section{Idaho National Laboratory}




\section{U3 AO7 30' Switchgear Room Cable Trays}

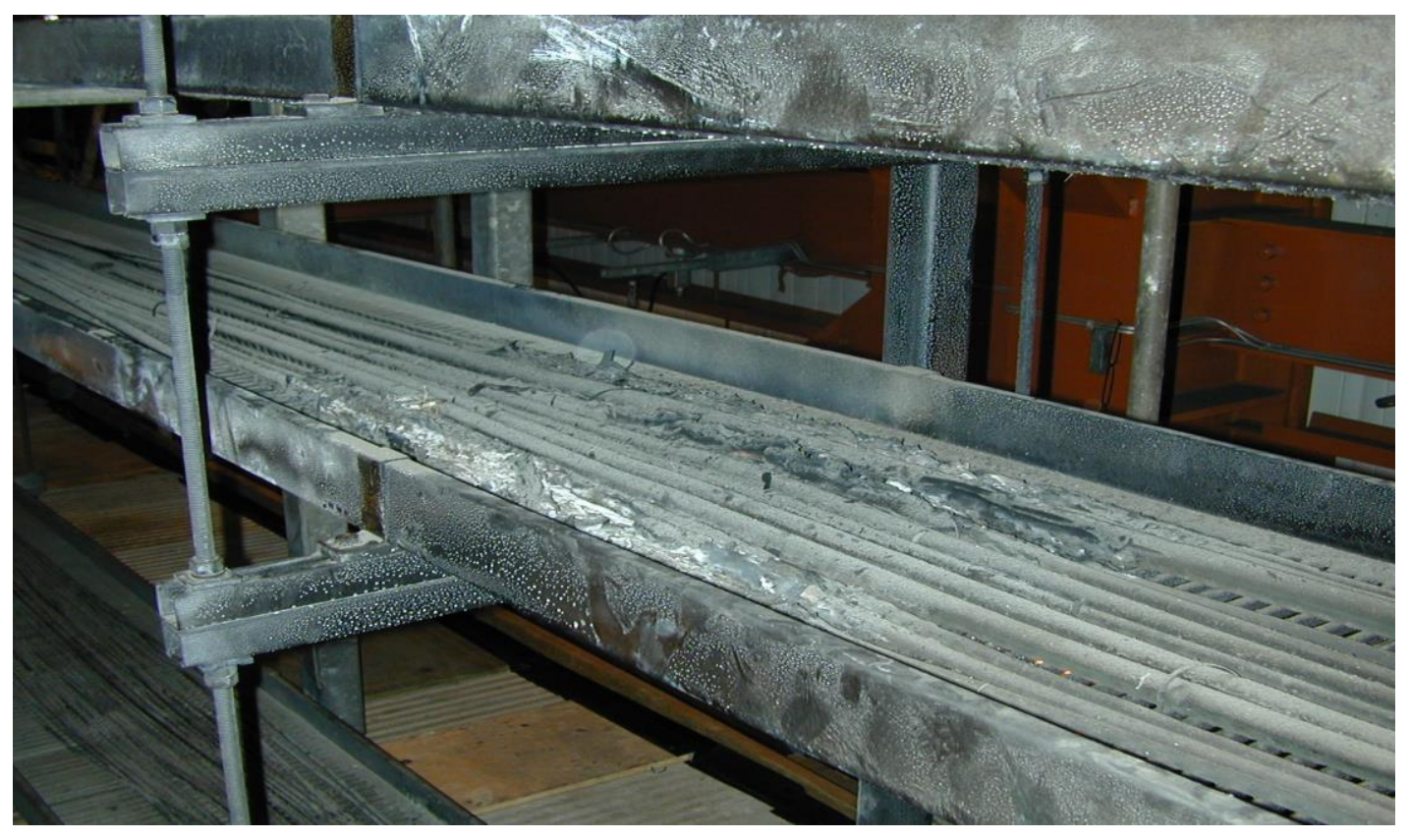

\section{Second Level Cable Tray above Bus A07}

\section{Idaho National Laboratory}




\section{U3 A07 30' Switchgear Room Cable Trays}

Second Level Cable Tray

Above Bus A07

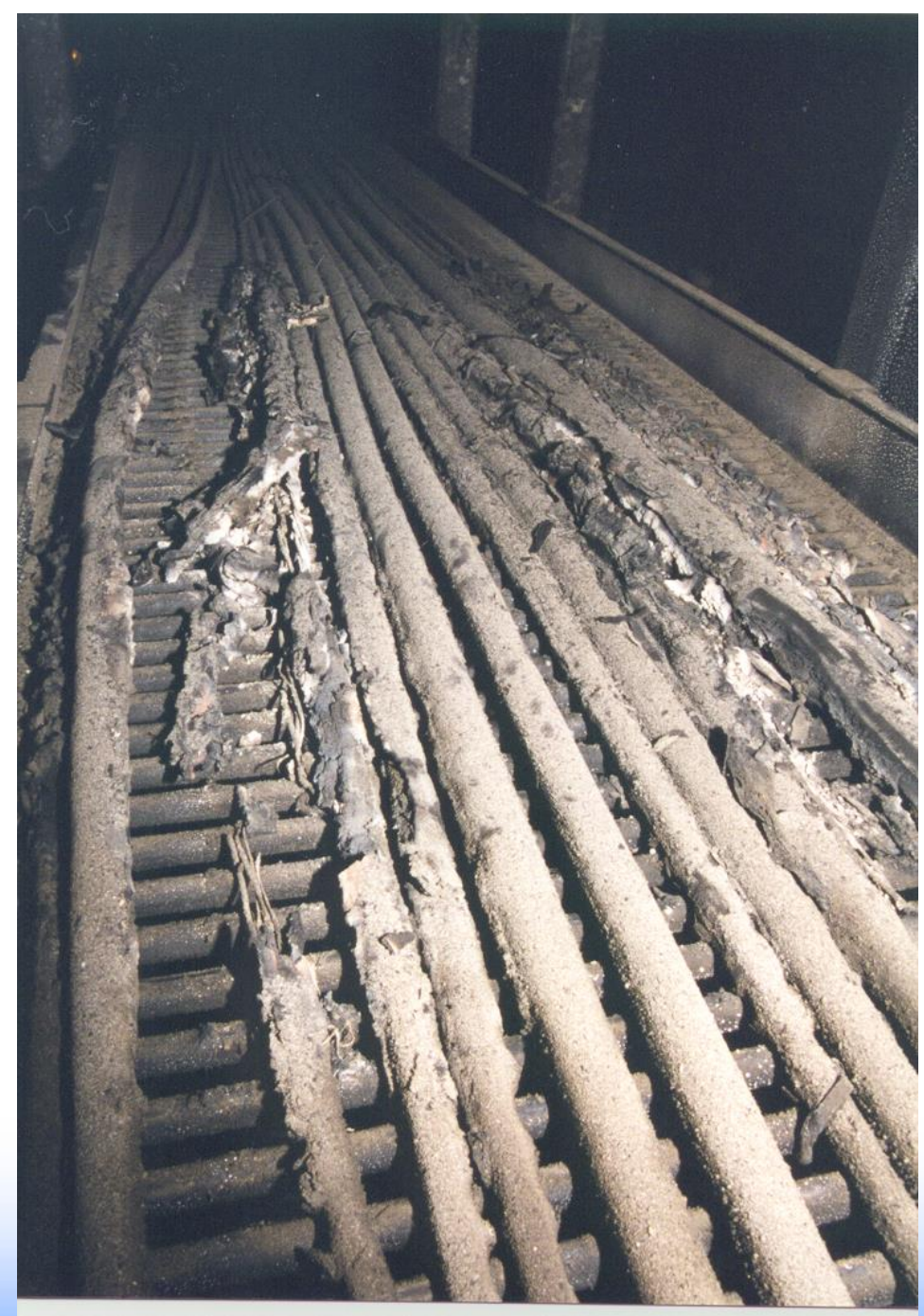




\section{U3 A07 30' Switchgear Room Cable Trays}

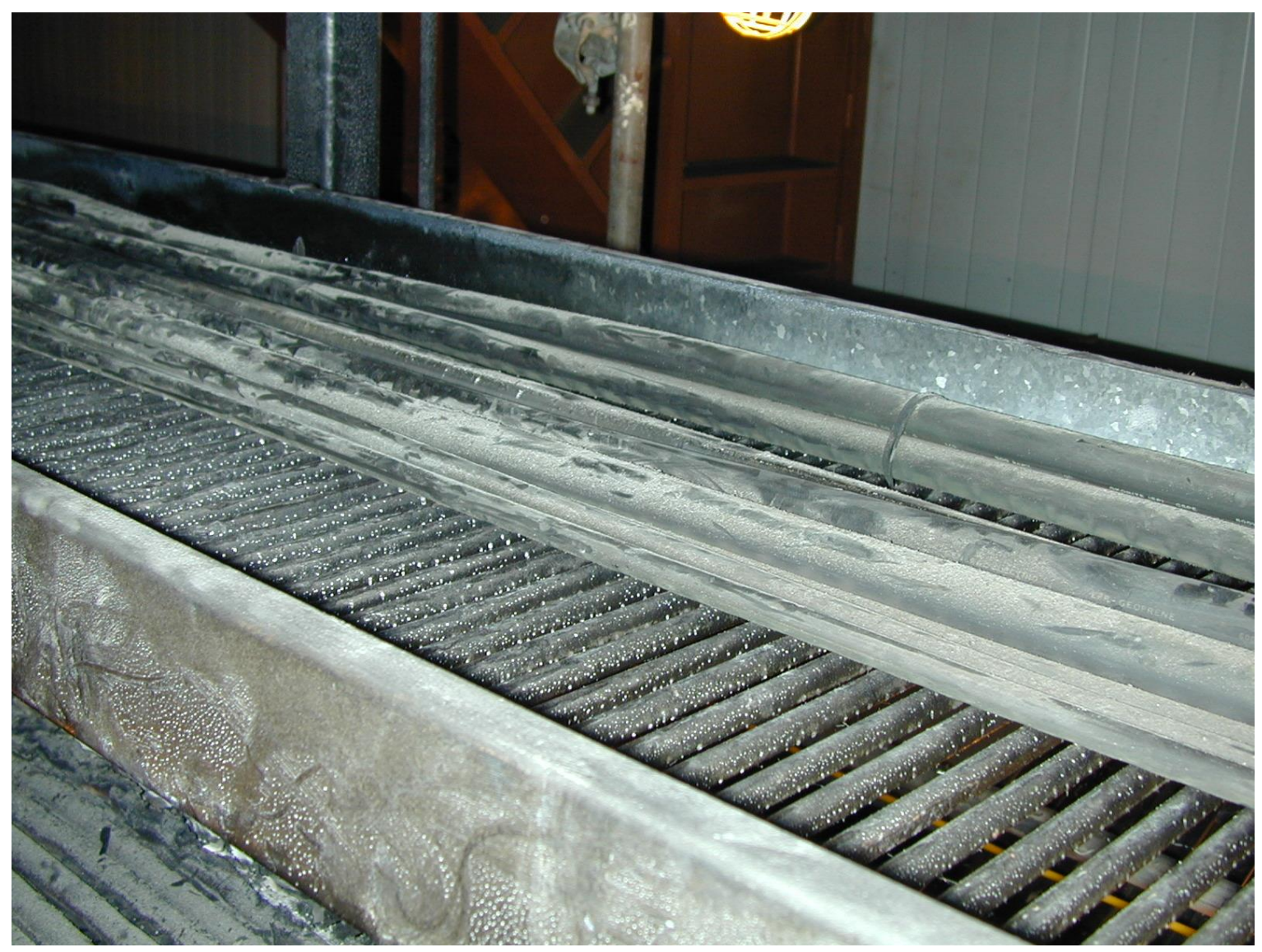

Third Level Cable Tray Above Bus A07

\section{Idaho National Laboratory}




\title{
U3 AO7 30' Switchgear Room Cable Trays
}

\author{
Third Level Cable \\ Tray above Bus \\ A07
}

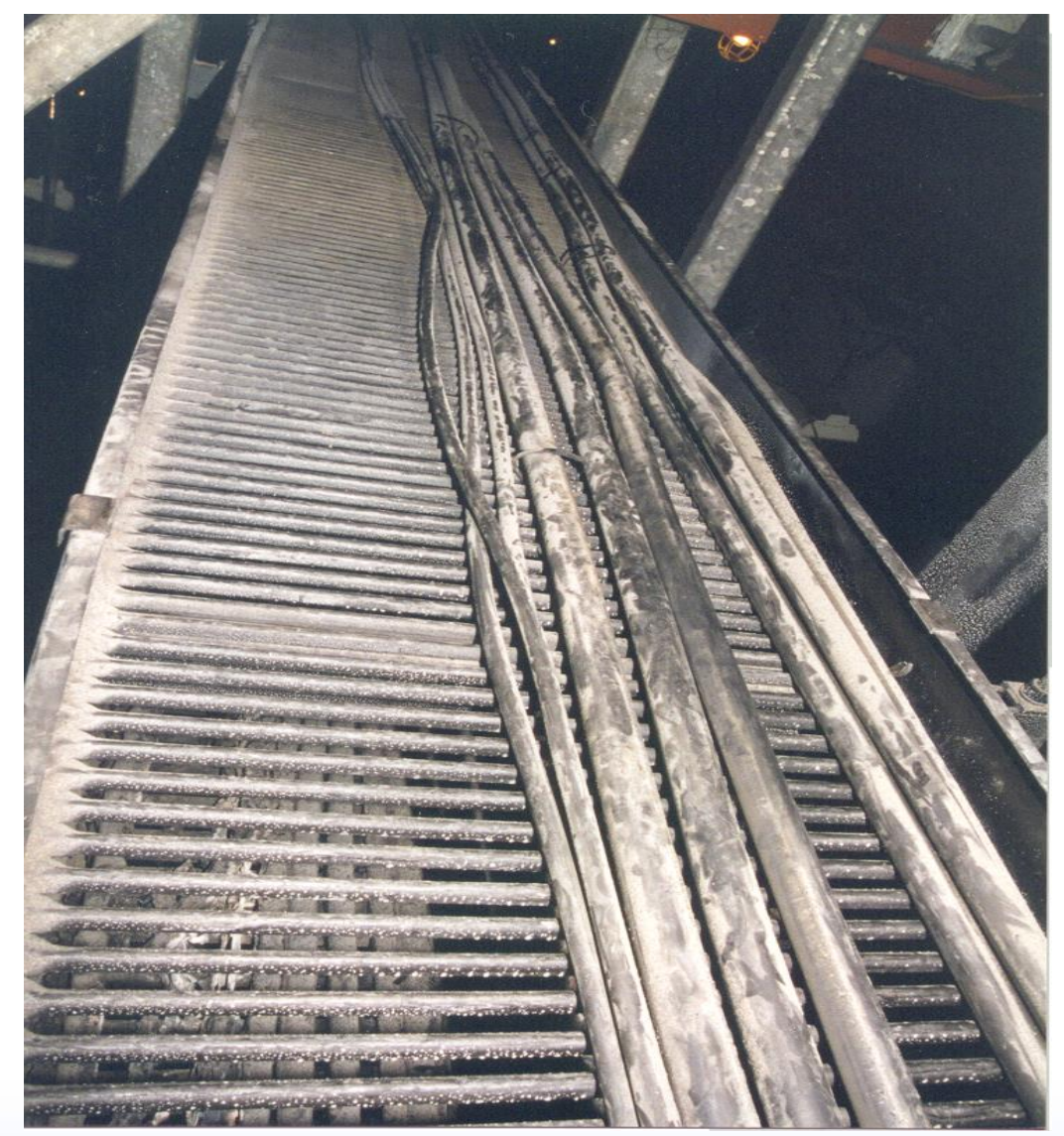




\section{Effects Of Initial Pressure Spike}

- Back door of Cubicle 14 blown off by high pressure pulse

- Soot pattern shows that pulse originated in lower right corner at Phase A input

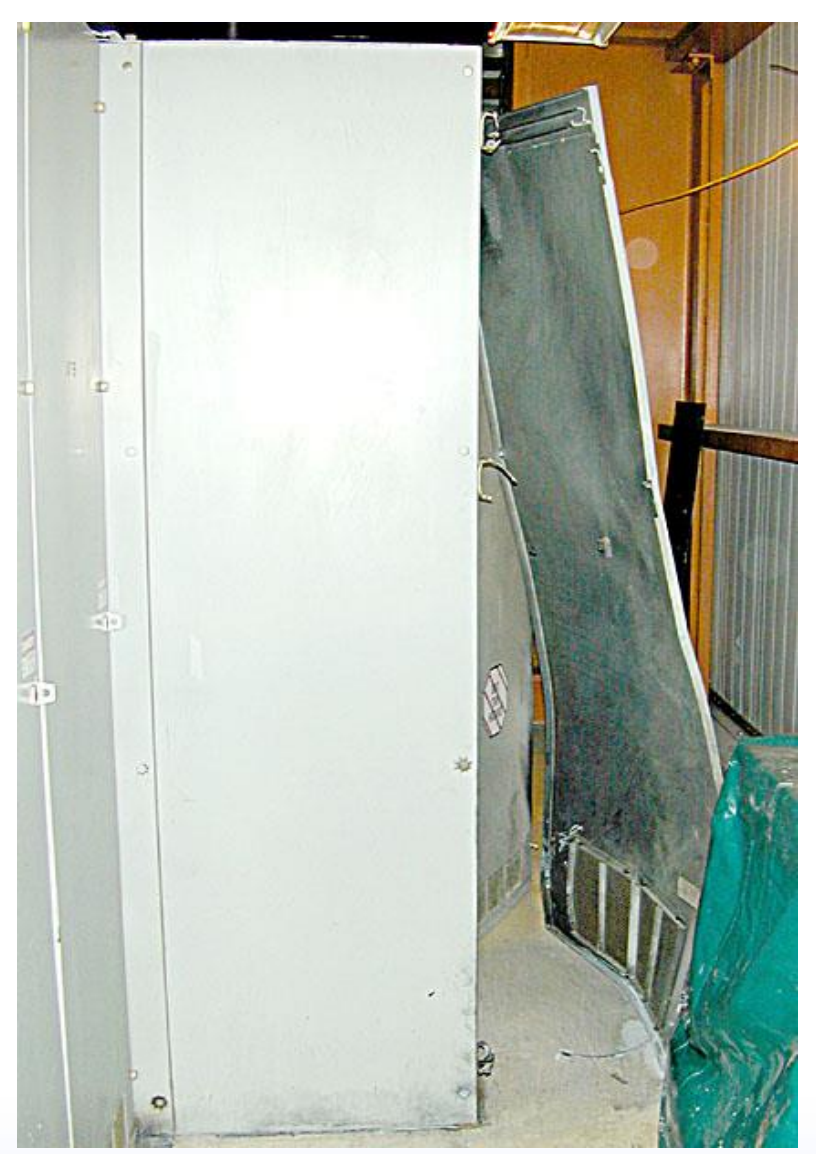

\section{Idaho National Laboratory}




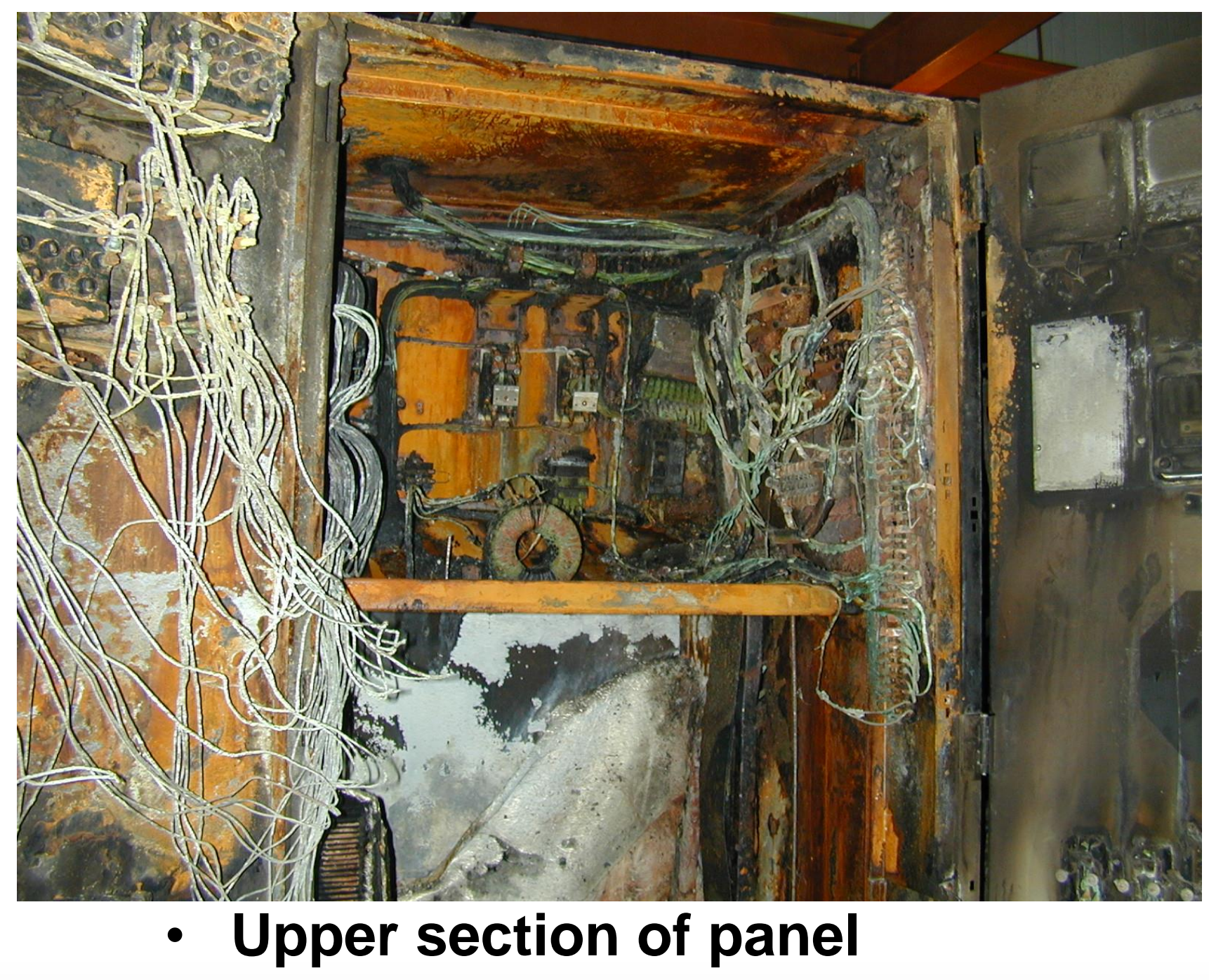

Idaho National Laboratory 


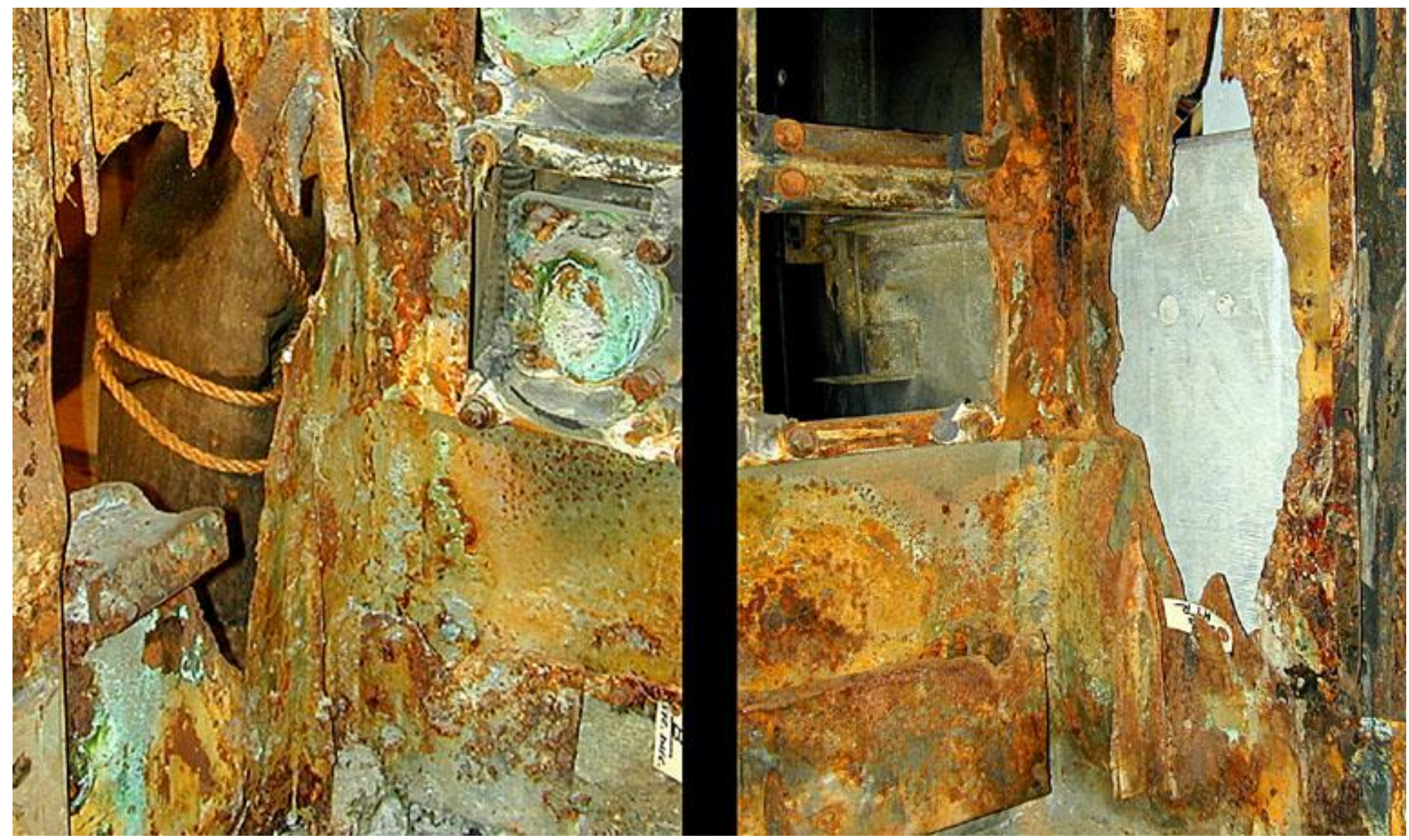

- Holes in sides of 3A0712 cubicle caused by arcing. Left: A phase to ground, right: $C$ phase to ground 


\section{Fire Characterization Rules For SDP}

- Consider arcing faults for certain types of equipment

- 440V and up only

- Switchgear, breakers, motor control centers only

- Frequency given in worksheet for applicable fire ignition sources

- Separate values given for thermal fires and HEAF

- Both apply! (two for one sort of thing)

- HEAF frequency is per panel section just like any other fire frequency 


\section{Initial Energetic Release}

- Assume that the door(s) to the faulting cubicle are blown open (creates an open panel fire)

- Assume that equipment in the first neighboring cubicle/panel in each direction will also be damaged

- An empty panel section will not stop propagation of initial fault (as shown by San Onofre event)

- Go to first occupied section

- Initial fault assumed to actuate next higher level of circuit protection

- A fault in one switchgear cubicle will cause a loss of power to the entire bank because the input power will trip offline

- Not recoverable (until the initial fault is isolated) 


\section{Enduring Fire}

- The enduring fire created by HEAF is treated using only one fire size: $200 \mathrm{~kW}$

- Severity factor is $\mathbf{1 . 0}$

- Don't use expected and high-confidence approach, all fires caused by HEAF are $200 \mathrm{~kW}$

- If there are any trays above the faulting panel, the first/lowest tray in each stack will be ignited at time 0 so long as it is within 5 feet of the top of the panel

- Propagate fire through additional trays using general rules for cable tray fire growth

- Any combustible materials within 3 feet horizontally of the front or rear surface of the panel will ignite at time zero

- Damage targets in the same region fail at time zero 


\section{Module 6B - Cable Tray Fires}




\section{Fires In Cable Tray Stacks}

- Fire spread is rule-based

- Two specific pieces of info used:

- Fires will release $\mathbf{4 0 0}$ kW per square meter of cable tray

- Fires will propagate horizontally at $\mathbf{1 0}$ feet per hour

- No distinction made between thermoset and thermoplastic cables 


\section{Exposure Fires And Ignition Of Lowest Tray}

- First decide if you can ignite the lowest tray

- Is lowest tray within zone of influence?

- Yes $\Rightarrow$ fire can spread to other trays

- Use FDT to calculate plume temperature at location of lowest tray

- Use distance to tray bottom

- Assume lowest tray ignites based on plume temperature and time to damage/ignition table

- Call time to ignition of lowest tray $t_{1}$ 


\section{Spread To Subsequent Trays}

- Additional trays are ignited as follows:

- Second tray 4 minutes later (elapsed time $t_{1}+4 \mathrm{~min}$.)

- Third tray 3 minutes later (elapsed time $t_{1}+7$ min.)

- Fourth tray 2 minutes later (elapsed time $t_{1}+9$ min.)

- Fifth tray 1 minute later (elapsed time $t_{1}+10$ min.)

- Higher trays 1 minute later (elapsed time $t_{1}+11$ min.)

- Cables assumed to fail when tray they are in ignites

- Separation distance does not matter!

- Be reasonable - a good size fire can easily jump a few feet of vertical separation $-8^{\prime}-10^{\prime}$ is limit for most fires

- If in doubt, you can use FDT to see if fire will jump vertical gap

- Assume the entire fire (total fire intensity) is in the highest tray you are confident will ignite

- Compare plume temperature at next tray to failure/ignition threshold 


\section{More Than One Stack?}

- Ignite lowest tray in adjacent stack at time that third tray in initial stack ignites

- Fire spread in second stack then follows the tray-bytray spread of initial stack, always lagging by two trays until entire stack is involved 


\section{Self-Ignited Cable Fires}

- Fire starts within a cable tray due to a fault in the cables

- Only considered for cables that do not meet IEEE-383 low flame spread standard

- This is the only place we talk about qualified vs. unqualified instead of thermoplastic vs. thermoset

- Most industry cables are qualified - ask licensee!

- Watch PE/PVC cables - may be qualified or may be unqualified

- Meeting the flame spread standard is enough in this case don't need all the additional EQ environmental exposure stuff 


\section{Self-Ignited Cable Fires}

- Find: of all the places the fire might ignite, what are the critical locations

- The place or set of places where the fire will do the worst damage

- We apply a weighting factor to fire frequency to reflect percentage of trays represented by the critical location

- WF = (Linear feet of tray in critical location) / (Total linear feet of tray in the room)

- ESTIMATE - don't pull out the tape measure 


\section{Self-Ignited Cable Fires}

- From there the same fire spread rules apply as for other fire scenarios 


\section{Module 6C - Reverse Engineering The Hot Gas Layer}




\section{Hot Gas Layer}

- FDS2 involves hot gas layer damage

- In few cases will any single fire ignition source burning by itself be enough to create a hot gas layer

- Check your case, but you need a big fire in a small room

- Exceptions might be large oil fires, oil filled transformers

- That usually means the fire has to spread to create a damaging hot gas layer

- Fire spread takes time, and the question boils down to how much time? 


\section{Hot Gas Layer}

- We work this problem backwards

- Use the FDT hot gas layer tool to estimate the fire size (i.e., HRR) required to cause a damaging hot gas layer

- Figure out how much fire spread is need to create a fire that big

- Figure out how much time is needed to spread fire that far - that is damage time 


\section{Hot Gas Layer}

- First, using FDT, decide how big a fire it takes to get damaging HGL

- Start with HRR of the fire ignition source

- If HGL temperature at $\mathbf{1 0}$ minutes is greater than or equal to the damage threshold

- Use HGL temperature at 10 minutes

- Use damage time table for the calculated temperature

- Total time to damage is $\mathbf{1 0}$ minutes plus damage time from look-up table

- Implies minimum time of $\mathbf{1 0}$ minutes

- If HGL temperature reaches threshold within $\mathbf{3 0}$ minutes

- Time to damage is time to reach damaging HGL plus damage time at damage threshold (e.g., 28 minutes) 


\section{Hot Gas Layer}

- If fire ignition source is not enough (HGL temperature doesn't reach damage threshold within $\mathbf{3 0}$ minutes) fire spread is needed to create damaging hot gas layer

- If fire spread is not possible (no ignition targets within zone of influence), then this is not a credible FDS2 scenario - drop scenario

- If fire spread is possible (at least one ignition target within zone of influence), increase fire size in FDT until temperature at 10 minutes reaches damage threshold and record required HRR

- Don't try to get too fine an answer, steps of $50 \mathrm{~kW}$ are fine 


\section{Hot Gas Layer}

- Now we have to figure out how far the fire has to spread to create a fire this big:

- You will look for a fire spreading into cable trays

- Cable trays are assumed to burn at $400 \mathrm{~kW} / \mathrm{m}^{2}$

- Calculate square meters (or square feet) of tray required to get fire size needed

- Remember - the ignition source is also burning, trays only have to make up the difference: subtract out HRR for ignition source

- Determine if there are enough trays in the area to get a fire this big

- If no, then the FDS2 scenario is not credible

- If yes, need to estimate time for fire to grow this far using cable tray fire spread rules 


\section{Hot Gas Layer}

- Once we have extent of fire needed, we have to reverse engineer the cable tray fire spread model

- Time to ignite first tray $\left(t_{1}\right)$ comes from plume temperature and time to damage/ignition - FDS1

- Remaining trays propagate as normal:

- Second tray $-t_{1}+4 \mathrm{~min}$.

- Three trays $-t_{1}+7 \mathrm{~min}$.

- Four trays $-t_{1}+9$ min

- Five trays $-t_{1}+10$ min.

- Rest of stack $-t_{1}+11$ min.

- Spreadsheet will do this for you! 


\section{Hot Gas Layer}

- Given following information it's cookbook:

- Total HRR needed to get damaging HGL

- HRR for fire ignition source (subtracted from above total HRR)

- How many trays in the stack

- Time to first tray ignition

- Width of trays or cable bundles

- Spreadsheet does the cooking for you 


\section{Module 6D: Flexibility}




\section{Let's Talk About Flexibility}

- It is common for PRA practitioners to exercise flexibility in the order in which they pursue the quantification steps/factors

- It is the intent that SDP retain this flexibility

- You will have to use your judgment

- Discussed in IMC 0308, Att. 3, App. F 


\section{Flexibility}

- This is going to take practice and confidence on your part

- Flexibility is not necessary, you will get to the same answer either way, but you may save time/effort

- Exercising flexibility is most effective for a finding that is going to go Green in the end anyway

- Question is, "is there a quicker path to a screening result?"

- Biggest challenge is to ensure you don't double count 


\section{One Caution On Flexibility}

- If you alter the order of steps, you need to use the screening criteria that go with the step that moved up in the process

- For example, if you move Step 2.8 (refined CCDP) up to the top of Phase 2, you need to use the 1E-6 general screening criterion, not the tables in Step 2.1 


\section{Flexibility Example 1:}

- Impacted fire area has very few fire ignition sources or sources present are not significant

- It may be desirable to develop refined fire frequency early

- Helps most if close to screening level already, or when all sources are likely to screen out

- May get you the "no credible fire scenario" answer

- Move fire ignition source counting/screening to first task in Phase 2

- Can use refined fire frequency in subsequent steps 


\section{Flexibility Example 2:}

- Existence of diverse SSD paths not threatened by possible fire scenarios

- May be desirable to pursue CCDP early in Phase 2 - e.g., put Step 2.8 before Step 2.1

- Use refined CCDP in subsequent steps in place of nominal CCDP value from Step 2.1

- You may avoid need to develop specific fire scenarios altogether 


\section{Flexibility Example 3:}

- Redundant tray is in room, but in non-degraded one-hour fire wrap

- $Q$ : Is it worth pursuing scenarios that attack the redundant tray in detail?

- Scoping calculation can estimate importance

- Look at manual non-suppression probability at one hour (we will give the minimum 1-hour credit to non-degraded barrier regardless)

- Multiply by room fire frequency (either Phase 1 or Phase 2 refined value)

- Loss of redundant train usually means can't credit SSD, so CCDP $=1$

- Product of DF $x$ PNS manual $\times F_{\text {room }}$ bounds contribution of these scenarios

- If product is low enough, (i.e., well below 1E-6) you may not want to analyze these scenarios in further detail. 